The author(s) shown below used Federal funds provided by the U.S. Department of Justice and prepared the following final report:

Document Title: Juvenile Domestic and Family Violence: The Effects of Court-Based Intervention Programs on Recidivism

Author(s): $\quad$ Brenda Uekert ; Inger Sagatun-Edwards ; Ann Crowe ; Tracy Peters ; Fred Cheesman ; Dina Kameda

Document No.: $\quad 216614$

Date Received: December 2006

Award Number: $\quad$ 2003-IJ-CX-1031

This report has not been published by the U.S. Department of Justice. To provide better customer service, NCJRS has made this Federallyfunded grant final report available electronically in addition to traditional paper copies.

Opinions or points of view expressed are those of the author(s) and do not necessarily reflect the official position or policies of the U.S. Department of Justice. 

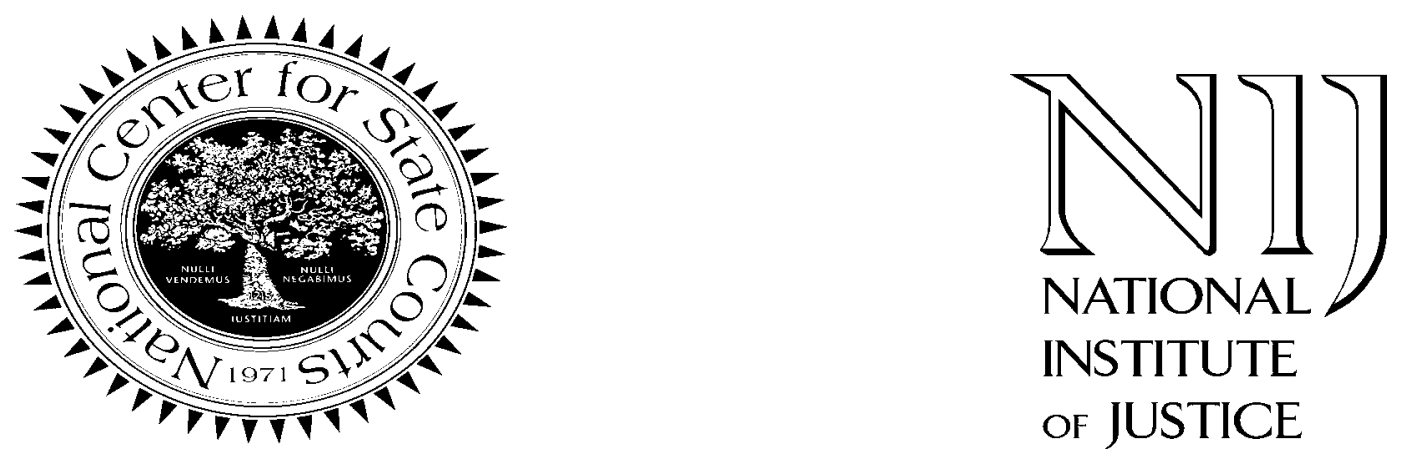

\section{Juvenile Domestic and Family Violence: The Effects of Court-Based Intervention Programs on Recidivism}

July 31, 2006

The National Center for State Courts

Brenda Uekert, $\mathrm{PhD}$

Inger Sagatun-Edwards, $\mathrm{PhD}$

Ann Crowe, EdD

Tracy Peters, MA

Fred Cheesman, $\mathrm{PhD}$

Dina Kameda, MS

This project was supported by Grant No. 2003-IJ-CX-1031 awarded by the National Institute of Justice, Office of Justice Programs, U.S. Department of Justice. Points of view in this document are those of the author and do not necessarily represent the official position or policies of the U.S. Department of Justice or the National Center for State Courts. 


\section{Table of Contents}

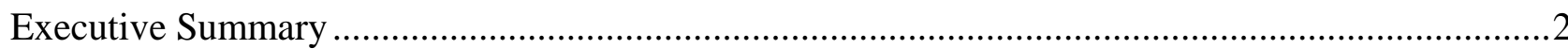

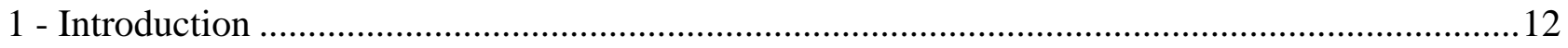

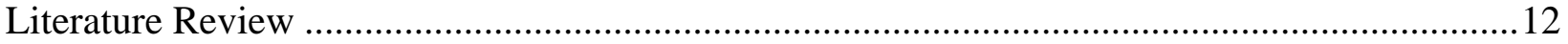

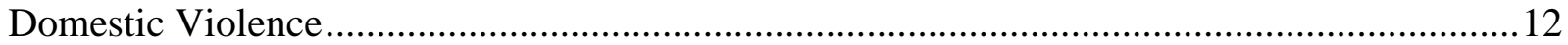

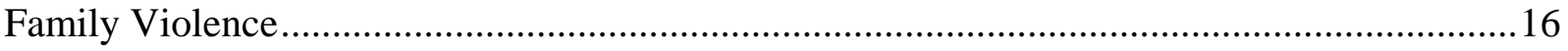

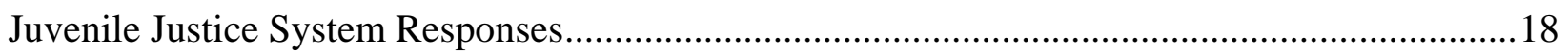

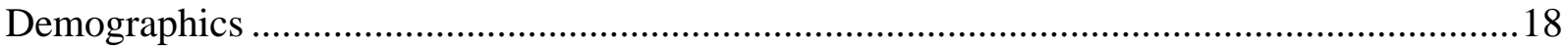

California Juvenile Justice ..................................................................................................19

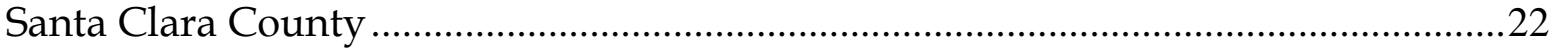

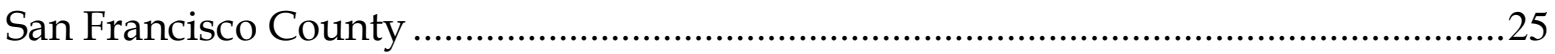

Contra Costa County ………………………………..................................................2

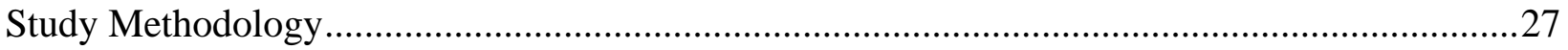

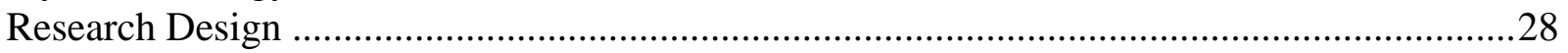

Case Selection and Sampling Frame....................................................................................30

Data Collection and Analysis ..........................................................................................33

Study Limitations ....................................................................................................................34

2 - The Nature of Juvenile Domestic and Family Violence ..................................................................38

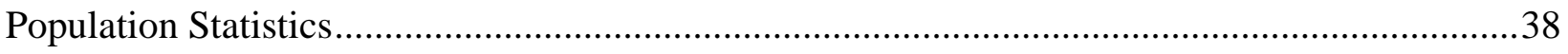

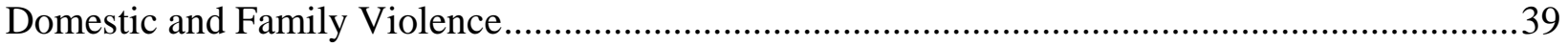

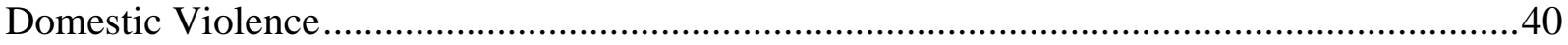

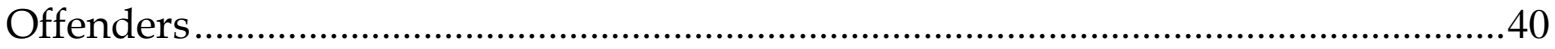

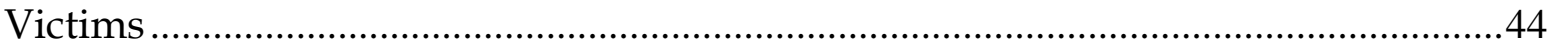

The Nature of Violence ...............................................................................................45

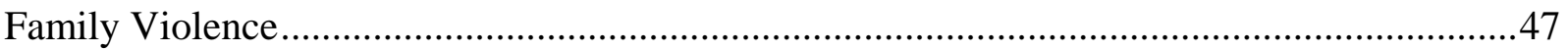

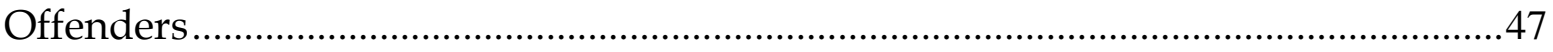

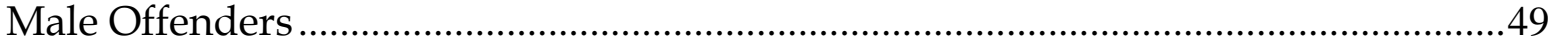

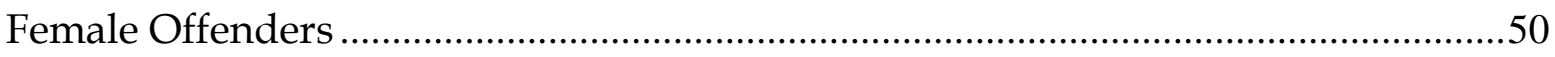

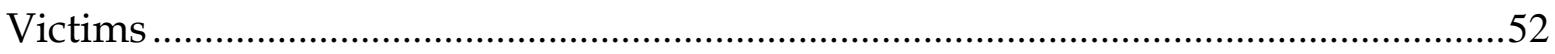

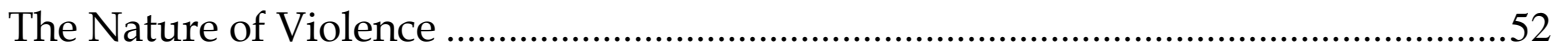

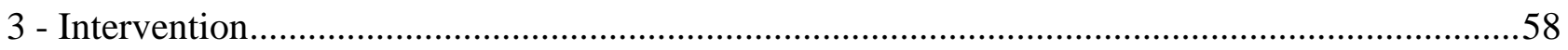

Probation Supervision and Conditions …………………....................................................6

Formal versus Informal Probation ..........................................................................................61 


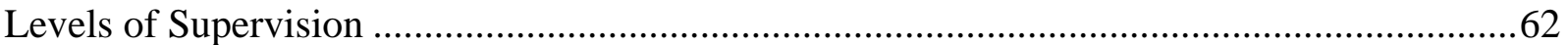

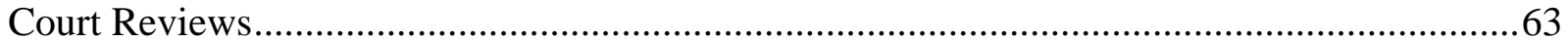

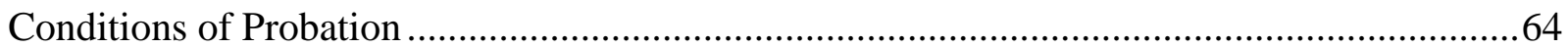

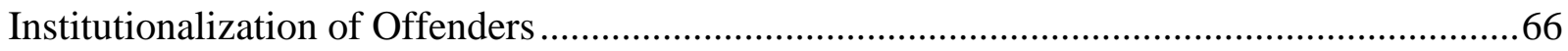

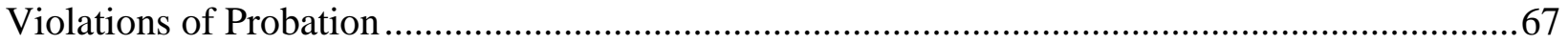

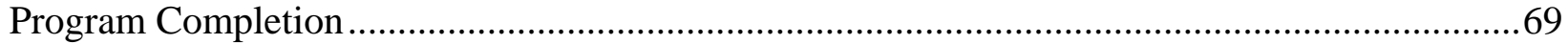

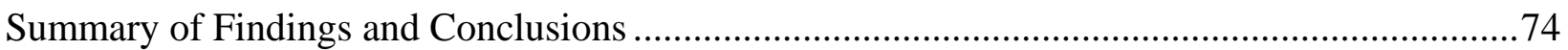

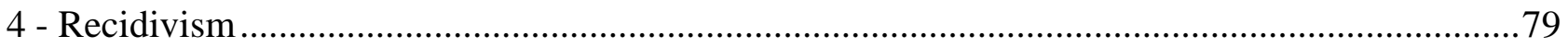

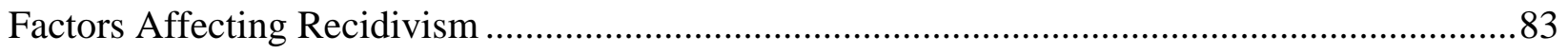

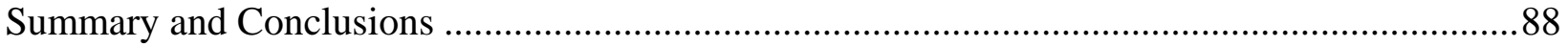

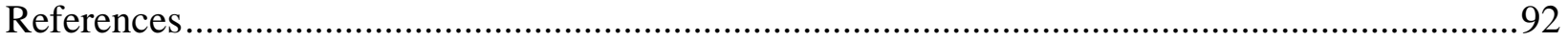

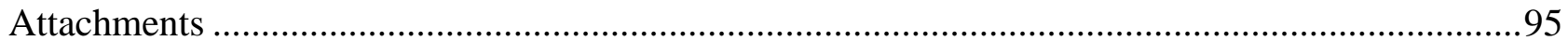




\section{Acknowledgement}

The research team thanks the dedicated staff of the juvenile justice systems in Santa Clara County, San Francisco County, and Contra Costa County for opening their processes and files for the sake of research. We thank all those agencies and community-based organizations who were kind enough to discuss their programs with us. It is our hope that the valuable information we learned in this study will benefit justice systems throughout the nation and further our understanding of juvenile domestic and family violence. 


\section{Abstract}

This study tested the effectiveness of two court-based intervention programs in California (Santa Clara County, San Francisco County) that addressed juvenile domestic and family violence. The court-based intervention programs included an intake assessment process for domestic and family violence, specialized prosecution and defense, a dedicated docket, intensive supervision, offender programs, and victim services. Probation and court records of juvenile domestic/family violence offenders provided the source of data to compare the intervention programs with a third county that did not have a specialized response (Contra Costa County).

Data on program completion showed that (1) Santa Clara County had the lowest rate of successful program completion, and (2) offenders with prior delinquency records were less likely to successfully complete probation and program requirements than were those without prior records. All things being equal, the likelihood of successfully completing the probation program increased if the offender did not violate probation, the offender was placed on electronic monitoring, the offender was not in Santa Clara County, and the offender was young.

Primary findings from the study include the following:

- The specialized intervention programs in both Santa Clara and San Francisco counties had a deterrent effect on first-time offenders. The deterrent effect, which lasted up to two years following the date of the incident, was especially apparent in Santa Clara County.

- Recidivism rates for offenders with prior records were remarkably consistent across sites. One year after the incident, about thirty percent of offenders with prior delinquency had recidivated, regardless of any specialized intervention.

- The greatest determinant of the probability of recidivism was background characteristics of the offender. The factors that significantly influenced the probability of recidivating were: (1) the type of violence, (2) the victim's gender, (3) the number of prior referrals of the offender to juvenile court, (4) whether the offender was abused as a child and/or the parents have a history of domestic/family violence, (5) the number of probation violations, and (6) successful program completion.

Three conclusions were drawn from the study. First, the court-based intervention programs, as implemented in Santa Clara and San Francisco counties, had a deterrent effect on first-time offenders. Second, the most challenging juvenile population to rehabilitate was domestic/family violence offenders with prior records. Third, strategies that increase the number of offenders who successfully complete the probation program may lower recidivism rates. 


\section{Executive Summary}

In California, the Santa Clara County Superior Court and the San Francisco Superior Court created unique approaches to address both juvenile domestic and family violence. The Santa Clara County Juvenile Domestic and Family Violence Court, begun in 1999, was the first of its kind in the nation. Two years later, a similar program began operating in San Francisco County_the Youth Family Violence Court. The court-based programs shared the following features: (1) an intake process that included assessment for domestic and family violence, (2) specialized prosecution and defense, (3) dedicated docket, (4) intensive supervision, (5) offender programs, and (6) victim services. Yet operational differences, such as the use of formal probation and a law enforcement protocol, distinguished the two programs.

In 2003, the National Center for State Courts, in partnership with the American Probation and Parole Association, and Dr. Inger Sagatun-Edwards of San Jose State University, received a grant from the National Institute of Justice to study the effectiveness of the Santa Clara County and San Francisco County court-based intervention programs. For comparison purposes, a third county —Contra Costa County—-that did not espouse a specialized juvenile domestic/family violence program was added to the study design. The methodology involved two separate phases: contextual analysis and program evaluation. Contextual analysis, conducted through site visits, was necessary to identify variances in court/probation processing and case treatment and was a prerequisite to the collection of data. Program evaluation included analysis of the minors' background, incident data, and outcome evaluation, which focused on the impact of court, probation, and treatment on individual levels. The program evaluation involved coding probation and court files in each of the three counties to (1) document the sociodemographic, experiential, and delinquency backgrounds of juvenile domestic/family violence offenders, (2) profile victim backgrounds and the nature of the incident, (3) collect information on probation conditions, intervention programs, and probation 
violations, and (4) gather information on subsequent arrests and convictions for domestic and family violence offenses and any new re-arrests. In addition to coding specific information, research assistants used probation and court files to write narratives describing the offender's family background, nature of the violence, and success in the intervention program. Finally, juvenile and adult recidivism information was collected from juvenile probation and court record files and the California adult criminal record system. The final study group included 304 closed cases (202 cases from Santa Clara County, 40 cases from San Francisco County, and 62 cases from Contra Costa County).

Because Contra Costa County did not have a specialized juvenile domestic/family violence program and did not identify these types of cases, research staff had to pull and read files from a subset of cases in which the offender was charged with at least one of four penal code violations that were indicative of a domestic or family violence crime. Cases that clearly involved a domestic or family violence relationship were included in the sample. Limitations of the study include the small number of cases in San Francisco and Contra Costa counties, dramatic differences in juvenile populations between counties, and reliance on official sources of data.

\section{Offender Characteristics}

Family violence incidents comprised the bulk of cases (70 percent) that entered the system as either family or domestic violence. The data strongly indicated that domestic violence offenders (1) tended to be older, (2) were more likely to be male, (3) were more likely to have a previous delinquency record, and (4) were less likely to have a history of mental illness than family violence offenders.

The vast majority of domestic violence offenders were young men—90 percent of offenders were male and the average age was 16.4. However, the ten percent of female offenders is larger than 
the percentage often reported for adult female offenders. There was remarkable consistency across

sites in the following areas:

- Domestic violence offenders who entered the juvenile justice system were overwhelmingly male.

- Most offenders had a prior juvenile record — those with records had an average of 4.6 prior referrals.

- About one-third of the probation reports indicated that the offender had a mental illness.

- About one-third of the probation files reported a history of domestic violence among the parents.

- Probation files indicated larger problems within the family including criminal records for the parents and reports of substance abuse.

Family violence offenders were more likely to be male, but a sizeable proportion of offenders in our study were female-37 percent. There were very few, if any, differences between male and female family violence offenders. Family violence offenders were young; the average age was 15 . Similar to the data on domestic violence, the data on family violence varied somewhat across jurisdictions. In particular, the data suggested that the sample in Contra Costa County, which did not have a specialized intervention program, consisted of juveniles who were more likely to have a record of previous delinquency — 67 percent of offenders had prior juvenile records compared to 37 percent in Santa Clara County and 50 percent in San Francisco County. Despite these differences, there were a number of striking similarities in the population of family violence offenders who had been processed in the juvenile justice system. In particular, the offenders shared the following backgrounds.

- Family violence offenders were young. The average age of the offenders was 15 years of age.

- The majority of offenders (63 percent) were male.

- Most offenders (64 percent) had been diagnosed with a mental illness.

- A significant proportion of offenders had a prior juvenile record (46 percent), although this varied by county. 
- A high percentage of offenders' parents had a history of domestic violence, a criminal justice record, or a substance abuse problem.

In capsule, juvenile offenders who entered the system as a result of committing a domestic or family violence offense had histories that were likely to include a combination of prior delinquency, diagnoses of mental health (especially for family violence offenders), history of abuse as a child, and family histories that include parental violence. These background characteristics suggest challenges to the justice system in devising intervention programs that both address the needs of these young offenders and sanction their behavior.

\section{The Nature of Violence}

Victim/survivor profiles, the severity of the incident, and weapons of choice offer some insights into the nature of violence. Victims of domestic violence incidents were overwhelmingly female (90 percent), with an average age of 16.8. About one-third of the victims had children in common with the offender. Almost one of every four domestic violence incidents occurred while the victim was pregnant. The primary method of violence was bodily force-guns and knives were seldom used.

The majority of victims of family violence offenses were female (73 percent). More than half of the victims were mothers of the offenders. About one of every four family violence incidents involved more than one victim. Bodily force was the most common weapon used in family violence cases.

\section{Justice System Interventions}

The legal culture in Santa Clara, San Francisco, and Contra Costa counties were quite different. Of the three counties, Santa Clara’s approach best approached “zero tolerance,” and was exemplified by a law enforcement protocol that required officers to bring juvenile domestic and 
family violence offenders to juvenile hall for intake. In San Francisco and Contra Costa counties, there was not formal protocol that guides law enforcement in their response to these juvenile offenders. The “wide net” cast by Santa Clara County was demonstrated by examining the number of domestic/family violence cases per 100,000 population (15 to 19 year olds). By this measure, 72 teens per 100,000 entered the Santa Clara specialized program, compared to 13 teens per 100,000 in Contra Costa who can be identified through probation records as domestic or family violence offenders. The San Francisco program, which also included a specialized intake process at juvenile hall, handled 43 cases per 100,000 population. Consequently, the juvenile domestic violence/family violence populations were quite different in the counties. For example, 67 percent of the family violence offenders in Contra Costa County had prior records, compared to 37 percent in Santa Clara County.

In addition to the specialized court services described above, juvenile domestic/family violence offenders received conditions of probation similar to those expected in the general juvenile caseload. Multiple conditions of probation were placed on offenders. Most commonly, probation conditions included: (1) attend school regularly, (2) submit to warrantless search and seizure, (3) comply with curfews, (4) abstain from alcohol or drugs, and (5) participate in individual counseling. The majority of offenders were ordered to participate and complete a domestic violence intervention program. Offenders in Santa Clara and San Francisco counties averaged six to seven court reviews during the time they were under probation. Finally, the conditions of probation across counties suggested that the Santa Clara County court placed more conditions on its probationers than those in other counties. For example, there were 14 conditions placed on at least 50 percent of the juvenile domestic/family violence probationers in Santa Clara County. In contrast, the San Francisco and Contra Costa County courts placed 7 and 9 conditions, respectively, on at least half of its 
probationers. This suggests that compliance in Santa Clara County may be more likely to be compromised as the average probationer has multiple probation conditions.

Probation was typically assigned for one year. Yet the probation period, on average, lasted more than a year as probationers were unable to complete all the conditions of probation and often violated probation. The average amount of time between incident date and the closure date was 611 days (the median was 579 days). Generally, probationers could expect to spend at least 18 months on probation.

\section{Probation Compliance and Program Completion}

More than half of all juvenile domestic or family violence offenders violated the terms and conditions of probation. This figure ranged from 71 percent in Contra Costa County to 52 percent in Santa Clara County - the median number of violations (two violations) was consistent across counties. Offenders with prior juvenile delinquency were more likely to violate probation than those without prior records (67 percent versus 48 percent). The probation conditions most often violated were: (1) attend school regularly, (2) comply with curfews, and (3) abstain from alcohol or other drugs.

Content analysis of the textual information from the case files was used to code the success of program completion. Cases that were coded as "successful completion” included cases that were closed because the probationers had successfully completed the requirements of probation, and cases in which probationers had made progress in the program before they "aged out” of the juvenile system. As such, information on the completion of the programs was subjective and influenced by probation department practices as well as the availability of information recorded in the case files. A cross-tabulation analysis showed that (1) Santa Clara County had the lowest rate of successful program completion, and (2) offenders with prior delinquency records were less likely to 
successfully complete probation and program requirements than were those without prior records.

The percentage of juveniles with prior delinquency records who completed the program was 60 percent, while the percentage of juveniles without prior records who completed the program was 68 percent.

Logistic regression showed that four variables significantly influenced the probability of successful program completion: (1) violation of probation, (2) electronic monitoring, (3) county, and (4) age of the offender. All things being equal, the likelihood of successfully completing the probation program increased if the offender did not violate probation, the offender was placed on electronic monitoring, the offender was not in Santa Clara County, and the offender was young. Results suggest real-world strategies, such as electronic monitoring and age-specific programming, which could positively impact successful program completion. Furthermore, the relatively lower rates of successful program completion in Santa Clara County likely reflected the high levels of intensive supervision and legal culture, rather than offender performance.

\section{Programmatic Effects on Recidivism}

The study was designed to investigate the impact of a specialized program on recidivism rates. The most accurate information on recidivism data was re-arrest data. As has been noted in previous studies on recidivism, reliance on official government data is flawed, as arrest data captures only those incidents that became known to law enforcement and resulted in an arrest. Nevertheless, arrest data is readily available and measured identically across counties.

The study theorized that the intervention programs in Santa Clara and/or San Francisco counties would result in a lower recidivism rate when compared to a county that did not have a court-based intervention program. The data showed that the general re-arrest rate was similar across counties (ranging from 48 percent in Santa Clara and Contra Costa counties to 53 percent in 
San Francisco count). Likewise, re-arrest rates for domestic or family offenses did not vary significantly across counties, ranging from 28 percent in San Francisco County to 33 percent in

Santa Clara County). However, more sophisticated analyses of recidivism data showed that:

- The specialized intervention programs in both Santa Clara and San Francisco counties had a deterrent effect on first-time offenders. The deterrent effect, which lasted up to two years following the date of the incident, was especially apparent in Santa Clara County, where just 3 percent of first-time offenders recidivated within six months after the incident, compared to 16 percent in Contra Costa County.

- Recidivism rates for offenders with prior records were remarkably consistent across sites. One year after the incident, 28 to 30 percent of offenders with prior delinquency had recidivated, regardless of any specialized intervention.

A multivariate regression analysis identified the factors that best predict recidivism among this population of juvenile offenders. The six factors that significantly influenced the probability of recidivating and their influence on recidivism are provided below.

1. Having a female victim increased the odds of recidivism by 2.5 times compared to the odds when the victim was a male.

2. Failure to successfully complete the probation program increased the odds of recidivating by 2.2 when compared to those who successfully completed the program.

3. Having been abused as a child and/or having parents with a history of domestic/family violence doubled (2.1) the odds of recidivism, all things being equal.

4. Each prior referral to juvenile court increased the odds of recidivism by 1.5 times.

5. Each probation violation occurring while the offender was either participating in the program or on probation increased the odds of recidivating by 1.5 times.

6. If the incident was a family violence incident, the odds of recidivism was increased by .3 when compared to domestic violence incidents.

Factors that did not appear to make a difference in predicting recidivism included county, age, gender and ethnicity of the offender, family relationship, substance abuse, mental illness, severity of 
incident, offender admission of charges, number of days institutionalized, court reviews, type of disposition, and probation supervision.

In sum, the explanatory model that emerged from the logistic regression of the probability of re-arrest reflected characteristics of the offender (prior delinquency, history of abuse in the family), the nature of violence (type of violence, gender of victims), and offender compliance with probation conditions (probation violations, successful completion of program). The importance of successful program completion offers a silver lining for juvenile courts and probation departments. Strategies to increase successful program completion, without compromising the program, should hold promise. It is worth repeating that juveniles who successfully completed the probation program were less likely to recidivate than others. Although once again, past delinquency was a factor that affected successful program completion—70 percent of offenders without prior delinquency successfully completed the probation program, compared to 47 percent of those with previous records.

\section{- The greatest determinant of the probability of recidivism was background}

characteristics of the offender. The factors that significantly influenced the probability of recidivating were: (1) the type of violence, (2) the victim's gender, (3) the number of prior referrals of the offender to juvenile court, (4) whether the offender was abused as a child and/or the parents have a history of domestic/family violence, (5) the number of probation violations, and (6) successful program completion.

Three conclusions were drawn from the study. First, the court-based intervention programs, as implemented in Santa Clara and San Francisco counties, had a deterrent effect on first-time offenders. Second, the most challenging juvenile population to rehabilitate was domestic/family violence offenders with prior records. Third, strategies that increase the number of offenders who successfully complete the probation program may lower recidivism rates. 


\section{Closing Observations}

Both the Santa Clara County and the San Francisco County specialized juvenile domestic and family violence courts have proven to be innovative programs addressing a serious social issue. Case information demonstrates that many of the offenders assigned to these courts come from families with a history of parental domestic violence, child abuse, criminal behaviors, and substance abuse. Many of the minors have mental health issues. Most have prior histories of delinquency, and many already have children at a very young age. While the background of these minors makes it very difficult to effect change, the evaluation conducted by the National Center for State Courts found that the specialized court program had a deterrent effect for first time offenders and those that completed the entire court ordered programs. Minors with prior delinquency were less likely to complete the program, and more likely to recidivate.

In order to break "the cycle of violence" it is important to initiate programs that address the pressing issues of juvenile domestic violence (teen relationship violence) and family violence. The two counties have found similar, yet different ways of doing so. In constructing such specialized courts, it is important to be cognizant of the problem of "casting too wide a net," especially in the family violence cases which often could be seen as status offenses (being beyond the control of parents). Our results showed that the interventions were most beneficial for younger and first time offenders. Care must be taken to initiate programs with age appropriate services and graduated sanctions. 


\section{1 - Introduction}

Most juvenile justice systems do not offer any specialized programs or supervision of juveniles who commit crimes of domestic and family violence. The Santa Clara County Superior Court and the San Francisco County Superior Court are among the few exceptions, instituting unique approaches to addressing both juvenile domestic and family violence. This introduction offers a literature review, an overview of the Santa Clara, San Francisco, and Contra Costa juvenile justice system's response to domestic and family violence, and details of the methodology used to test the effectiveness of court-based intervention programs.

\section{Literature Review}

Domestic violence (including dating violence) and family violence (e.g., sibling and parental violence) are separate phenomena, characterized by variances in the nature of the violence and in the backgrounds of offenders and victims. Yet domestic and family violence share two common features. First, the research indicates that domestic and family violence among adolescents has longlasting effects and is a serious problem in the United States. Second, domestic and family violence committed by juveniles is largely invisible to the public eye.

\section{Domestic Violence}

The literature on dating and domestic violence focuses on prevalence, effects, risk factors, and legislative responses. Four findings are of particular significance:

1. A high percentage of adolescent women have been physically or sexually abused by a dating partner, yet the crime remains a "hidden epidemic."

2. Dating violence is associated with long-term physical and emotional harm.

3. Dating and domestic violence is more prevalent for certain at-risk teens.

4. State laws have tended to overlook dating and domestic violence committed by minors. 
The National Violence Against Women Survey estimates that approximately 1.5 million women are raped and/or physically assaulted by an intimate partner every year (National Institute of Justice, 2000). This type of violence is the largest cause of injury to women ages 15 to 44 (National Institute of Justice). The National Crime Victimization Survey estimates that approximately 22 percent of all female victims of violence in the United States were attacked by an intimate partner, compared to just 3 percent of all male violence victims (Bureau of Justice Statistics, 2001). According to the Federal Bureau of Investigation, in 1997 almost one-third (29 percent) of all female homicide victims were killed by their husbands or boyfriends, a rate that has remained relatively constant since 1976 (Owens-Manley, 1999).

While the prevalence of domestic violence among adults has been acknowledged, the occurrence of domestic or dating violence among adolescents was ignored until recently. In 2001, a groundbreaking study published in the Journal of the American Medical Association (JAMA) suggested the perversity and detrimental impact of dating violence among adolescents (Silverman, Raj, Mucci, \& Hathaway, 2001). The study of adolescent girls in ninth through twelfth grades found that:

- $\quad$ One in five female students reported being physically and/or sexually abused by a dating partner.

- Physical and sexual dating violence against adolescent girls is associated with increased risk of substance use, unhealthy weight control behaviors, sexual risk behaviors, pregnancy, and suicidality.

The authors concluded that "dating violence is extremely prevalent among this population, and adolescent girls who report a history of experiencing dating violence are more likely to exhibit other serious health risk behaviors” (p. 572).

In the last few years, several articles have appeared on the subject of "teen dating violence" or "teen relationship violence.” Prevalence estimates vary widely, partly due to different definitions 
of the violence and different measures used for the abuse. However, despite the broad estimates of prevalence estimates, it is clear that a substantial number of adolescents are engaged in teen dating violence, and that there is a high probability of recidivism in adolescent dating abuse (Foshee, Benefield, Ennett, Bauman, \& Suchindran, 2004).

Dating/domestic violence among adolescents has been linked to specific risk factors. Domestic violence in the youth population is very often an outcome of learned behavior, as research has shown repeatedly the negative effects of growing up in a violent household. For instance, O’Keefe (1997) found that male high school students were more likely to inflict violence against a dating partner when they had witnessed interparental violence and were more likely to believe that male-female dating violence was justifiable when they had witnessed such violence. Wolfe and Feiring (2000) found that risk factors for dating violence included a history of maltreatment, alcohol and drug use, relationship conflict, socioeconomic disadvantage, early attachment problems, attitudes justifying violence, and exposure to community violence. Morris, Anderson, and Knox (2002) indicated the following risk factors for the perpetration of sexual abuse and/or assault: exposure to violent parents at home, being a victim of physical or sexual assault, having parents who encourage gang membership, and knowing a perpetrator of sexual violence. Sagatun-Edwards, Hyman, Lafontaine, and Nelson-Serrano (2003), who studied the impact of the Santa Clara County Juvenile Domestic and Family Violence Court, found that domestic violence offenders were more likely to have parents with a history of domestic violence, criminal backgrounds, and substance abuse. A number of other studies have also demonstrated that interparental violence or child abuse was an important predictor that a youth would commit dating violence (Bank \& Burraston, 2001; Breslin, Riggs, O'Leary, \& Arias, 1990; Chapple, 2003; Foo \& Margolin, 1994; Marshall \& Rose, 1990; Wolfe, Wekerle, Scott, \& Straatman, 2004). However, some studies have also found no correlation (Arriago \& Foshee, 2004;Lavoie, Tremblay, Vitaro, Vezina, \& McDuff, 2002). 
Juvenile domestic violence appears to begin in the early teen years (Bethke \& Dejoy, 1993).

Of particular risk are teen mothers: About 41 percent of adolescent mothers become victims of intimate partner violence within 24 months after giving birth to their children (Harrykissoon, Rickert, \& Wiemann, 2002). A study by the American Nursing Association found that pregnant and parenting teens were at greatest risk for abuse in their relationships (Justice Research and Statistics Association, 1995). Sagatun-Edwards et al. (2003) found that more than 30 percent of the domestic violence offenders and victims in Santa Clara's court-based intervention program had children together, and that many of the victims reported that they had experienced violence while pregnant. Domestic violence among youth is not unique to a particular race, ethnicity, or socioeconomic status. Studies supporting a link to race have been inconclusive and contradictory. For instance, Makepeace (1987) suggested that teen dating violence is higher among African Americans, while Lane and Gwartney-Gibbs (1985) indicated higher levels of dating violence among Caucasian youth. Sagatun-Edwards et al. (2003) found that domestic violence juvenile offenders coming to the attention of a specialized court tended to be Hispanic males. The most comprehensive study yet (Silverman et al., 2001) concluded that dating violence showed no clear racial and ethnic differences.

Traditionally, juvenile courts and state laws have ignored the prevalence of adolescent domestic and family violence and the special problems it presents. Domestic violence laws vary considerably from state to state. Even within a state's penal, family, health, and civil codes, the definition of domestic violence can vary. Two common restrictions frequently result in the practical exclusion of adolescents from the protection of domestic violence statutes. First, many states have marriage, cohabitation, or parental requirements-21 states do not include dating violence in their definitions of domestic violence (National Center for Victims of Crime, 2002). Second, some states have age restrictions in their domestic violence legislation that exclude minors (Levesque, 1997; 
National Center for Victims of Crime). Even teens who are co-parents or who were or are cohabitants are denied relief in twelve states because these statutes specifically require majority status or emancipation (Suarez, 1994). For example, until recently California penal code defined domestic violence as:

abuse committed against an adult or a fully emancipated minor who is a spouse, former spouse, cohabitant, former cohabitant, or person with whom the suspect has had a child or is having or has had a dating or engagement relationship (C.R.S $\S 13700$ (b)).

In September 2002, the California governor approved Assembly Bill 2826. The Bill expanded sections 836 and 13700 of the penal code so that "domestic violence” now includes “abuse against any minor who is involved in one of those relationships or who previously had one of those relationships with the suspect.”

The exclusion of minors from domestic violence laws in many states carries over to protection orders. Only seventeen states provide a mechanism for minor victims of dating violence to apply for protective orders, and some of those states require the involvement of an adult (National Center for Victims of Crime, 2002). The current state of affairs led Levesque (1997) to conclude:

The failure to incorporate adolescents into domestic violence policies engenders a brutal social reality: adolescents are left without legal recourse and without mandated or otherwise available services. In essence, therefore, adolescent battering remains invisible (p. 357).

\section{Family Violence}

Family violence, such as violence between siblings or child and parent, appears to be increasingly problematic in the United States. However, there are no comprehensive studies of family violence that offer reliable data on incidence and prevalence. Nevertheless, the following statements are emerging as the cornerstone of future studies: 
This document is a research report submitted to the U.S. Department of Justice. This report has not been published by the Department. Opinions or points of view expressed are those of the author(s) and do not necessarily reflect the official position or policies of the U.S. Department of Justice.

1. Violence between siblings appears to be common.

2. Youth who are violent toward their parents often have a history of child abuse.

3. Findings from a specialized court program suggest that youth family violence may be associated with gender and mental illness.

Sibling violence may be a common feature of family life. In Lockwood's (1997) study of violence among adolescents, 15 percent of all violent incidents involved a family member-mostly siblings or cousins. Wilson and Fromuth (1997), in a retrospective study of college students, found that 65 percent of the students reported experiencing very severe physical abuse by a sibling, with 17 percent reporting injuries as a result of the family violence. Wiehe (1997) argued that sibling abuse is often an unrecognized form of violence that can leave terrible scars for life.

Youth violence directed toward parents is not very well understood. Brezina (1999) suggested that teen violence toward parents often is due to lack of parental attachment and can best be explained as having been learned from a model of parental punitiveness. Sagatun-Edwards et al. (2003) found that family violence offenders in the Santa Clara court program were likely to have been abused children, and that family violence offenders were twice as likely to victimize their parents than their siblings. Some researchers have focused on the extreme form of parental abuseparricide. For example, Mones (1994) found that most youth who kill their parents have been severely abused over a long period. In fact, child abuse is so well recognized as a precursor to parricide that the "abused child syndrome" has been used successfully as a defense in several notable cases involving children who have killed their parents (Sagatun \& Edwards, 1995).

The number of juvenile family violence cases entering the court system represents a small proportion of the actual levels of juvenile violence. Since few juvenile courts or probation officers screen for this type of violence, and there may be no formal charges brought against the youth, it is difficult to gauge how much family violence affects the juvenile justice system. In a study of the Miami-Dade County Juvenile Court, Langer (1997) found that a "significant portion” of cases 
processed by the court involved juveniles who had perpetrated violence against their parents or siblings, with the primary victims being mothers.

The Sagatun-Edwards et al. (2003) study of the Santa Clara Juvenile Domestic and Family Violence Court found that white females with a history of mental illness composed a large percentage of family violence offenders. In fact, more than 40 percent of the family violence offenders had a history of mental illness (Sagatun-Edwards et al.). If this finding can be replicated to other jurisdictions, it has broad implications on the ability of the justice system to respond to complex mental health issues in the juvenile population.

\section{Juvenile Justice System Responses}

California provided the setting for this study. Three juvenile justice systems located in the San Francisco Bay area participated in the study. Two of the counties — Santa Clara and San Francisco-have specialized court-based intervention programs to address juvenile domestic and family violence, but with notable differences in case processing and case volume. The third county, Contra Costa, was selected due to its proximity to Santa Clara and San Francisco and because it does not have a specialized program. Essentially, the Santa Clara and San Francisco programs are programmatic sites that can be compared with Contra Costa County, a site that does not have a specialized court or probation program for juvenile domestic/family violence offenders.

\section{Demographics}

All three counties are ethnically diverse, but differ in the composition of various racial and ethnic groups. Exhibit 1.1 shows the population of each county by race and ethnicity. Santa Clara is by far the largest county, with almost 1.7 million residents. Santa Clara County is more heavily Hispanic/Latino than either San Francisco or Contra Costa. Santa Clara and San Francisco have 
sizeable Asian communities (26 and 31 percent, respectively), compared to Contra Costa (11

percent). Contra Costra has the largest African-American population.

\section{Exhibit 1.1: County Population by Race and Ethnicity, 2000}

\begin{tabular}{lccc} 
& Santa Clara & San Francisco & Contra Costa \\
\cline { 2 - 4 } Population, 2000 & $1,682,585$ & 776,733 & 948,816 \\
\hline Race & & & \\
White/Caucasian & $53.8 \%$ & $49.7 \%$ & $65.5 \%$ \\
Black/African American & $2.8 \%$ & $7.8 \%$ & $9.4 \%$ \\
\hline American Indian/Alaska Native & $0.7 \%$ & $0.4 \%$ & $0.6 \%$ \\
Asian & $25.6 \%$ & $30.8 \%$ & $11.0 \%$ \\
\hline Native Hawaiian/Other Pacific Islander & $0.3 \%$ & $0.5 \%$ & $0.0 \%$ \\
Some other race & $12.1 \%$ & $6.5 \%$ & $8.1 \%$ \\
\hline Two or more races & $4.7 \%$ & $4.3 \%$ & $5.1 \%$ \\
\hline Ethnicity & & & \\
$\quad$ Hispanic or Latino & $24.0 \%$ & $14.1 \%$ & $17.7 \%$ \\
\hline
\end{tabular}

Source: U.S. Census Bureau, 2000

\section{California Juvenile Justice}

The Juvenile Court (a division of the Superior Court) oversees the juvenile justice system in

California. The probation department is an arm of the court and oversees the day to day operation of

the juvenile justice system. Generally, the juvenile justice system works in the following manner. ${ }^{1}$

1. A law enforcement officer responds to incidents involving juvenile offenders. The officer has the discretion to release juveniles to their parents, cite the offenders, or take the juveniles to juvenile hall.

2. Once taken to juvenile hall, offenders will be interviewed by an intake officer from the county probation department, which runs juvenile hall. The intake officer has the discretion to accept and "book" juveniles or release them to their parents.

3. If the juvenile is booked, the probation department has the discretion to solve the case without court action, but in serious cases the probation officer must consult with the district attorney. Only the district attorney has the legal authority to file a petition alleging that the youth should come under the jurisdiction of the court. The district attorney can also request that the juveniles be "remanded" to adult court because of the nature of their offenses.

4. Juveniles appear in court first at a detention hearing (if they have been detained). The second hearing is at an adjudication hearing (also called a jurisdictional hearing) at which time the judge determines whether the charges are true.

\footnotetext{
${ }^{1}$ See the California Welfare and Institutions Code, 2006.
} 
5. At the disposition (sentencing) hearing, the judge will receive the probation/social worker's written report, medical, psychiatric or other reports, and other evidence or arguments.

a. For minors whose petitions are sustained in juvenile court, the offenders may be placed on probation in the community, placed in a foster care or group home, incarcerated in the county’s juvenile ranch or camp, or sent to the California Youth Authority.

b. Juveniles may be declared "wards" of the court, in which the "care, custody and control" of the minors are taken from their parents or guardian and given to either the County Probation Department or the California Youth Authority.

The Center on Juvenile and Criminal Justice (2003) reports that for every 1,000 youths who are cited by the police in California, only 100 will be referred to a probation department. Data from 2003 indicates that the probation department made a total of almost 155,000 dispositions in juvenile cases in 2003-about one-third of cases were closed at intake. Exhibit 1.2 outlines the process starting with probation department dispositions and proceeding to juvenile court-ordered sanctions.

\section{Exhibit 1.2: California Juvenile Justice Dispositions and Sanctions, 2003}

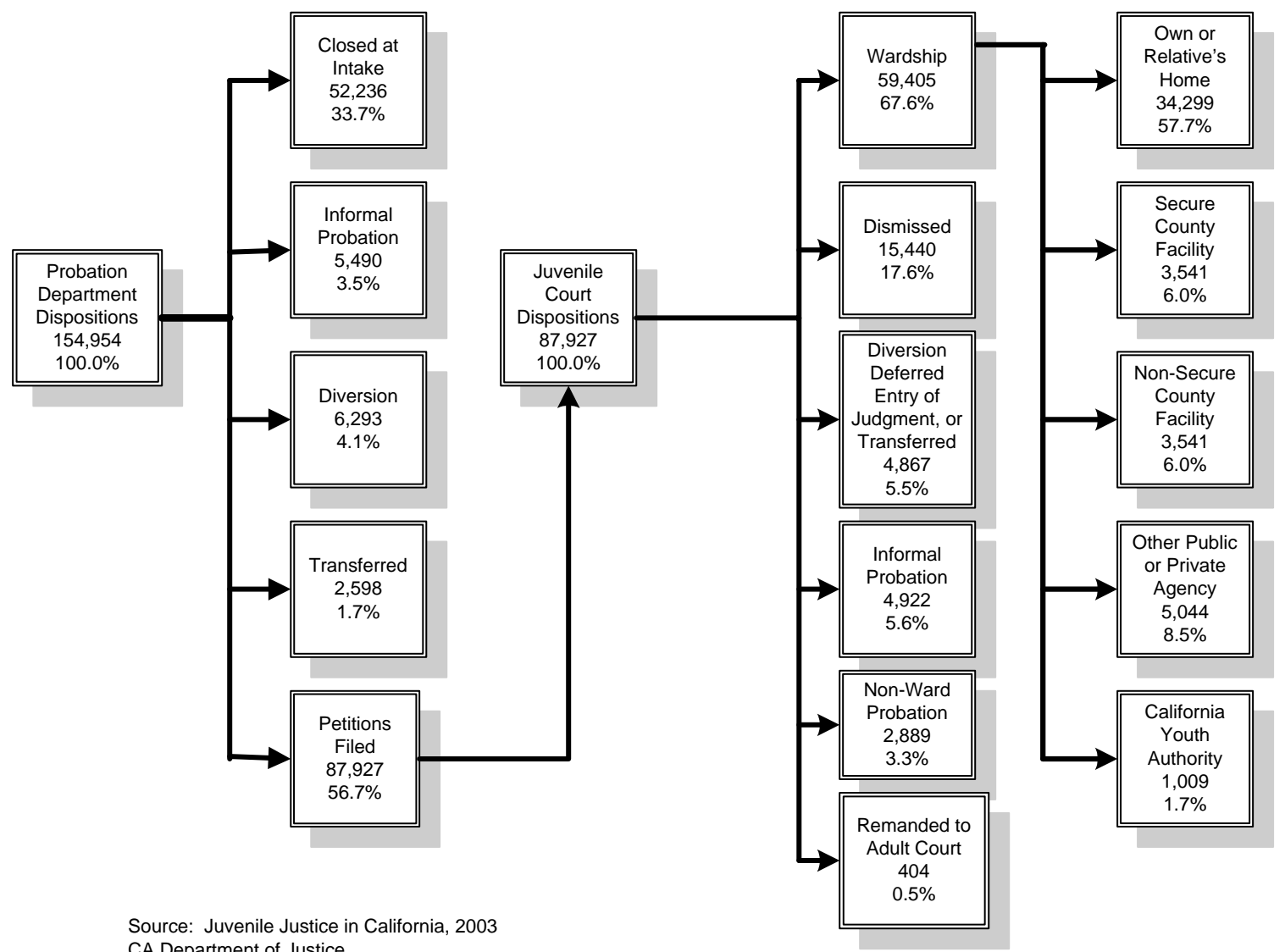


The types cases studied in this project are “602” delinquent offenses— offenses that would be considered criminal if committed by persons over age $18 .^{2}$ Generally, juvenile cases may be handled either formally or informally, depending on the type of offense, the background of the offender, and the availability of resources. State law requires the probation officer to refer serious cases to the district attorney for review and for determination of the charges. The District Attorney's Office determines if the case will proceed through the courts or be turned back to probation for informal supervision. If the district attorney decides that there is enough evidence of wrongdoing to file a court petition, a 602 Petition to have the case heard in front of a juvenile court judge will be filed. ${ }^{3}$ If the court finds the facts stated in the petition to be true, the child becomes a "ward" of the court as a delinquent.

California Welfare and Institutions Code, Section 654, addresses informal supervision and diversion programs. Diversion programs, usually for first-time, non-violent offenders, may be run by county probation offices, county district attorneys' offices, or community-based organizations. If the case is handled through a diversion program or informal supervision, the juvenile may be required to pay restitution, participate in counseling and/or educational programs, or participate in community service or mediation programs. By statute, participation in a diversion program must not exceed six months, and if a juvenile does not participate in an ordered program within 60 days, a petition may be filed with the juvenile court.

Cases that are handled formally are adjudicated in an Adjudicatory or Jurisdictional hearing where a judgment is made concerning the juvenile’s guilt. A juvenile record is created, although

\footnotetext{
2 Status offenses such as truancy are referred to as 601 offenses.

3 The District Attorney's office may send the referral back to the probation officer if they feel the juvenile would benefit from informal supervision.
} 
records can later be sealed. ${ }^{4}$ In some cases that are handled informally the minor does not admit guilt and chooses to follow certain conditions of probation. In such cases, a juvenile record is not generated unless a 602 Petition is later brought forward and found true by the court. Appendix B provides additional information on the decision points in the California juvenile justice system.

\section{Santa Clara County}

Santa Clara County is a large urban county (population about 1.7 million), best known for Silicon Valley with San Jose as the largest city $(950,000)$. In 1999, the Santa Clara County Juvenile Domestic and Family Violence Court was established in San Jose, California—-the first of its kind in the nation. ${ }^{5}$ The District Attorney's Office, the Public Defender's Office, and all law enforcement agencies in the county participated in developing protocols for case referrals and processing, and team members hold monthly meetings. The majority of domestic/family violence cases in Santa Clara are put on formal probation—93 percent of family violence offenders receive formal probation. The program features a special intake unit to identify cases involving domestic or family violence. Key components of the court-based program include the following6:

- Assessment. Domestic and family violence cases are identified at the intake process by specially trained probation officers who conduct a detailed risk assessment. ${ }^{7}$

4 Any person who has a juvenile record and is at least 18 years old and/or five or more years have passed since the termination of juvenile probation, last arrest, or closure may petition the court to have his or her record sealed. There are some exceptions based on type of crime and current conditions.

5 The program was initiated by Judge Eugene Hyman of the Santa Clara County Superior Court, with augmented funding for the specialized domestic/family violence unit provided by the Santa Clara County Board of Supervisors. Additional funding was provided for evaluation and some of the intervention components in a grant from the Juvenile Delinquency Prevention Branch of California’s Office of Criminal Justice.

6 See Sagatun-Edwards et al. (2003) for a complete overview of the processes and procedures of the Santa Clara County Juvenile Domestic and Family Violence Court.

7 California’s domestic violence statute (C.R.S $\$ 13700$ (b) is applicable to fully emancipated minors The probation intake unit focuses on violations of section 273.5, 243(e), PC 245, and PC 422 of the California Penal Code or any other criminal acts occurring between persons as defined in section 6211 of the California Family Code. (While PC 273.5, the main PC domestic violence code, does not include age limitations, it only applies to persons who are married, co-habitants or have a child together. Minors who frequently do not fall into those categories are more commonly charged with 243(e, 245 or 422.) Several other acts such as terrorism and stalking directed toward an intimate partner or family member, and vandalism directed towards property of an intimate partner or family member, are included under the domestic/family violence rubric. In addition, the intake unit also focuses on risk factors such as a family history of child abuse, domestic violence, or criminal background. 
This document is a research report submitted to the U.S. Department of Justice. This report has not been published by the Department. Opinions or points of view expressed are those of the author(s) and do not necessarily reflect the official position or policies of the U.S. Department of Justice.

- Specialized Prosecution and Defense. Both the District Attorney's Office and the Public Defender's Office have specially trained attorneys to handle juvenile domestic and family violence cases.

- Dedicated Docket. One afternoon a week is set aside exclusively for domestic and family violence cases. ${ }^{8}$

- Intensive Supervision. Batterers are subject to periodic reviews by the court, as well as intensive probation supervision in a specialized domestic violence/family violence unit that stresses accountability and competency skills for healthy relationships.

- Offender Programs. The teen group batterers program is a major component of the court-based intervention, supplemented by substance abuse programs, mental health programs, or other counseling as needed.

- Victim Services. Victims are offered direct and confidential victim advocacy, support groups, legal assistance, court accompaniment, assistance with Victim/Witness claims, and resource referrals.

All service providers that come into contact with the domestic violence and family violence cases receive special training in issues related to domestic and family violence. This includes probation department staff, the judge, law enforcement officers, court personnel, juvenile hall and county ranch staff, attorneys, and other service providers. Local law enforcement plays a key role in the creation of the program and all county law enforcement agencies have agreed to a protocol that requires officers to take juveniles accused of domestic or family violence to juvenile hall—the majority of offenders are detained until they appear in the Juvenile Domestic and Family Violence Court for a detention hearing. If a petition alleging domestic/family violence is filed by the District Attorney's Office, the case is assigned to the specialized juvenile domestic/family violence court, which hears such cases every Wednesday. If the petition is sustained at the adjudicatory hearing, offenders are typically assigned to the specialized probation unit where they are subjected to intensive supervision. Offenders are ordered into appropriate treatment and intervention programs and must return to the court for review hearings (typically varying from 30 to 60 days, depending on the seriousness of the case).

The law enforcement protocol that requires all suspected domestic/family violence offenders to be brought to the juvenile hall for assessment, and the broad definition of what constitutes 
domestic/family violence, result in a rather large volume of cases in Santa Clara. It should also be noted that domestic/family violence cases may also include other potential charges, such as gangrelated, property, or other violence charges related to a domestic/family violence incident. The specialized probation unit has a ceiling of 70 active cases; thus some of the cases identified as domestic/family violence cases by the intake unit are assigned to regular geographic units while still heard in the specialized court calendar. ${ }^{9}$

The teen group batterers programs have a curriculum especially directed at the young teen offenders. In Santa Clara County, three to four different providers run the teen group batterers program. All are separated by gender, and most by domestic/family violence offenders. Minors and/or parents are required to pay $\$ 15$ per session, while the county provides for the rest of the expenses. During the time of the data collection, the Board of Supervisors had just cut the funding for the teen batterers program due to overall budget constraints, and the court and probation department were exploring different avenues of funding.

An important aspect of the Santa Clara County specialized court are the monthly meetings called by the judge with attendance by all staff and service providers involved in the project, including the probation officers and a community worker from the specialized probation unit, the teen group batterers program service providers, representatives from the District Attorney’s and the Public Defender's Offices, court staff, juvenile hall and ranch staff, mental health agencies, Victim Witness staff, legal staff, victim advocacy agencies, school representatives, and evaluation researchers from San Jose State University. An important indirect benefit of the program is the increased communication and cooperation across different agencies.

8 The typical weekly caseload is twenty to thirty cases.

9 The high proportion of family cases with a mental health diagnosis also led to the establishment of a specialized mental health court calendar a few years ago, and many cases are now assigned to that court. Similarly, subsequent to the time period included in this data collection, due to the high caseload and the different nature of the family 
The Santa Clara model may be described as primarily a "formal probation" model. The model looks at any juvenile domestic violence or family violence incident as a serious problem and assumes that early formal intervention is the best way to prevent further incidents. This model must be viewed in the context of the larger community setting. In general, Santa Clara County is known to have a strong law enforcement and prosecution response to crime, and San Jose prides itself on being the safest large city in the U.S. according to official crime statistics.

\section{San Francisco County}

San Francisco County has a much smaller population than Santa Clara County with a population of 776,733 in 2000. The city of San Francisco and the County of San Francisco are contiguous. In September 2001, a new specialized domestic/family violence court program began operating in San Francisco County's Unified Family Court, first based on the Santa Clara County program.

The San Francisco program shares many similarities to the Santa Clara program—a specialized docket, review hearings, specialized probation unit, designated district attorney and public defender, intensive supervision, victim services, and offender programs. Yet the program varies in philosophy from the Santa Clara County court program, with most cases placed on informal probation under court supervision (only about 25 percent of family violence offenders in this study received formal probation). The county also does not have a law enforcement protocol that requires all suspected domestic/family violence cases to be brought to the juvenile hall for assessment by the specialized probation intake unit. Instead, law enforcement often brings less serious cases to the attention of various community agencies for informal intervention. Thus, the 
case load of domestic/family violence cases in San Francisco County is much smaller than that of Santa Clara County.

The Family Violence Court holds hearings once every other Thursday and requires offenders to appear at review hearings every two weeks, at least initially. The smaller caseload in San Francisco makes it possible for the judge and the probation department to devote more time to each case. As in Santa Clara County, all personnel who come in contact with the domestic/family violence cases are given specialized training in domestic and family violence issues. Similarly, cases with domestic/family violence charges are typically referred to the dedicated court, even if other charges are also involved. However, as the specialized court in San Francisco only meets every other week, many cases are also referred to the regular delinquency calendars. Teen victims are offered a life-skills program sponsored by SAGE, and offenders are assigned primarily to individual teen batterers counseling funded by the County Public Health agency. There is no co-payment required for the offenders and their families.

According to the San Francisco model, juveniles are more likely to conform to the courtimposed conditions if they know that the petition will be dismissed at the end of successfully completing all programs. Thus, the San Francisco model can be described as primarily an "informal supervision and deferred entry of judgment (DEJ) program." Again, as in Santa Clara, other options, such as formal probation are also exercised, depending on the seriousness of the case. The San Francisco model must be seen in the larger context of San Francisco County, which tends to have a much more liberal and less law enforcement-oriented response to crime than Santa Clara County. 


\section{Contra Costa County}

Contra Costa County is in the Bay Area and has a population of 948,816 (2000 Census). The county has several middle sized cities, but not any single large city. Contra Costa County does not have a law enforcement protocol that requires all domestic/family violence cases to be brought to the attention of the juvenile hall. The juvenile court and probation department do not screen for domestic or family violence and do not have any specialized staff to address this particular problem.

Probation supervision and conditions of probation are determined on a case-by-case basis. The county favors the use of formal probation—68 percent of family violence offenders included in this sample received formal probation. In cases that clearly involve domestic violence, the probation department may refer juveniles to a domestic violence intervention program in the community. However, the most common response to cases involving domestic or family violence is assignment to an anger management program. As Contra Costa County does not have a specialized juvenile domestic and family violence program, cases that come in with other, perhaps more serious charges are therefore less likely to be seen as specific domestic/family violence cases.

The Contra Costa probation department has a highly regarded program that assigns probation officers to schools, where they act as resource officers. The probation department is proactive and supports school-based activities to prevent juvenile delinquency. It also has a probation unit with intensive supervision, but not devoted to domestic/family violence cases. It appears that the county is more similar to Santa Clara County in its use of formal probation and declaring the minor a ward of the court than to San Francisco County.

\section{Study Methodology}

In 2003, the National Center for State Courts, in partnership with the American Probation and Parole Association and Dr. Inger Sagatun-Edwards of San Jose State University, received a 
grant from the National Institute of Justice to study the effectiveness of the court-based intervention programs. The study design was based on results from an evaluation of the Santa Clara court, conducted by Dr. Sagatun-Edwards of San Jose State University and her colleagues. SagatunEdwards et al. (2003) found that the Santa Clara program "is effective for those completing it, at least for the follow up period of one to two years."10

\section{Research Design}

The Sagatun-Edwards et al. (2003) study led to three primary research questions. First, are the backgrounds and descriptors of the domestic/family violence population similar in different jurisdictions? Second, how will the interventions in a specialized domestic/family violence court differ from one county to the next? Third, are there any positive long-term recidivism results from such interventions? The implementation of the San Francisco program in 2001 proved an ideal setting to study the effectiveness of different court-based intervention models. Furthermore, the addition of a comparison county without such a program (Contra Costa County) added to the explanatory strength of statistical modeling. Thus, a quasi-experimental research design incorporating two "experimental” groups and a “comparison group” was used to examine program effects on recidivism and offender behaviors. ${ }^{11}$

The methodology involved two separate phases: contextual analysis and program evaluation. Contextual analysis was necessary to identify variances in court/probation processing and case treatment and was a prerequisite to the collection of data. The program evaluation included an analysis of the background of the minors in the program, the incidents and interventions involved,

10 The evaluation was supported by a three-year grant from the California Office of Criminal Justice Planning (\#JU98011381).

11 Permission and/or court orders were obtained from the Presiding Judge of the Juvenile Court in all three counties to code juvenile probation and court records for this study. 
and most importantly, an outcome evaluation focusing on the impact of court, probation, and treatment on individual levels. ${ }^{12}$ The types of questions addressed in the methodology included the following:

1. What is the sociodemographic background and delinquency record of the juvenile offenders of domestic and family violence? Are there variances by type of violence (domestic versus family)?

2. What is the offender's history of parental family violence, abuse, criminality and substance abuse? Are there differences based on the type of violence?

3. How were the intervention programs implemented? How do the programs vary across sites? How are juveniles in the control group treated?

4. What is the relationship between the intervention programs and recidivism rates for new domestic and family violence offenses? Have the programs affected other types of delinquency or adult crimes and probation violations?

5. What is the recidivism rate for the minors in the intervention programs compared to those in the control group? Is the program linked to other types of positive or negative offender behaviors (e.g., completion or dropping out of school)?

The contextual analysis was based on site visits to all three sites; the initial site visit was conducted in March 2004, with a follow-up visit in March 2005. In Santa Clara and San Francisco counties, the research team interviewed agency and community-based staff participating in the programs, observed court hearings, and collected agency protocols and reports. In Contra Costa County, staff interviewed the presiding juvenile judge and probation staff. An interview protocol guided the interview sessions to ensure that similar types of information were collected across all participating sites. Site visits were used to develop an implementation guide, which can be found at the end of this report, and to inform the study.

The program evaluation was designed to primarily to assess the effectiveness of the intervention programs on recidivism and offender behavior. In this phase, the research team (1) documented the sociodemographic, experiential, and delinquency backgrounds of juvenile domestic/family violence offenders, (2) explored the intervention programs' effects on offender

12 A description of the Santa Clara County court process is already available. For this reason, the evaluation of the Santa Clara County court involved follow-up with staff rather than a full-scale evaluation. 
behavior in general, and (3) determined recidivism rates for domestic/family violence juvenile offenders. The major sources of information were probation files, court records, and adult criminal records. Recidivism data was collected from juvenile probation files as well as criminal record checks. Adult records were checked up to August 31, 2005-allowing a period of six years from the time in which the Santa Clara program first began operations, and four years from the time in which the San Francisco court program first started. In Contra Costa County, adult criminal records were checked from September, 1999 through August, 2005. The adult criminal records were provided from the probation department or court personnel in all three counties, using the records from CJIC, the California Criminal Justice Information Control. Each county was asked to search the records for all the cases in our juvenile data files.

\section{Case Selection}

A decision was made early on to only code the closed cases in all three jurisdictions, so as to be able to capture the final outcome of each case. The major challenge in the selection of cases was drawing a comparable sample of cases across all three counties. In Santa Clara County and San Francisco County, the probation departments provided a list of all the cases assigned to their juvenile domestic/family violence courts for the following periods:

1. September 1999 to August 2003 for Santa Clara County, ${ }^{13}$ and

2. September 2001 to August 2003 for San Francisco County.

Since there was no such list available in Contra Costa, researchers first had to identify domestic/family violence cases from the general caseload. After a review of offenders in the Santa

13 In Santa Clara County, such a list was only available through June 2003; the remainder of the cases assigned to the court were found by going through the specialized Juvenile Court files. 
Clara Juvenile Domestic and Family Violence Court, the Contra Costa cases were initially selected by the major domestic/family violence penal codes and other batterer/assault codes that potentially might have involved a teen relationship violence or family violence incident. The Probation

Department technical staff in Contra Costa County searched all their case records during the period from September 1999 to August 2003 for cases adjudicated with the charges listed below. The research team also asked the staff to indicate whether the case was still open or closed. The charges in the search included:

Penal Code 273.5 - willfully inflicting upon a person who is his or her spouse, former spouse, cohabitant, former cohabitant, or the mother or father of his or her child, corporal injury resulting in a traumatic condition.

Penal Code 243(e) - battery committed against a spouse, a person with whom the defendant is cohabiting, a person who is the parent of the defendant's child, former spouse, fiancé, or fiancée, or a person with whom the defendant currently has, or has previously had, a dating or engagement relationship.

Penal Code 245 - assault upon the person of another with a deadly weapon or instrument other than a firearm or by any means of force likely to produce great bodily injury.

Penal Code 422 - any person who willfully threatens to commit a crime which will result in death or great bodily injury to another person, with the specific intent that the statement, made verbally, in writing, or by means of an electronic communication device, is to be taken as a threat.

In Contra Costa County, this search resulted in a list of 381 potential cases. A research assistant reviewed all the probation files to determine which cases involved a domestic or family violence relationship between the parties. The number of cases with qualifying offenses in Contra Costa totaled 381 active and closed cases; of these 78 closed cases (20.5 percent) were found to involve domestic or family violence as of September 30, 2005, when we finished our coding.

A number of cases identified as domestic or family violence, primarily in Contra Costa County, were dismissed either before reaching the court or because the court determined that the case was a dependency case rather than a delinquency case. These cases were excluded from our analyses as they were not comparable to our sample of cases that received the court-based 
intervention in Santa Clara and San Francisco Counties. There were a total of 304 cases included in the entire sample-Santa Clara County accounted for 66 percent of all cases. ${ }^{14}$ The final number of domestic/family violence cases included in the study is shown in Exhibit 1.3 (the timeframes are based on the initiation of the Santa Clara County and San Francisco County court programs).

Exhibit 1.3: Timeframe for Data Collection and Follow-up

\begin{tabular}{lccc} 
Sample selection and timeframes & Santa Clara & San Francisco & Contra Costa \\
\hline $\begin{array}{l}\text { Domestic/Family Violence Offenders, } \\
\text { September 1999 to August 2001 }\end{array}$ & $\begin{array}{c}\text { Intervention } \\
\text { Program } \\
\mathrm{N}=67\end{array}$ & No Program & No Program \\
\hline $\begin{array}{l}\text { Domestic/Family Violence Offenders, } \\
\text { September 2001 to August 2003 }\end{array}$ & $\begin{array}{c}\text { Intervention } \\
\text { Program } \\
\mathrm{N}=135\end{array}$ & $\begin{array}{c}\text { Intervention } \\
\text { Program } \\
\mathrm{N}=40^{*}\end{array}$ & $\mathrm{~N}=40$ \\
\hline TOTAL & $\mathrm{N}=202$ & $\mathrm{~N}=40$ & $\mathrm{~N}=22$ \\
\hline
\end{tabular}

* Ten of the San Francisco cases occurred prior to September 2001 but were transferred to the specialized court when it was implemented.

Exhibit 1.3 notes that in San Francisco, ten cases assigned to the specialized domestic/family violence court were initially adjudicated prior to the initiation of the court and then assigned to the court program when it opened. The lower number of cases assigned to the court in San Francisco compared to Santa Clara County in the period September 2001 to August 2003 is likely due to the fact that San Francisco is a much smaller county, that it does not have a law enforcement protocol requiring all domestic/family violence cases to be delivered to the intake unit at the juvenile hall, and that minor cases are more likely to be handled by other community agencies. In Contra Costa County, cases were included for the same time period as in Santa Clara County.

14 Note that the programming in Santa Clara County (and to some degree in San Francisco County) included additional charges to those listed above for Contra Costa County, such as penal codes related to stalking, terrorism, and vandalism of partners' or family members' property. We did not ask probation staff in Contra Costa to search for these additional codes due to the additional time and effort it would have entailed. 


\section{Data Collection and Analysis}

Permission was first granted by the Presiding Judge of each Delinquency Court to review juvenile probation and court files in order to code relevant information. An extensive code book was developed by the research team prior to the data collection and pre-tested on a number of cases. Both quantitative and qualitative data were collected. Coding sheets were used to quantify data collected from probation files, court files, and criminal record checks (see Attachment A). The actual coding took place at the probation department or juvenile court file rooms at each site, and an extensive Excel spreadsheet was developed to keep track of which cases had been coded and which cases had moved from "active” to "closed” status. At each site, several cases assigned to the specialized courts were still "active” at the end of the coding period (September 2005) or were missing from the file rooms. Such missing cases were most often due to a change in jurisdiction to another county or state. The coding sheet included a section to write in textual information from probation files that addressed three issues:

1. Offender's family background (especially in terms of child abuse/neglect and victimization).

2. Description of actual incident.

3. Description of success/failure and reasons for such.

Quantitative data were entered into a SPSS database and analyzed using bivariate and multivariate statistical tests, with survival analysis used to address recidivism rates. Textual information was entered into a NVivo database where it was subjected to content analysis. The combination of quantitative and qualitative data provided a rich description of the nature of violence and increased the explanatory power of the study. 
This document is a research report submitted to the U.S. Department of Justice. This report has not been published by the Department. Opinions or points of view expressed are those of the author(s) and do not necessarily reflect the official position or policies of the U.S. Department of Justice.

\section{Study Limitations}

The study is limited in a number of ways. First, the samples are not entirely comparable because not all cases come to the attention of the probation department or courts. Of the three counties, Santa Clara has a law enforcement protocol that requires officers to bring juveniles involved in domestic or family violence cases to juvenile hall. The San Francisco program was developed with little to no law enforcement input, and local staff was uncertain whether the police department was following any protocols that would mandate juvenile hall in these types of cases. Nor does law enforcement in Contra Costa follow a protocol in juvenile cases involving domestic or family relationships. Consequently, police officer discretion and informal practices vary across sites and affect both the number and type of cases that come to the attention of the court.

Second, the final number of cases included in the study varies from county to county. While the Santa Clara County court study size is over 200, there were only 40 cases documented in San Francisco County and 62 cases in Contra Costa County that could be identified as juvenile family or domestic violence during the study period. The small number of cases in both San Francisco and Contra Costa counties has implications for statistical analyses. However, while these small number of cases was less than ideal, it afforded interesting descriptive data and multivariate analyses.

Third, the juvenile population is markedly different in the counties. In particular, the Contra Costa County juvenile offender population is more likely to have prior juvenile records than those in either Santa Clara or San Francisco County. The law enforcement approach of Santa Clara County draws a "wider net" of juveniles into the system. While this approach aims at addressing the problem before it escalates, the end result is that the juvenile offender populations in the counties under study differ on key background factors. Future studies that have larger numbers of cases should consider matching the offenders on several variables to increase comparability. This method was not available for the small sample sizes available in this study. 
Fourth, the project relies on probation and court files to assess program effectiveness.

Although these files included qualitative information based on probation officers' interviews with both offenders and victims, this study did not include separate interviews with offenders and victims and therefore lacks a first hand qualitative component based on their perspectives. While the proposal called for focus groups, they could not be conducted due to logistics and ongoing concerns about confidentiality. ${ }^{15}$ It is our hope that future studies can collect first-hand information from both offenders and victims. ${ }^{16}$

Fifth, the quality of the information collected is only as good as the information documented in official reports. In many cases, information was simply missing. In particular, information about a family history of child abuse and family violence was only coded if it was included in the probation and/or court files. Some probation officers were more likely to probe for this type of background information than others and run parental criminal and dependency records for the cases involved. To some extent, probation files were more likely to include background information than the court files. Research assistants in Santa Clara County had to use court files to code case information for the last three months of the data collection (as the specialized probation unit no longer had a master list available of all the cases assigned to those months and no staff to retrieve archived probation files),

15 The institutional review board had serious concerns that confidentiality could be maintained in a focus group setting.

16 The relative lack of information about victims in our study is mostly due to the fact that victims are not required to talk to or to provide information to the probation department. Also, identifying victim information could not routinely be released to victim services or victim advocacy agencies due to confidentiality concerns, thus making it less likely that victims would in fact take advantage of the information offered to them about available victim services. 
after originally relying on probation files as the primary source of information. ${ }^{17}$ The court files were not as complete as probation files in terms of family background and probation officers’ interview notes. Consequently, some of the data in Santa Clara County may be a residual effect of the change in the source of the data.

In spite of these limitations, the study methodology produced rich data that can be analyzed using statistical tools as well as content analysis. Yet some caution must be taken in drawing conclusions across sites. The three sites differ in population size and ethnic make-up, intervention programs, scope of definitions of domestic/family violence, law enforcement protocol and practices, juvenile offender backgrounds, and political climates. The results should therefore be interpreted as shedding light on how different counties deal with similar issues, rather than as giving definite answers as to which approach is most effective in preventing future domestic and family violence. Many more variables are involved than simply the particular response to domestic and family violence in the juvenile justice system. Nevertheless, much can be learned about the nature of domestic and family violence, and how different jurisdictions respond to this serious issue.

\section{Implications for Future Research}

An experimental design that randomly assigns juvenile offenders of domestic and family violence to varying doses of intervention is a challenging proposition in the real world of juvenile justice. The court operates under the dictate of equal treatment under the law, and does not lend itself to random assignments to different experimental treatment conditions. Even if such an experimental design could be implemented and produce a respectable number of cases without violating ethical and human subjects standards, a quantitative focus may overlook important nuances

17 The probation department suffered budget cuts part way through the study that made access to probation files extremely time-consuming and tedious. Research assistants had to rely on court files to complete the coding process. 
of the program that have an impact on the subjects. A triangulated approach that incorporates both quantitative and qualitative methodologies is warranted in future studies of juvenile domestic and family violence. In particular, the methodology should incorporate voices from the juveniles impacted by the program. Researchers may also choose to concentrate on either teen domestic violence or family violence. Finally, it is critical that any intervention programs be established with evaluation in mind, if at all possible. Studies such as this one that occur after-the-fact, are limited by the data and information that already exist. If an evaluation could be built into the design of a specialized court program, the research and project team could have the opportunity to develop measures and record information that can be used to scientifically demonstrate outcomes. 


\section{2 - The Nature of Juvenile Domestic and Family Violence}

In the Santa Clara and San Francisco County court programs, domestic violence was defined as violence between intimates, including spouses, boyfriend/girlfriend, and dating partners. Juvenile family violence was defined as violence between family members, including teens who engage in violence toward their siblings, parents, grandparents, aunts and uncles, and cousins. While Santa Clara County initially had separate domestic violence and family violence probation officers, both Santa Clara and San Francisco court-based intervention programs generally address domestic and family violence in a similar fashion. But this study finds that domestic violence and family violence are very different phenomena, with offenders sharing little in common. Key findings include the following:

\section{Population Statistics}

The vast majority of cases that involve domestic or family violence in the three jurisdictions in this study fall under the category of family violence. The types of cases that are brought to the attention of the probation department and courts are greatly affected by law enforcement protocols. In Santa Clara County, the protocol required officers to bring juvenile domestic and family violence offenders to juvenile hall for intake. In San Francisco and Contra Costa counties, there is no formal protocol that guides law enforcement in their response to these juvenile offenders. Exhibit 2.1 shows the proportion of family violence and domestic violence cases in each of the three counties.

Exhibit 2.1: Proportion of Domestic and Family Violence Cases in Three Counties Percentage of Cases

\begin{tabular}{lccc} 
& Number of Cases & Domestic Violence & Family Violence \\
\cline { 2 - 4 } Contra Costa & 62 & 21.0 & 79.0 \\
\hline San Francisco & 40 & 15.0 & 85.0 \\
\hline Santa Clara & 202 & 36.1 & 63.9 \\
\hline TOTAL & $\mathbf{3 0 4}$ & $\mathbf{3 0 . 3}$ & $\mathbf{6 9 . 7}$ \\
\hline
\end{tabular}


The cases that come to the attention of the probation department and courts are probably just a fraction of all domestic and family violence cases. Exhibit 2.2 provides data on the number of cases per 100,000 population, using the 2000 Census age group that most closely corresponds to our population (ages 15 to 19). The numbers of cases entering the system in one calendar year (2002) were used to ensure consistency across counties.

\section{Exhibit 2.2: Number of Juvenile Court Cases per 100,000 Population}

\begin{tabular}{lccc} 
& Santa Clara & San Francisco & Contra Costa \\
\cline { 2 - 4 } Number of 15 to 19 year olds, Census 2000 & 108,026 & 33,334 & 63,124 \\
\hline Number of Domestic Violence Cases, 2002 & 19 & 2 & 2 \\
$\quad$ Per 100,000 population & 17.6 & 6.0 & 3.2 \\
\hline Number of Family Violence Cases, 2002 & 59 & 12 & 6 \\
Per 100,000 population & 54.6 & 36.0 & 9.5 \\
\hline Total Domestic \& Family Violence Cases, 2002 & 78 & 14 & 8 \\
Per 100,000 population & 72.2 & 42.0 & 12.7 \\
\hline
\end{tabular}

The data show that the Santa Clara program, which includes a law enforcement protocol, casts the widest net -72 teens per 100,000 enter the program, compared to 13 teens per 100,000 in Contra Costa who can be identified through probation records as domestic or family violence offenders. The San Francisco program, which also includes a specialized intake process at juvenile hall, handled 42 cases per 100,000 population in 2002. In each county, family violence cases were at least three times more prevalent than domestic violence cases. These data indicate justice system responses_-they should not be interpreted as incidence rates.

\section{Domestic and Family Violence}

Domestic violence and family violence cases are very different phenomena. While some of the characteristics vary somewhat by jurisdiction, the following data strongly suggest that domestic violence offenders (1) tend to be older, (2) are more likely to be male, (3) are more likely to have a previous delinquency record, and (4) are less likely to have a history of mental illness than family violence offenders. Variables that showed statistically significant variances and for which there 
was consistency across sites are shown in Exhibit 2.3. Significant variances in offender

backgrounds warrant separate discussions of domestic violence and family violence. The narratives collected from the probation files also indicate contextual differences between domestic and family violence.

\section{Exhibit 2.3: Key Variables Distinguishing Domestic Violence and Family Violence Offenders}

\begin{tabular}{lcc|cc} 
& \multicolumn{2}{c|}{ Domestic Violence } & \multicolumn{2}{c}{ Family Violence } \\
\cline { 2 - 5 } Gender & $\mathrm{n}$ & Percentage & $\mathrm{n}$ & Percentage \\
\cline { 2 - 5 } Male & 83 & 90.2 & 133 & 62.7 \\
Female & 9 & 9.8 & 79 & 37.3 \\
\hline Age & & & & \\
Mean Age & 16.4 & 15.1 & \\
Median Age & 17.0 & & \\
\hline Offender Has a Record of Prior Juvenile Delinquency & & 97 & 46.0 \\
Yes & 55 & 59.8 & 114 & 54.0 \\
Not Indicated & 37 & 40.2 & & \\
\hline Offender Diagnosed with Mental Illness & & 125 & 64.1 \\
Yes & 27 & 34.2 & 70 & 35.9 \\
Not Indicated & 52 & 65.8 & & \\
\hline
\end{tabular}

\section{Domestic Violence}

The vast majority of domestic violence offenders are young men—90 percent of offenders are male and the average age is 16.4. Victims are overwhelmingly female (90 percent), with the average age of 16.8. About one-third of victims have children in common with the offender, and 23 percent of the incidents occurred while the victim was pregnant.

\section{Offenders}

The number of domestic violence offenders identified in the three counties is small. In addition, the differential ways in which the populations were selected necessitate the use of caution in the interpretation of offender statistics. Some of the data, such as race/ethnicity and school 
attendance, are an artifact of local demographics, juvenile justice processes, and sampling

procedures. Yet there is remarkable consistency across sites in the following areas:

- Domestic violence offenders who enter the juvenile justice system are overwhelmingly male.

- Most offenders have a prior juvenile record - those with records had an average of 4.7 prior referrals.

- About one-third of the probation reports indicated that the offender had a mental illness.

- About one-third of the probation files reported a history of domestic violence among the parents.

- Probation files indicated larger problems within the family, such as parents with a history of domestic violence, parental criminal records, and parental substance abuse problems.

Exhibit 2.4 provides background data for domestic violence offenders.

\section{Exhibit 2.4: Backgrounds of Domestic Violence Offenders in Three Counties}

\begin{tabular}{|c|c|c|c|c|}
\hline & Total & Santa Clara & San Francisco & $\begin{array}{c}\text { Contra } \\
\text { Costa }\end{array}$ \\
\hline Number of Cases & 92 & 73 & 6 & 13 \\
\hline \multicolumn{5}{|l|}{ Offender Characteristics } \\
\hline Male Offenders & $90.2 \%$ & $89.0 \%$ & $100.0 \%$ & $92.3 \%$ \\
\hline \multicolumn{5}{|l|}{ Race/Ethnicity } \\
\hline -- African American & $8.7 \%$ & $2.7 \%$ & $33.3 \%$ & $30.8 \%$ \\
\hline -- Asian or Pacific Islander & $8.7 \%$ & $9.6 \%$ & $0.0 \%$ & $7.7 \%$ \\
\hline -- Caucasian & $22.8 \%$ & $21.9 \%$ & $0.0 \%$ & $38.5 \%$ \\
\hline -- Hispanic & $58.7 \%$ & $64.4 \%$ & $66.7 \%$ & $23.1 \%$ \\
\hline -- Other & $1.1 \%$ & $1.4 \%$ & $0.0 \%$ & $0.0 \%$ \\
\hline Language other than English spoken at home & $39.7 \%$ & $42.9 \%$ & $66.7 \%$ & $0.0 \%$ \\
\hline Mean age at time of incident & 16.4 & 16.4 & 16.3 & 16.4 \\
\hline Prior juvenile delinquency & $59.8 \%$ & $56.2 \%$ & $66.7 \%$ & $76.9 \%$ \\
\hline -- Mean number of prior referrals & 4.7 & 5.0 & 2.0 & 4.6 \\
\hline Minor attending school at time of incident & $70.5 \%$ & $74.3 \%$ & $83.3 \%$ & $41.7 \%$ \\
\hline Offender living at home & $87.9 \%$ & $91.7 \%$ & $66.7 \%$ & $76.9 \%$ \\
\hline Offender living with both parents & $35.9 \%$ & $34.2 \%$ & $33.3 \%$ & $46.2 \%$ \\
\hline Offender has a mental illness & $34.2 \%$ & $37.5 \%$ & $33.3 \%$ & $16.7 \%$ \\
\hline \multicolumn{5}{|l|}{ Family History } \\
\hline Offender abused as a child & $21.0 \%$ & $21.2 \%$ & $0.0 \%$ & $30.0 \%$ \\
\hline Parents have history of domestic violence & $27.8 \%$ & $26.9 \%$ & $20.0 \%$ & $42.9 \%$ \\
\hline Parents have a criminal justice record & $37.8 \%$ & $36.5 \%$ & $25.0 \%$ & $57.1 \%$ \\
\hline Parents have substance abuse problem & $38.8 \%$ & $37.3 \%$ & $20.0 \%$ & $62.5 \%$ \\
\hline
\end{tabular}

Narratives from the probation files provide details into the lives of domestic violence offenders who have entered the juvenile justice system. Of the 92 narratives of domestic violence 
offenders, as recorded from probation files, only a few did not suggest a history of child abuse, domestic violence, family violence, substance abuse, or a combination of these characteristics. The difference between the quantitative information coded above from standardized probation/court forms and the narrative information reported through probation officers interviews may reflect the fact that the latter is more likely to reveal this type of information.

Most of the probation reports in all three counties detailed histories of violence within the family and criminal activity among family members. The narratives provided below of male offenders are typical.

Offender lived with mother and stepfather and according to reports referred to by the probation officer in his report, the family home had both domestic violence and family violence. One Child Protective Services (CPS) report lists several incidences of abuse perpetrated by his mother as well as a history of sexual abuse by an aunt when the offender was young.

The biological mother reported being physically abused by her ex-husband and stated that the minor witnessed some of the abuse, and that none of the incidents were reported to police. However, as a direct result of one of the assaults, the mother lost her unborn child.

Mother now has live-in boyfriend (and both have criminal records and histories of substance abuse) and offender claims domestic violence in the home, but all allegations could not be confirmed. Offender has been in the system since age 11 with 21 referrals to police/probation. These offenses have ranged from trespassing to car theft to battery to threats. A probation officer report mentioned that most of these offenses were against females.

A sampling of the narratives of male offenders in which a troubled background was not indicated follow below.

Mom and dad still together and teacher character references report them to be concerned and involved parents who are taking appropriate actions to ensure he learns his lesson. Both teachers attributed the behavior to "immaturity" and "lack of forethought."

The offender reports no history of domestic violence in his family's background. The offender's parents have no criminal record or any history of drug or alcohol abuse. The offender's parents are strongly supportive of their son getting the proper help he needs to stay out of trouble. 
Previous juvenile delinquency was not uncommon—over half of the offenders in the system had prior juvenile records. Santa Clara County, which draws the largest net of offenders into its domestic/family violence program, had the lowest percentage of juveniles with prior offenses (56 percent) while Contra Costa had the highest (77 percent). For most of the male offenders, this was their first offense related to domestic violence. Their past records of juvenile delinquency are varied, from auto theft to truancy to shoplifting to substance abuse.

Minor has been caught by police with marijuana and "meth" and has been arrested for driving without a license, vehicle theft, and tampering months prior to the domestic violence incident.

Minor has been on and off probation since eleven years of age and known to hang out with gang members.

Minor's first referral was for shoplifting a cap at age 11. Second referral at age 12 was for residential burglary and by age 14 the minor was expecting a child and arrested for auto theft.

Mental health issues were reported in about one-third of cases. According to probation records, the offenders in the Santa Clara County intervention program were more likely to have been diagnosed with a mental illness than those in the Contra Costa County juvenile population. The San Francisco County group, at only six domestic violence cases, was too small to make conclusive statements. Depression was by far the most commonly reported mental health diagnosis (16 percent), followed by attention deficit hyperactivity disorder (8 percent), learning disability (7 percent), and substance abuse disorder (7 percent). The diagnoses are the result of psychiatric evaluations and a review of medical records.

The offender, himself, is extremely depressed. There have been numerous instances in which the offender reported having ideas of committing suicide, the latest instances being after the current altercation with the victim.

Minor was taking 40 milligrams of Prozac for 1-1/2 years to control his depression. He also has been attending weekly therapy for 3-1/2 years. Four years ago, minor had two hospital stays. Both times he tried to kill himself by cutting his wrists. 
This document is a research report submitted to the U.S. Department of Justice. This report has not been published by the Department. Opinions or points of view expressed are those of the author(s) and do not necessarily reflect the official position or policies of the U.S. Department of Justice.

Although the parents did not indicate any mental illness in the family, the minor was diagnosed with serious mental health issues: Conduct Disorder, Alcohol Abuse, and Adjustment Disorder.

Only 9 of the 92 domestic violence cases involved a female offender. The small number of female offenders precludes statistical analyses comparing male and female offenders. However, a review of the narratives from probation reports suggests similarly troubled backgrounds. In addition, a number of the probation reports indicated that offenders had been previous victims of sexual abuse. Mental health issues were also indicated in a number of cases.

Father is incarcerated in state prison for sexually abusing minor and her brother. According to minor's social worker, minor's main goal for the past two years was to become pregnant. Minor was diagnosed with depression at age 15 and was prescribed Prozac and Praxil. Minor was hospitalized for four suicide attempts.

There were three separate reports reported to CPS all referring to the offender of the current offense as the victim in the report. No investigations took place; however, the offender's boyfriend is currently in county jail waiting for his trial for statutory rape of his girlfriend (the current offender).

The domestic violence offenders in all three samples across counties display family backgrounds themed with child abuse, domestic violence, substance abuse, and criminal activity. While some of the offenders appeared to come from non-violent law-abiding households, they represent a small fraction of the population. Yet the domestic violence offenders in this population cannot be generalized to the larger population, as many offenders will never receive attention from the authorities. The quantitative and qualitative data strongly support the claim that domestic violence offenders who enter the juvenile justice system involuntarily are likely to have extremely challenging family situations that will affect future success.

\section{Victims}

In general, probation and court files contain very little information about the victims. The quality and quantity of victim information collected appear to vary considerably from one county to the next. Despite a number of differences, some generalities can be made about domestic violence 
victims who have had their cases addressed in the juvenile justice system. Domestic violence

victims are overwhelmingly female (90 percent). The average age of the victim is 16.8 . About onethird of the victims have children in common with the offender. Exhibit 2.5 provides basic information on domestic violence victims.

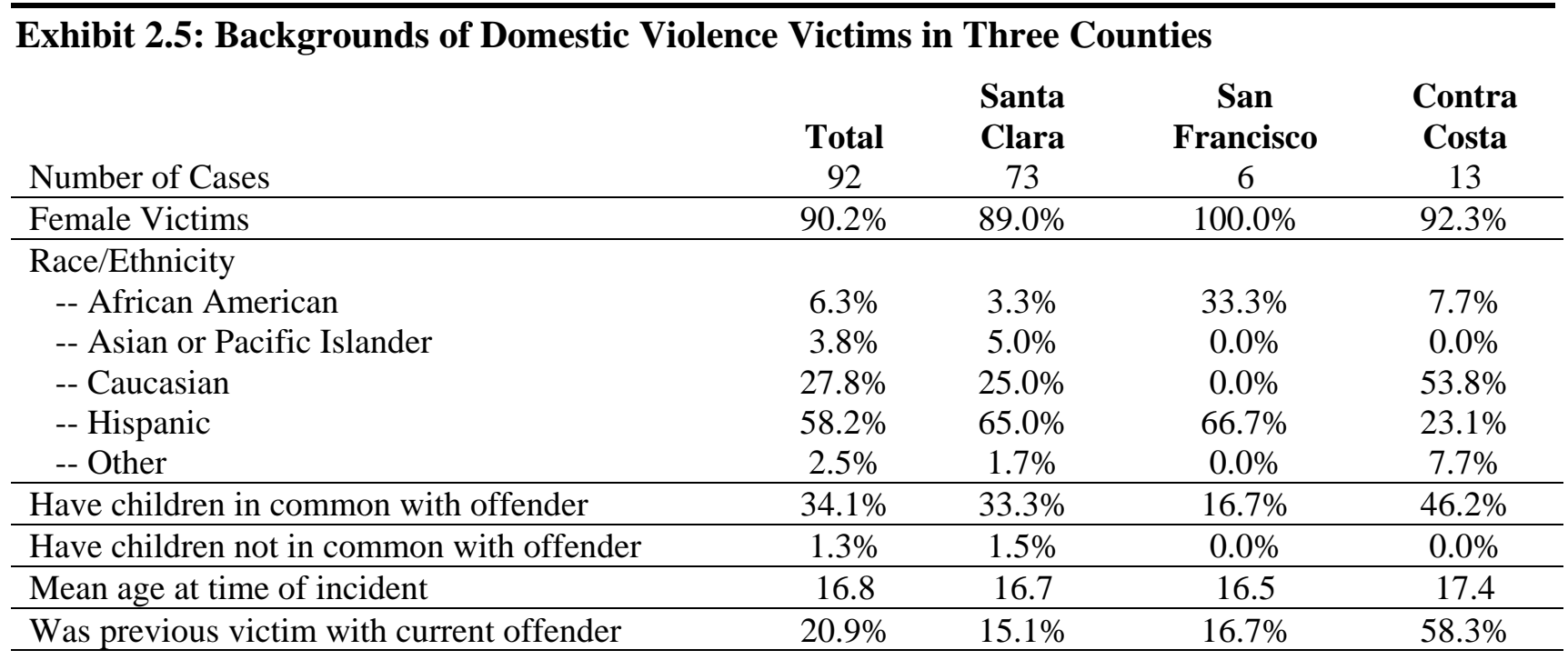

\section{The Nature of Violence}

More than 20 percent of the domestic violence incidents occurred while the victim was pregnant. The primary method of violence was bodily force—guns and knives were seldom used. About one half of the domestic violence incidents were considered "mild," and another 42 percent of incidents classified as "moderate." The determination of the degree of physical severity of the incident was a subjective assessment of the information provided in the probation files, guided by the following definitions. An incident was considered "mild" if it did not leave any marks and medical attention was not needed. A "moderate" incident was one in which the victim received physical marks but did not require medical attention. An incident was labeled as "severe" if it required medical attention. Exhibit 2.6 provides an overview of the incidents. 


\section{Exhibit 2.6: Overview of Domestic Violence Incidents}

\begin{tabular}{lcccc} 
& Total & $\begin{array}{c}\text { Santa } \\
\text { Clara }\end{array}$ & $\begin{array}{c}\text { San } \\
\text { Francisco }\end{array}$ & $\begin{array}{c}\text { Contra } \\
\text { Costa }\end{array}$ \\
\cline { 2 - 5 } Number of Cases & 92 & 73 & 6 & 13 \\
\hline Incident involved multiple victims & $12.0 \%$ & $5.5 \%$ & $16.7 \%$ & $46.2 \%$ \\
\hline Offender under influence of alcohol during incident & $10.7 \%$ & $7.4 \%$ & $0.0 \%$ & $40.0 \%$ \\
\hline Offender under influence of drugs during incident & $7.4 \%$ & $8.8 \%$ & $0.0 \%$ & $0.0 \%$ \\
\hline Offender and victim lived together at time of incident & $23.6 \%$ & $21.1 \%$ & $33.3 \%$ & $33.3 \%$ \\
\hline Incident occurred while victim was pregnant & $23.3 \%$ & $22.8 \%$ & $16.7 \%$ & $30.0 \%$ \\
\hline Degree of severity of offense & & & & \\
-- Mild & $53.3 \%$ & $55.8 \%$ & $67.6 \%$ & $61.5 \%$ \\
-- Moderate & $41.3 \%$ & $34.1 \%$ & $26.5 \%$ & $38.5 \%$ \\
$\quad--$ Severe & $5.4 \%$ & $10.1 \%$ & $5.9 \%$ & $0.0 \%$ \\
\hline Primary weapon of violence & & & & \\
-- Gun & $1.1 \%$ & $1.4 \%$ & $0.0 \%$ & $0.0 \%$ \\
$\quad--$ Knife & $7.9 \%$ & $8.6 \%$ & $0.0 \%$ & $7.7 \%$ \\
-- Other object & $11.2 \%$ & $12.9 \%$ & $0.0 \%$ & $7.7 \%$ \\
$\quad--$ Physical, no weapons or objects & $77.5 \%$ & $75.7 \%$ & $100.0 \%$ & $76.9 \%$ \\
\hline Felony offenses & $34.4 \%$ & $34.7 \%$ & $80.0 \%$ & $15.4 \%$ \\
\hline
\end{tabular}

Nearly all incidents involved a male offender and a female victim. A snapshot of a number of

incidents is provided below.

Victim was pregnant by minor. When victim discussed the issue with minor, he first told her that she wasn't really pregnant and that he didn't want to talk about it. He also said "get rid of it" then keep it, then that she was going to hell if she had an abortion and that the baby was not even his. At one point, minor threatened to kick victim in the stomach to kill the fetus. Finally, victim had an abortion because she was unable to raise it herself, and did not want to raise a child with minor.

Witness called police to report fight between a "man" and a woman where the man was "throwing her to the ground" repeatedly. Police arrived on scene and woman "cozied up" to the "man." But police could see four separate areas of her body actively bleeding. Both said they had fought but that it was over and the woman refused to cooperate, give information, or receive medical attention. Based on the visible injuries, the offender was arrested for public intoxication and domestic violence.

The offender and the victim had been living together because they had gotten pregnant. In the morning of the date the incident was reported, the offender and the victim began arguing as the offender believed the victim was cheating on him. When the victim denied the accusations, the offender pushed her onto the bed and began punching her on the legs. The victim then slapped the offender out of self-defense, which angered the offender. The offender again struck her, this time punching her on her arms. 
There were only nine instances in the entire study in which young women were brought into the probation unit for a domestic violence incident. The narratives of some of these incidents are included below.

The victim grabbed offender and put her in his car while they argued for about five minutes. Police reported that victim and minor were involved in an argument, during which she tore his shirt and slapped him in the face, causing him to bleed. According to offender, she was shoved in victim's car and he was "in her face." Offender was two months pregnant with victim's child at the time of the incident.

The offender supposedly started the entire incident by walking up to the victim and pouring water over his head. She walked away from the victim, the victim chased her down and pulled her hair and the two fell to the ground. The two became entangled in a physical altercation. The school security guard pulled the two apart, and before he was able to fully separate the two, offender lunged over the shoulder of the guard and punched the victim in the eye, causing a burst blood vessel and visible scratches.

The offender and the victim were both reportedly high on methamphetamine at the time of the incident. When the victim attempted to get out of the car, the offender grabbed his shirt, ripping it off, and scratching the victim's chest area and right arm.

\section{Family Violence}

Family violence offenders are more likely to be male, but a sizeable proportion of offenders in our sample are female—37 percent. Family violence offenders are young; the average age is 15 . Victims are most likely to be females (73 percent). More than half of the victims are the mothers or stepmothers of the juveniles.

\section{Offenders}

Similar to the data on domestic violence, the data on family violence vary somewhat across jurisdictions. In particular, the data suggest that the sample in Contra Costa County, which did not have a specialized intervention program, consists of juveniles who are more likely to have a record of previous delinquency—67 percent of family violence offenders had prior juvenile records compared to 37 percent in Santa Clara and 50 percent in San Francisco. Offenders with juvenile records averaged 2.5 prior referrals. The prior juvenile delinquency rate between the counties with 
intervention programs and the county without such a program is consistent with expectationsscreening at intake and the availability of a specialized program increase the likelihood that cases will be properly identified and triaged into the courts.

Despite these differences across counties, there are a number of striking similarities in the population of family violence offenders who have been processed in the juvenile justice system. In particular, the offenders share the following backgrounds.

- Family violence offenders are young. The average age of offenders is 15 years of age.

- The majority of offenders (63 percent) are male.

- Most offenders (64 percent) have been diagnosed with a mental illness.

- A significant proportion of offenders have a prior juvenile record, although this varies by county.

- A high percentage of offenders' parents have a history of domestic violence, a criminal justice record, or a substance abuse problem.

Exhibit 2.7 provides background data for family violence offenders. 
Exhibit 2.7: Backgrounds of Family Violence Offenders in Three Counties

\begin{tabular}{lcccc} 
& Total & $\begin{array}{c}\text { Santa } \\
\text { Clara }\end{array}$ & $\begin{array}{c}\text { San } \\
\text { Francisco }\end{array}$ & $\begin{array}{c}\text { Contra } \\
\text { Costa }\end{array}$ \\
\cline { 2 - 5 } Number of Cases & 212 & 129 & 34 & 49 \\
\hline Offender Characteristics & & & & \\
\hline Male Offenders & $62.7 \%$ & $61.2 \%$ & $61.8 \%$ & $67.3 \%$ \\
\hline Race/Ethnicity & & & & \\
-- African American & $16.6 \%$ & $3.1 \%$ & $32.4 \%$ & $40.8 \%$ \\
-- Asian or Pacific Islander & $8.1 \%$ & $8.6 \%$ & $11.8 \%$ & $4.1 \%$ \\
-- Caucasian & $32.2 \%$ & $35.9 \%$ & $11.8 \%$ & $36.7 \%$ \\
-- Hispanic & $34.6 \%$ & $43.8 \%$ & $23.5 \%$ & $18.4 \%$ \\
-- Other & $8.5 \%$ & $8.6 \%$ & $20.6 \%$ & $0.0 \%$ \\
\hline Language other than English spoken at hom & $23.7 \%$ & $26.1 \%$ & $29.0 \%$ & $9.7 \%$ \\
\hline Mean age at time of incident & 15.1 & 15.1 & 15.3 & 15.0 \\
\hline Prior juvenile delinquency & $46.0 \%$ & $36.7 \%$ & $50.0 \%$ & $67.3 \%$ \\
$\quad--$ Mean number of prior referrals & 2.5 & 2.2 & 2.4 & 2.8 \\
\hline Minor attending school at time of incident & $81.6 \%$ & $81.4 \%$ & $97.1 \%$ & $71.4 \%$ \\
\hline Offender living at home & $98.1 \%$ & $100.0 \%$ & $100.0 \%$ & $91.8 \%$ \\
\hline Offender living with both parents & $41.5 \%$ & $41.9 \%$ & $38.2 \%$ & $42.9 \%$ \\
\hline Offender has a mental illness & $64.1 \%$ & $62.6 \%$ & $72.7 \%$ & $61.7 \%$ \\
\hline Family History & \multicolumn{3}{l}{} & \\
\hline Offender abused as a child & $40.1 \%$ & $28.2 \%$ & $54.8 \%$ & $64.1 \%$ \\
\hline Parents have history of domestic violence & $37.0 \%$ & $30.1 \%$ & $68.8 \%$ & $30.8 \%$ \\
Parents have a criminal justice record & $41.4 \%$ & $36.1 \%$ & $46.4 \%$ & $59.3 \%$ \\
\hline Parents have substance abuse problem & $43.0 \%$ & $36.7 \%$ & $46.4 \%$ & $64.5 \%$ \\
\hline
\end{tabular}

\section{Male Offenders}

The sizeable population of female family violence offenders affords the opportunity to draw comparisons between male and female offenders. A review of narratives from the probation files shows that almost all of the male offenders come from families with histories of child abuse, domestic violence, family violence, or substance abuse. The following excerpts from the probation files of male family violence offenders are typical.

...the father was jailed after it was found that he abused the minor physically. Minor was approximately four years old at the time. Primary father figure was the stepfather who has been with the minor until recently. Reportedly, the stepfather regularly abused mother, which minor witnessed on a number of occasions and the police report that they were called out to the home "almost every day.” Minor's grades have been F's for the most part and school attendance has been an ongoing problem. 
This document is a research report submitted to the U.S. Department of Justice. This report has not been published by the Department. Opinions or points of view expressed are those of the author(s) and do not necessarily reflect the official position or policies of the U.S. Department of Justice.

There was a child protective services (CPS) report alleging the father had hit this offender, but the allegation was unsubstantiated. Another CPS report concerned possible sexual fondling by a maternal uncle, but the uncle returned to North Carolina, so nothing further. A third CPS report concerned strangulation marks on the offender's younger brother subsequent to a fight between the boys (offender and younger brother).

Mother has been referred to CPS for general neglect and possible physical abuse of halfbrother, but no actions taken. Offender has juvenile records including several fights and vandalism.

Biological father was investigated by CPS three times for physical abuse of this offender. Two cases were substantiated and the last was investigated and closed because report was only "fear of abuse." Mother denies domestic violence in marriage but police reports say otherwise and her father is in prison for killing her mother.

Mother and father both have drug/alcohol problems and relationship was characterized by domestic violence and child abuse. Older sibling institutionalized for murder. Offender previously on probation and court ordered anger management, but no proof of completion and case was vacated successfully one month prior to incident.

Almost two-thirds of male family violence offenders had some form of mental illness diagnosed (64 percent). The most common diagnoses were attention deficit hyperactivity disorder (20 percent), depression (19 percent), substance abuse disorder (15 percent), learning disability (8 percent), and conduct disorder (7 percent).

Offender has been in therapy since age six and has been diagnosed with ADHD, depression, and opposition/defiant disorder and was thought to be progressing to borderline personality disorder.

He was diagnosed ADHD at age six and has been on medication and receiving psychological services intermittently since.

\section{Female Offenders}

Unlike the domestic violence offender population, a large proportion of family violence offenders are female. The female offenders have very similar backgrounds to male offenders. On average, both male and female offenders are age 15 at the time of the incident. The same proportion of female family violence offenders have a prior juvenile record as male family violence offenders, although male offenders have a higher number of prior referrals than female offenders. In addition, rates of mental illness are similar. The only variance between male and female offenders is that 
female offenders are slightly more likely to come from families where there is a history of child abuse, domestic violence, criminal activity, and substance abuse. However, the differences between genders do not reach statistical significance. Exhibit 2.8 provides data on the backgrounds of male and female family violence offenders.

\section{Exhibit 2.8: Backgrounds of Male and Female Family Violence Offenders}

\begin{tabular}{lccc} 
& Total & Male & Female \\
\cline { 2 - 4 } Number of cases & 212 & 133 & 79 \\
\hline Mean age at time of incident & 15.1 & 15.1 & 15.1 \\
\hline Prior juvenile delinquency & $46.0 \%$ & $45.5 \%$ & $46.8 \%$ \\
-- Mean number of prior referrals & 2.5 & 2.8 & 1.9 \\
\hline Offender has a mental illness & $64.1 \%$ & $63.7 \%$ & $64.8 \%$ \\
\hline Offender abused as a child & $40.1 \%$ & $37.9 \%$ & $43.7 \%$ \\
\hline Parents have history of domestic violence & $37.0 \%$ & $34.8 \%$ & $40.6 \%$ \\
\hline Parents have a criminal justice record & $41.4 \%$ & $38.4 \%$ & $46.8 \%$ \\
\hline Parents have substance abuse problem & $43.0 \%$ & $38.4 \%$ & $50.7 \%$ \\
\hline
\end{tabular}

Narratives from the probation files of female family violence offenders provide a glimpse into their

family backgrounds.

CPS removed the children from the mother after a history of reports of neglect and abuse. The mother was later arrested and jailed for child abuse. The offender had been drifting between friends' houses, her older sister's house, and her mother's van and not attending school regularly.

Dysfunctional childhood with both parents using drugs and alcohol, having numerous law violations, domestic violence and suspected neglect, physical and sexual abuse of children. Offender is a middle child and diagnosed with ADD and bipolar disorder. Offender ran away from home on several occasions and was sexually molested during one absence.

The family has moved around a lot due to the mother's inability to sustain a job because of drug use and time in jail; thus, the minor and her siblings have not experienced a stable environment the majority of their lives. The minor's father has served time on several occasions for offenses such as: carrying a loaded firearm, carrying a concealed weapon, robbery, assault with a deadly weapon, possession of marijuana for sale, ...totaling about 40 arrests. The minor's mother has been arrested on 10 different occasions.

Female offenders were as likely to have a diagnosis of mental illness as male offenders—64 percent of both male and female offenders had a mental health diagnosis. The most common diagnoses for female family violence offenders were depression (23 percent), attention deficit 
hyperactivity disorder (11 percent), substance abuse disorder (11 percent), anxiety disorder (9

percent), and learning disability (8 percent). The combination of family backgrounds and mental

health issues creates numerous challenges in developing a program that can adequately address the myriad problems and issues faced by these teens.

\section{Victims}

The victims of family violence are overwhelmingly female (73 percent). More than half of the victims are mothers of the offenders (54 percent). Many of the victims were previously identified as a family violence victim of the offender. Exhibit 2.9 provides additional details.

\section{Exhibit 2.9: Backgrounds of Family Violence Primary Victims in Three Counties}

\begin{tabular}{lcccc} 
& Total & $\begin{array}{c}\text { Santa } \\
\text { Clara } \\
129\end{array}$ & $\begin{array}{c}\text { San } \\
\text { Francisco } \\
\text { Number of Cases }\end{array}$ & $\begin{array}{c}\text { Contra } \\
\text { Costa } \\
49\end{array}$ \\
\hline Female Victims & $72.6 \%$ & $75.2 \%$ & $79.4 \%$ & $61.2 \%$ \\
\hline Race/Ethnicity & & & & \\
-- African American & $17.0 \%$ & $4.0 \%$ & $35.3 \%$ & $38.3 \%$ \\
-- Asian or Pacific Islander & $8.7 \%$ & $9.6 \%$ & $14.7 \%$ & $2.1 \%$ \\
-- Caucasian & $34.5 \%$ & $36.0 \%$ & $14.7 \%$ & $44.7 \%$ \\
-- Hispanic & $34.5 \%$ & $44.8 \%$ & $26.5 \%$ & $12.8 \%$ \\
-- Other & $5.3 \%$ & $5.6 \%$ & $8.8 \%$ & $2.1 \%$ \\
\hline Relationship to Offender & & & & \\
-- Mother/stepmother & $54.2 \%$ & $59.0 \%$ & $52.9 \%$ & $42.9 \%$ \\
-- Father/stepfather & $17.0 \%$ & $14.8 \%$ & $11.8 \%$ & $26.5 \%$ \\
-- Parent's cohabiting partner & $2.4 \%$ & $1.6 \%$ & $0.0 \%$ & $6.1 \%$ \\
-- Brother & $7.1 \%$ & $7.0 \%$ & $8.8 \%$ & $6.1 \%$ \\
-- Sister & $13.2 \%$ & $12.4 \%$ & $20.6 \%$ & $10.2 \%$ \\
-- Other & $6.1 \%$ & $5.4 \%$ & $5.9 \%$ & $8.2 \%$ \\
\hline Mean age at time of incident & 36.7 & 36.1 & 36.7 & 38.3 \\
\hline Was previous victim with current offender & $25.1 \%$ & $18.1 \%$ & $21.9 \%$ & $47.7 \%$ \\
\hline
\end{tabular}

\section{The Nature of Violence}

About one-fourth of all family violence cases involved more than one victim. The majority of cases did not result in medical attention and were considered "mild” from an injury standpoint. 
The percentage of felony offenses varied considerably by county. Exhibit 2.10 provides an

overview of the incidents.

\section{Exhibit 2.10: Overview of Family Violence Incidents}

\begin{tabular}{lcccc} 
& Total & $\begin{array}{c}\text { Santa } \\
\text { Clara }\end{array}$ & $\begin{array}{c}\text { San } \\
\text { Francisco }\end{array}$ & $\begin{array}{c}\text { Contra } \\
\text { Costa }\end{array}$ \\
\cline { 2 - 5 } Number of Cases & 212 & 129 & 34 & 49 \\
\hline Incident involved multiple victims & $24.1 \%$ & $22.5 \%$ & $23.5 \%$ & $28.6 \%$ \\
\hline Offender under influence of alcohol during incident & $10.1 \%$ & $11.0 \%$ & $0.0 \%$ & $16.7 \%$ \\
\hline Offender under influence of drugs during incident & $8.7 \%$ & $8.3 \%$ & $0.0 \%$ & $18.2 \%$ \\
\hline Degree of severity of offense & & & & \\
-- Mild & $59.0 \%$ & $55.8 \%$ & $67.6 \%$ & $61.2 \%$ \\
-- Moderate & $32.5 \%$ & $34.1 \%$ & $26.5 \%$ & $32.7 \%$ \\
-- Severe & $8.5 \%$ & $10.1 \%$ & $5.9 \%$ & $6.1 \%$ \\
\hline Primary weapon of violence & & & & \\
-- Gun & $2.4 \%$ & $1.6 \%$ & $6.3 \%$ & $2.1 \%$ \\
-- Knife & $11.7 \%$ & $7.2 \%$ & $15.6 \%$ & $20.8 \%$ \\
-- Other object & $25.4 \%$ & $24.8 \%$ & $25.0 \%$ & $27.1 \%$ \\
-- Physical, no weapons or objects & $59.0 \%$ & $65.6 \%$ & $53.1 \%$ & $45.8 \%$ \\
\hline Felony offenses & $25.6 \%$ & $27.3 \%$ & $52.9 \%$ & $2.0 \%$ \\
\hline & & & & \\
\hline
\end{tabular}

The narratives of family violence incidents involving male offenders demonstrate the types

of events that led to an incident in which law enforcement was called to the scene.

Father refused offender permission to go to the movies with friends. Offender went on bike anyway. Parents retrieved him from movie theatre and verbal argument ensued until he and his twin brother left in family vehicle. Once home, offender went to garage and grabbed a bat to do damage to father's vehicle but dad chased him into the house and cornered him. Offender swung and struck father's hand with bat, so father wrestled him to the ground and took bat.

Minor came home angry and was arguing with his brother over a video game. The victim (stepmother) tried to separate the minor and his brother. Then the offender punched her in the mouth with a closed fist. The victim's tooth was broken at the root and she received medical attention.

The offender began yelling at his mother to take him to the store. Instead of taking him to the store, the mother gave the offender a couple dollars to try and appease the offender. At this time, the offender's sister came into the room and told the mother that the offender should not be rewarded for negative behavior. The offender began shoving his sister. The mother stuck out her arm and blocked the swing of the bat. The bat struck the mother's arm causing severe pain. The mother's roommate who witnessed the event called 911 and the offender ran out of the residence.

The offender wanted to watch a particular television program, but mother would not unlock the channel. She suggested instead they watch an educational tape together. He began throwing objects at her, such as a pillow and pencil. When he threw an aluminum 
can at her, she walked out. She returned moments later to try to watch the tape with him. He argued against it, then fetched the metal wheel assembly from his skateboard, and struck her in the left arm, cutting her badly. He said, "I hit you. I kill you."

Family violence incidents involving female offenders were similar confrontations to the authority of parents.

Offender would come and go from home as she pleased and upon return the day of this incident, an argument broke out between the offender, the mother and a younger sister. The sisters began pushing and wrestling and the mother split them up. The offender then retrieved a knife from the kitchen, held it over her head, said "I'm going to kill you" and approached her sister sitting on the couch while bringing the knife down in a stabbing motion. The mother grabbed her wrist and wrestled her to the ground.

The victim (mother) stated that her daughter was grounded and that she returned home late in the afternoon and became engaged in a verbal confrontation with her mother. The minor was upset over her grounding and attempted to leave the residence. The victim attempted to keep her daughter inside the house, but the minor pushed the victim and she fell to the ground.

The physical altercation began between the offender (daughter) and victim (father) when the father told his daughter she was forbidden to associate with a friend who was at the house to take the offender out. The offender became very upset and ran out of the house toward her friend's car. The offender's father grabbed her and tried to restrain the offender. At this point, the two fell over a small picket fence in the front yard breaking three boards off the fence. The father let go of his daughter. The offender picked up a fence board and hit her father across the left shoulder then ran inside the house and locked the door. The offender came to the door with a butcher knife and chased the victim to the front yard. The offender threw the knife at her father but missed.

\section{Summary of Findings}

Domestic violence is violence between intimates (e.g., boyfriends/girlfriends, dating partners, spouses), while family violence is violence between family members (e.g., siblings, parents, grandparents, cousins). Juvenile family violence is much more common than juvenile domestic violence across each of the three counties included in this study. Of all domestic/family violence cases, the Santa Clara County court program had the largest proportion of domestic violence offenders (36 percent) when compared to the San Francisco County court program (15 percent) and Contra Costa County (21 percent). 
Domestic violence offenders differed from family violence offenders in a number of ways. Generally, domestic violence offenders (1) tend to be older, (2) are more likely to be male, (3) are more likely to have a previous delinquency record, and (4) are less likely to have a mental illness than family violence offenders. The vast majority of domestic violence offenders are young men90 percent of offenders are male and the average age is 16.4 . Victims are overwhelmingly female (90 percent), with the average age of 16.8. About one-third of victims have children in common with the offender, and 23 percent of the incidents occurred while the victim was pregnant. Thus many of these cases are involved in relationships that are beyond the "teen dating" concept. Family violence offenders are more likely to be male, but a sizeable proportion of offenders in our sample are female -37 percent. Family violence offenders are young; the average age is 15 . Victims are most likely to be females (73 percent). More than half of the victims are the mothers or stepmothers of the juveniles. The female family violence offenders have very similar backgrounds to male offenders.

There are very few differences in the nature of juvenile domestic and family violence across counties. However, the data show a major variance across counties in the population of juvenile offenders that reach the courts. Juvenile offenders in Contra Costa County, which did not have a specialized intervention program, are more likely to have a prior record than juveniles who participated in the Santa Clara and San Francisco programs. For example, 67 percent of family violence offenders in Contra Costa County had prior juvenile records compared to 37 percent in Santa Clara County and 50 percent in San Francisco County. This variance in the backgrounds of juvenile domestic/family violence offenders and severity across counties is likely to impact intervention strategies, program completion rates, and outcomes. 


\section{Policy Implications}

In general, there are two approaches to addressing juvenile domestic and family violence.

On the one hand, the Santa Clara County program is the epitome of a "zero tolerance" program that introduces formal intervention in most domestic and family violence incidents, regardless of severity. On the other hand, the Contra Costa County juvenile justice system does not specifically target domestic and family violence and does not have a specialized intervention for such cases. This difference of philosophy was demonstrated by the fact that 72 teens per 100,000 enter the Santa Clara County specialized juvenile domestic/violence program, compared to 13 teens per 100,000 in Contra Costa County who can be identified through probation records as domestic or family violence offenders.

A law enforcement protocol that mandates the arrest of juveniles who commit offenses categorized as domestic or family violence, such as the case in Santa Clara County, draws a wider net of juveniles into the system. A major outcome of this approach is that a larger percentage of juvenile domestic/family violence offenders will be first-time offenders, in comparison to counties that do not have a preferred or mandatory arrest policy. There are advantages and disadvantages to the "zero tolerance” approach. For instance, juveniles who enter the system receive education and skills aimed to halt a pattern of abuse and violence. Yet first-time offenders may find themselves trapped in the juvenile system when they cannot successfully complete probation conditions. The advantages and disadvantages and the implications on juveniles must be carefully considered prior to implementation of specialized programs. Furthermore, programs that offer graduated sanctions may be most appropriate to addressing the needs of both first-time and multiple offenders.

Finally, the troubled backgrounds of juveniles who enter the system as domestic/family violence offenders have policy implications. Many of the teens have mental health issues and histories that include parental domestic violence and abuse as a child. Programs that do not address 
early victimization and dysfunctional family life are unlikely to have a long-term effect on teens.

Any intervention program, no matter how well-implemented, will be hard-pressed to meet the needs of juveniles with such serious problems. 


\section{3 - Intervention}

Intervention includes a host of options and can range from minor sanctions to

institutionalization. This chapter explores detention in juvenile hall prior to the detention hearing, the use of formal probation, probation supervision and conditions, and institutionalization of offenders. Compliance with probation is then assessed by examining probation violations and program completion. The chapter concludes with a review of probation officers' assessment of the juveniles’ social adjustment to the demands of the program.

\section{Overview of Intervention Approaches}

The intervention programs in Santa Clara and San Francisco counties include a variety of programs, in addition to intensive supervision and court reviews. For example, a sample of probation conditions and programs offered in Santa Clara County follows:

- Protective or “stay away” orders;

- Attendance at 26-week batterer intervention programs;

- Frequent court review of the probationer for compliance with probation;

- Detention in a county facility, as well as placement services, long-term California Youth Authority alternative placement, or the California Youth Authority, to ensure safety and accountability;

- Parenting Without Violence classes if the youth has a child;

- Restitution to the victim for any losses related to the offense;

- Prohibition against weapons possession or the presence of weapons in the offender's home;

- Search of the person or place of residence or business of the minor and seizure of any items prohibited by conditions of probation or the law by law enforcement, probation, or the offender's school teachers at any time of the day or night, with or without probable cause, and with or without warrant;

- Counseling and education if substance abuse issues are present and special education accommodations when necessary;

- Drug and alcohol testing of the offender at the request of any police officer or probation officer with or without probable cause, and with or without a warrant; 
This document is a research report submitted to the U.S. Department of Justice. This report has not been published by the Department. Opinions or points of view expressed are those of the author(s) and do not necessarily reflect the official position or policies of the U.S. Department of Justice.

- Strict curfew, compliance with protective orders, and school attendance to prevent new law violations;

- Mandatory school, employment, or vocational training attendance;

- Fines and fees to hold the offender accountable;

- Gang orders (if applicable) to help prevent new criminal offenses; and

- Psychological or family counseling.

A particular challenge for courts and probation departments in addressing teen dating, domestic, and family violence is the lack of established teen-oriented batterers programs.

Furthermore, there is no literature on the effectiveness of teen battering programs in particular, as so few of them exist. For the most part, the teen batterer programs rely on the Duluth model, which is based on the feminist theory that patriarchal ideology, which encourages men to control their partners, causes domestic violence. The appropriateness of this model for teen batterers has not been shown. In addition, counselors in both Santa Clara and San Francisco have had to develop programs to address teen family violence. While intensive supervision and court reviews are easily quantified, the impact of intervention programs that are in their infancy are difficult to evaluate.

The level of intervention in the three counties varies on four levels. First, juvenile domestic and family violence offenders in Santa Clara and San Francisco counties are subjected to frequent court reviews. Second, the Santa Clara and San Francisco counties are under intensive supervision carried out by a specially trained unit. Third, the Santa Clara and San Francisco counties have incorporated intervention programs, specifically batterer intervention group or individual counseling, into their programs. Contra Costa County also offers batterer intervention programs to teens, but the decision to require participation is made on a case-by-case basis, and minors are referred to adult programs. Offenders in Santa Clara County are required to co-pay for each session (\$15 per session) of a 26-week program, whereas the offenders in San Francisco County are not required to pay for sessions. Fourth, San Francisco County is more reliant on informal probation 
than the other two counties. Exhibit 3.1 outlines major differences in intervention strategies

espoused by the counties under study.

\section{Exhibit 3.1: Overview of Intervention Strategies}

\begin{tabular}{lccc} 
& Santa Clara & San Francisco & Contra Costa \\
\hline Frequent court reviews & yes & Yes & No \\
Intensive supervision by specialized officers & yes & Yes & No \\
\hline Assignment to batterer intervention programs & routinely & routinely & case-by-case \\
Formal probation & yes & No & Yes \\
\hline
\end{tabular}

\section{Probation Supervision and Conditions}

This study focuses on the effects of a special intervention program that includes assignment to a specialized court with regular reviews and a specialized probation unit that provides a high level of supervision. The intervention program existed in both Santa Clara and San Francisco counties, while it was absent in Contra Costa County. This section of the report presents information on supervision in detention hall, the use of formal and informal probation, supervision levels, court reviews, conditions of probation, and institutionalization of offenders.

\section{Supervision in Detention Hall}

The probation department has supervision over juvenile halls. Data in Exhibit 3.2 show a statistically significant difference across counties in detention in juvenile hall practices. San Francisco County is more likely to detain juveniles in juvenile hall prior to the detention hearing; whereas Contra Costa County has the lowest rate. ${ }^{18}$ The data reflect local practices and may also be an outcome of the location and availability of space in juvenile hall.

\footnotetext{
18 Missing data are excluded from all analyses.
} 


\section{Exhibit 3.2: Detention in Juvenile Hall Prior to Detention Hearing}

\begin{tabular}{lcccc} 
& Total & $\begin{array}{c}\text { Santa } \\
\text { Clara }\end{array}$ & $\begin{array}{c}\text { San } \\
\text { Francisco }\end{array}$ & $\begin{array}{c}\text { Contra } \\
\text { Costa }\end{array}$ \\
\cline { 2 - 5 } Number of Cases & 303 & 201 & 40 & 62 \\
Percentage Detained & 74.6 & 74.6 & 87.5 & 66.1 \\
\hline
\end{tabular}

*significance $=.05$

Detention is affected by whether the incident involves domestic or family violence. In a family violence incident, probation authorities are more likely to detain the juvenile (79 percent) than in a domestic violence incident (64 percent). As the juvenile in a family violence case is more likely to live with the victim than a domestic violence offender, this variance suggests that living arrangements may be a factor that influences whether a juvenile will be detained in juvenile hall.

\section{Formal versus Informal Probation}

The use of informal probation—a diversionary tool in which the juvenile "voluntarily" participates in an intervention program under court supervision to avoid an official record—reflects the culture of the local legal system, rather than the nature of the crime. Exhibit 3.3 shows that the vast majority of cases are subjected to formal probation (85 percent). However, San Francisco County is much more likely to use informal probation (68 percent of the time) than either Santa Clara or Contra Costa County (5 and 13 percent, respectively). Nearly all of the informal probation cases were used in family violence cases.

\section{Exhibit 3.3: Informal and Formal Probation by County}

\begin{tabular}{lcccc} 
& Total & $\begin{array}{c}\text { Santa } \\
\text { Clara }\end{array}$ & $\begin{array}{c}\text { San } \\
\text { Francisco }\end{array}$ & $\begin{array}{c}\text { Contra } \\
\text { Costa }\end{array}$ \\
\cline { 2 - 5 } Number of Cases & 304 & 202 & 40 & 62 \\
\hline Informal Probation & $14.8 \%$ & $5.0 \%$ & $67.5 \%$ & $12.9 \%$ \\
Formal Probation & $85.2 \%$ & $95.0 \%$ & $32.5 \%$ & $87.1 \%$ \\
\hline
\end{tabular}

*significance $=.001$ 
Exhibit 3.4 shows the percentage of offenders assigned to the specialized court and probation unit. The Santa Clara sample includes some cases that did not receive both interventions - this was due to the fact that some cases had to be assigned to the geographic probation units when the specialized unit was at full capacity, and some cases handled by the specialized probation unit were handled by a court other than the specialized domestic/family violence court (e.g., mental health court).

\section{Exhibit 3.4: Specialized Court and Probation Supervision}

\begin{tabular}{lccc} 
& $\begin{array}{c}\text { Santa } \\
\text { Clara }\end{array}$ & $\begin{array}{c}\text { San } \\
\text { Francisco }\end{array}$ & $\begin{array}{c}\text { Contra } \\
\text { Costa }\end{array}$ \\
\cline { 2 - 4 } Number of cases & 202 & 40 & 62 \\
\hline Percentage assigned to DV/FV court & 91.6 & 100.0 & 0.0 \\
Percentage assigned to DV/FV probation unit & 92.0 & 100.0 & 0.0 \\
Percentage assigned to both DV/FV court and probation unit & 89.1 & 100.0 & 0.0 \\
\hline
\end{tabular}

\section{Levels of Supervision}

The level of probation supervision can include intensive supervision by a specialized unit, electronic monitoring, and placement outside of the home. Exhibit 3.5 provides data on those cases assigned to formal probation, by county and prior juvenile delinquency. There is a statistically significant difference between probation supervisions among the counties, with Santa Clara County relying on electronic monitoring in over 70 percent of its formal probation caseload. Santa Clara also uses placement outside of the home in 46 percent of its cases, compared to 25 and 30 percent in San Francisco and Contra Costa counties, respectively. Differences between probation for domestic violence offenders and family violence offenders were negligible. Instead, prior juvenile delinquency was strongly linked to levels of probation supervision—offenders with a prior record were placed outside the home in 46 percent of the cases compared with 35 percent of the cases in 
which a prior juvenile record was not established. The relationship between juvenile delinquency status and probation supervision was compounded by the high usage of electronic monitoring in Santa Clara.

Exhibit 3.5: Probation Supervision for Those on Formal Probation

\begin{tabular}{lcccc} 
& Total & $\begin{array}{c}\text { Santa } \\
\text { Clara }\end{array}$ & $\begin{array}{c}\text { San } \\
\text { Francisco }\end{array}$ & $\begin{array}{c}\text { Contra } \\
\text { Costa }\end{array}$ \\
\cline { 2 - 5 } Number on formal probation & 265 & 189 & 20 & 56 \\
\hline Probation only & $17.4 \%$ & $5.3 \%$ & $70.0 \%$ & $39.3 \%$ \\
Probation and electronic monitoring & $41.5 \%$ & $48.7 \%$ & $5.0 \%$ & $30.4 \%$ \\
\hline $\begin{array}{l}\text { Probation and placement outside of home } \\
\text { Probation, placements outside home, and } \\
\text { electronic monitoring }\end{array}$ & $22.3 \%$ & $21.2 \%$ & $25.0 \%$ & $25.0 \%$ \\
\hline *significance=.001 & $18.5 \%$ & $24.3 \%$ & $0.0 \%$ & $5.4 \%$ \\
\hline
\end{tabular}

\section{Court Reviews}

The Santa Clara and San Francisco programs feature multiple court reviews, whereas the Contra Costa courts do not typically bring offenders back to the court for periodic reviews. Exhibit 3.6 shows the mean and median number of court reviews in Santa Clara and San Francisco counties. The average number of court reviews is 6.2 reviews per case, with San Francisco offering a slightly higher number of court reviews. The data include only those cases assigned to the specialized court and omit missing data. There were no differences in the number of court reviews based on type of violence (domestic versus family violence).

\section{Exhibit 3.6: Average Number of Court Reviews in Santa Clara and San Francisco Counties}

\begin{tabular}{lccc} 
& Total & $\begin{array}{c}\text { Santa } \\
\text { Clara }\end{array}$ & $\begin{array}{c}\text { San } \\
\text { Francisco }\end{array}$ \\
\cline { 2 - 4 } Number of cases assigned to specialized court & 209 & 174 & 35 \\
\hline Mean number of reviews & 6.2 & 6.1 & 6.8 \\
Median number of reviews & 5.0 & 5.0 & 5.0
\end{tabular}




\section{Conditions of Probation}

The conditions of probation vary by county. Exhibit 3.7 shows the conditions of probation by county, in descending order. Multiple conditions of probation are placed on offenders. Most commonly, probation conditions include:

- Attend school regularly,

- Submit to warrantless search and seizure,

- Comply with curfews,

- Abstain from alcohol or drugs, and

- Participate in individual counseling.

A number of the conditions that are especially relevant to domestic and family violence offenders ranked lower on the list. In particular, the condition to attend, participate in, and satisfactorily complete a domestic violence program was ordered in 55 percent of the cases overall. However, this condition varied considerably by the type of violence -74 percent of domestic violence offenders received this probation condition, compared to 46 percent of the family violence offenders. In addition, coding for this variable may not be reliable as the specific terms of the condition may have changed as new judges transitioned into the specialized courts. Among the coding challenges was substantial variation in how the teen batterers' programs were assigned and administered. For example, San Francisco County used individual teen batterers counseling, while Santa Clara County used different service providers with different program conditions. In both counties with the specialized court, the protocol calls for all minors to participate in some form of teen batterer intervention, unless they are subsequently moved to a mental health court.

When examining only domestic violence cases, Santa Clara was most likely to order the probationer to attend, participate in and satisfactorily complete a domestic violence intervention program (77 percent), followed by Contra Costa (69 percent, with no special program for teens) and San Francisco (50 percent). While the Santa Clara County statistics for assignment to a domestic 
violence intervention program are higher than the other counties, they are less than the 100 percent indicated by the protocol—this is likely a result of the assignment of some probationers to more appropriate mental health or individualized treatment plans, rather than the domestic violence intervention programs. San Francisco’s low rate of assignment to a domestic violence intervention program is a result of the county's preferred use of individual DV/FV counseling. Conditions of no contact with victim or victim's family were also more relevant to domestic violence. In domestic violence cases, 63 percent of probationers were ordered no contact with the victim or victim’s family, compared with 5 percent of family violence probationers.

\section{Exhibit 3.7: Conditions of Probation for Juvenile Offenders under Informal or Formal Probation}

\begin{tabular}{lcccc} 
& Total & $\begin{array}{c}\text { Santa } \\
\text { Clara }\end{array}$ & $\begin{array}{c}\text { San } \\
\text { Francisco }\end{array}$ & $\begin{array}{c}\text { Contra } \\
\text { Costa }\end{array}$ \\
\cline { 2 - 5 } Number on formal or informal probation & 304 & 202 & 40 & 62 \\
\hline Attend school regularly & $81.3 \%$ & $83.7 \%$ & $80.0 \%$ & $74.2 \%$ \\
Submit to warrantless search and seizure & $80.6 \%$ & $83.2 \%$ & $62.5 \%$ & $83.9 \%$ \\
\hline Comply with curfews & $78.0 \%$ & $81.7 \%$ & $80.0 \%$ & $64.5 \%$ \\
Abstain from alcohol or other drugs & $77.6 \%$ & $78.7 \%$ & $65.0 \%$ & $82.3 \%$ \\
\hline Individual counseling & $73.4 \%$ & $69.8 \%$ & $72.5 \%$ & $85.5 \%$ \\
Submit to unannounced home visits & $72.0 \%$ & $79.7 \%$ & $45.0 \%$ & $64.5 \%$ \\
\hline Pay fines as directed & $68.4 \%$ & $83.7 \%$ & $22.5 \%$ & $48.4 \%$ \\
Submit to drug testing & $68.4 \%$ & $68.3 \%$ & $52.5 \%$ & $79.0 \%$ \\
\hline Pay restitution as directed & $67.1 \%$ & $80.7 \%$ & $25.0 \%$ & $50.0 \%$ \\
Do not possess or use firearms & $65.8 \%$ & $77.2 \%$ & $57.5 \%$ & $33.9 \%$ \\
\hline Attend, participate in, and satisfactorily & & & & \\
complete a DV program & $54.6 \%$ & $62.9 \%$ & $17.5 \%$ & $51.6 \%$ \\
Undergo substance abuse assessment and & & & & \\
treatment as directed & $45.1 \%$ & $58.4 \%$ & $15.0 \%$ & $21.0 \%$ \\
\hline Stay away from gangs & $44.4 \%$ & $60.4 \%$ & $5.0 \%$ & $17.7 \%$ \\
Comply with electronic monitoring, if ordered & $41.4 \%$ & $56.4 \%$ & $0.0 \%$ & $19.4 \%$ \\
\hline Perform community service & $35.5 \%$ & $38.1 \%$ & $27.5 \%$ & $32.3 \%$ \\
Comply with stay away orders & $23.4 \%$ & $30.7 \%$ & $10.0 \%$ & $8.1 \%$ \\
\hline No contact with victim or victim's family & $22.7 \%$ & $26.7 \%$ & $10.0 \%$ & $17.7 \%$ \\
Restricted contact & $18.4 \%$ & $24.8 \%$ & $7.5 \%$ & $4.8 \%$ \\
\hline Pay fees for batterer's intervention program & $8.9 \%$ & $11.9 \%$ & $2.5 \%$ & $3.2 \%$ \\
Attend, participate in, and satisfactorily & & & & \\
complete parenting program & $8.6 \%$ & $11.4 \%$ & $2.5 \%$ & $3.2 \%$ \\
\hline
\end{tabular}


The conditions of probation across counties suggest that the Santa Clara County court places more conditions on its probationers than those in other counties. For example, there were 14 conditions placed on at least 50 percent of the juvenile domestic/family violence probationers in Santa Clara County. In contrast, the San Francisco and Contra Costa County courts placed 7 and 9 conditions, respectively, on at least half of its probationers. This suggests that compliance in Santa Clara County may be more likely to be compromised as the average probationer has multiple probation conditions.

\section{Institutionalization of Offenders}

Of those sentenced to either formal or informal probation, 61 percent were institutionalized. This percentage is similar across sites, although the Santa Clara group of offenders received, on average, a much longer stay in a facility than the San Francisco or Contra Costa group. Yet the differences between counties do not reach a level of statistical significance. Nor were the differences between the types of violence (domestic versus family) statistically significant. Instead, the greatest predictor of institutionalization was prior juvenile delinquency. The strong relationship between prior juvenile delinquency and institutionalization also accounts for the higher percentage of institutionalization in Contra Costa County, which had a larger percentage of juveniles with prior records in its sample than the other two counties. Exhibit 3.8 shows the percentage of offenders who were institutionalized, and the median days served, by county and prior juvenile delinquency.

\section{Exhibit 3.8: Institutionalization of Juvenile Domestic and Family Violence Offenders}

\begin{tabular}{lcccc} 
& Total & $\begin{array}{c}\text { Santa } \\
\text { Clara }\end{array}$ & $\begin{array}{c}\text { San } \\
\text { Francisco }\end{array}$ & $\begin{array}{c}\text { Contra } \\
\text { Costa }\end{array}$ \\
\cline { 2 - 5 } Number of cases & 303 & 201 & 40 & 62 \\
Percentage institutionalized & 61.4 & 58.7 & 65.0 & 67.7 \\
Median days institutionalized & 30.0 & 59.0 & 20.5 & 10.0 \\
\hline
\end{tabular}

Prior Juvenile Delinquency 
This document is a research report submitted to the U.S. Department of Justice. This report has not been published by the Department. Opinions or points of view expressed are those of the author(s) and do not necessarily reflect the official position or policies of the U.S. Department of Justice.

Number of cases

Percentage institutionalized

\begin{tabular}{cc}
\hline Yes & No \\
\hline 152 & 151 \\
68.4 & 53.6 \\
60.0 & 26.0
\end{tabular}

*significance $=.01$

Placement outside the home varies across counties and is partly determined by the availability of local resources. Santa Clara and Contra Costa counties tend to rely on juvenile hall, while San Francisco is more likely to use group homes for placement of offenders. Exhibit 3.9 provides the percentages of offenders placed outside the home, by type of placement and by county.

\section{Exhibit 3.9: Placement outside the Home}

\begin{tabular}{lcccc} 
& Total & $\begin{array}{c}\text { Santa } \\
\text { Clara }\end{array}$ & $\begin{array}{c}\text { San } \\
\text { Francisco }\end{array}$ & $\begin{array}{c}\text { Contra } \\
\text { Costa }\end{array}$ \\
\cline { 2 - 5 } Number placed outside of home & 124 & 89 & 16 & 19 \\
\hline Juvenile Hall & $38.7 \%$ & $44.9 \%$ & $12.5 \%$ & $31.6 \%$ \\
County ranch & $31.5 \%$ & $39.3 \%$ & $0.0 \%$ & $21.1 \%$ \\
\hline Other family/relatives & $12.9 \%$ & $7.9 \%$ & $25.0 \%$ & $26.3 \%$ \\
Group Home & $7.3 \%$ & $2.2 \%$ & $37.5 \%$ & $5.3 \%$ \\
\hline
\end{tabular}

\section{Violations of Probation}

More than half of all probationers violated the terms and conditions of probation. This figure ranged from 71 percent in Contra Costa County to 52 percent in Santa Clara County. Exhibit 3.10 shows the percentage of violations and the average number of violations for those who violated. The data include only those cases in Santa Clara and San Francisco that were handled by both the specialized probation unit and the domestic/family violence court. The mean number of violations is high for Contra Costa County (3.3 violations), but this is accounted for by a case that involved 15 violations. The median number of violations shows no difference between the counties in terms of the number of violations for those offenders. 


\section{Exhibit 3.10: Probation Violations by County}

\begin{tabular}{lcccc} 
& Total & $\begin{array}{c}\text { Santa } \\
\text { Clara }\end{array}$ & $\begin{array}{c}\text { San } \\
\text { Francisco }\end{array}$ & $\begin{array}{c}\text { Contra } \\
\text { Costa }\end{array}$ \\
Number of cases & 282 & 180 & 40 & 62 \\
Percentage with violations & 57.4 & 52.2 & 60.0 & 71.0 \\
Mean violations, for those who violated & 2.4 & 2.0 & 1.9 & 3.3 \\
Median violations, for those who violated & 2.0 & 2.0 & 2.0 & 2.0 \\
& & & & \\
\hline
\end{tabular}

The type of violence was not a factor in the violation of probation, but prior juvenile delinquency affected the likelihood of violating probation. Exhibit 3.11 shows the percentage of probation violators and average violations by prior juvenile delinquency. Offenders with prior juvenile delinquency were more likely to violate probation than those without prior records (67 percent versus 48 percent). The number of violations did not vary significantly by prior record.

\section{Exhibit 3.11: Probation Violations by Prior Juvenile Delinquency}

Percentage with violations

Mean violations, for those who violated

Median violations, for those who violated
Prior Juvenile Delinquency

\begin{tabular}{ccc} 
Total & Yes & No \\
\hline 57.4 & 66.7 & 47.9 \\
2.4 & 2.1 & 2.0 \\
2.0 & 1.9 & 2.0
\end{tabular}

There were three probation conditions that were violated most often: (1) attend school regularly, (2) comply with curfews, and (3) abstain from alcohol or other drugs. Exhibit 3.12 provides data on the violations of probation conditions by county and includes only those offenders with probation violations. The data are influenced by the types of probation conditions initially ordered and suggest that all three counties require juveniles to attend school, comply with curfews, and abstain from alcohol or drugs. These conditions are common in all juvenile delinquency cases and do not reflect the specific nature of domestic and family violence. 


\section{Exhibit 3.12: Violations of Specific Probation Conditions by County}

\begin{tabular}{lcccc} 
& Total & $\begin{array}{c}\text { Santa } \\
\text { Clara }\end{array}$ & $\begin{array}{c}\text { San } \\
\text { Francisco }\end{array}$ & $\begin{array}{c}\text { Contra } \\
\text { Costa }\end{array}$ \\
\cline { 2 - 5 } Number of violators & 162 & 94 & 24 & 44 \\
\hline Attend school regularly & $48.1 \%$ & $47.9 \%$ & $45.8 \%$ & $50.0 \%$ \\
Comply with curfews & $43.2 \%$ & $40.4 \%$ & $33.3 \%$ & $54.5 \%$ \\
Abstain from alcohol or other drugs & $41.4 \%$ & $38.3 \%$ & $25.0 \%$ & $56.8 \%$ \\
\hline Attend, participate in, and satisfactorily complete & & & & \\
a domestic violence program & $21.6 \%$ & $27.7 \%$ & $8.3 \%$ & $15.9 \%$ \\
Comply with electronic monitoring, if ordered & $14.8 \%$ & $9.6 \%$ & $0.0 \%$ & $34.1 \%$ \\
Individual counseling & $14.8 \%$ & $13.8 \%$ & $20.8 \%$ & $13.6 \%$ \\
\hline No harassing or stalking & $9.9 \%$ & $17.0 \%$ & $0.0 \%$ & $0.0 \%$ \\
No contact with victim or victim's family & $7.4 \%$ & $9.6 \%$ & $4.2 \%$ & $4.5 \%$ \\
Perform community service & $7.4 \%$ & $8.5 \%$ & $4.2 \%$ & $6.8 \%$ \\
\hline Comply with stay away orders & $7.4 \%$ & $10.6 \%$ & $4.2 \%$ & $2.3 \%$ \\
Stay away from gangs & $6.8 \%$ & $8.5 \%$ & $0.0 \%$ & $6.8 \%$ \\
Undergo substance abuse assessment and & & & & \\
treatment as directed by probation & $6.8 \%$ & $8.5 \%$ & $0.0 \%$ & $6.8 \%$ \\
\hline Pay restitution as directed & $6.2 \%$ & $0.0 \%$ & $12.5 \%$ & $15.9 \%$ \\
Pay fines as directed & $5.6 \%$ & $1.1 \%$ & $8.3 \%$ & $13.6 \%$ \\
\hline
\end{tabular}

Probation is typically assigned for one year. Yet the probation period typically lasts more than a year as the probationer is unable to complete all the conditions of probation and often violates probation. The average amount of time between incident date and the closure date was 611 days (the median was 579 days). This figure includes all cases, even those that were closed early because of recidivism or because the minor "aged out" of the juvenile system. Generally, probationers could expect to spend at least 18 months on probation.

\section{Probation and Program Completion}

Program completion is dependent on probation conditions, program requirements, and probation officer assessment. The data collected in this study include textual summaries of the offender's performance while on probation—data that was entered into NVivo, a qualitative analysis software The research team reviewed each summary and created a variable called "program completion,” with the following labels: (1) successful completion, (2) unsuccessful completion, and (3) other. Successful completion of the probation/program period included (a) cases that were 
closed because the probationers had successfully completed the requirements of probation, and (b) cases in which probationers had made progress in the program before they "aged out" of the juvenile system. Unsuccessful completion of the program included cases in which (a) juveniles committed a new incident, (b) probationers “aged out” of the juvenile system without making progress, and (c) probationers could no longer be located. Finally, the "other" category includes cases where the probation files did not contain enough information to deem the case successful or unsuccessful, and cases in which the juvenile’s case was transferred out of a domestic/family violence program (e.g., juveniles were sent to a mental health program).

Exhibit 3.13 shows program/probation completion rates by county. Almost one-fourth of the case files from Santa Clara and San Francisco counties were coded as “other” in terms of program completion, compared to less than ten percent in Contra Costa County. The presence of a mental health court in Santa Clara County and considerable mental health resources in San Francisco County may explain some of this difference, as 50 percent of the cases classified as "other” involved juveniles who had a diagnosis of a mental health illness.

\section{Exhibit 3.13: Program/Probation Completion by County}

\begin{tabular}{lcccc} 
& Total & $\begin{array}{c}\text { Santa } \\
\text { Clara }\end{array}$ & $\begin{array}{c}\text { San } \\
\text { Francisco }\end{array}$ & $\begin{array}{c}\text { Contra } \\
\text { Costa }\end{array}$ \\
\cline { 2 - 5 } Number of juveniles & 304 & 94 & 24 & 44 \\
\hline Successful completion & $46.7 \%$ & $43.6 \%$ & $55.0 \%$ & $51.6 \%$ \\
Unsuccessful completion & $33.2 \%$ & $33.7 \%$ & $22.5 \%$ & $38.7 \%$ \\
Other - missing/unknown/transferred & $20.0 \%$ & $22.8 \%$ & $22.5 \%$ & $9.7 \%$ \\
\hline
\end{tabular}

Exhibit 3.14 includes only those cases in which program completion could be documented as “successful” or “unsuccessful.” Arguably, excluding the “other” category artificially increases the “success” rates in each county. Successful program completion rates varied from 56 percent in Santa Clara County to 71 percent in San Francisco County. The difference between counties did not reach the level of statistical significance. Exhibit 3.14 also examines the relationship between prior 
juvenile delinquency and program completion. About 70 percent of probationers who did not have prior records successfully completed the program, compared with 47 percent of those with prior records. This variance was statistically significant at the .001 level. Other variables, such as the type of violence (family versus domestic violence) were not statistically significant.

\section{Exhibit 3.14: Successful Completion of Program/Probation, by County and Prior Delinquency}

\begin{tabular}{|c|c|c|c|c|}
\hline & Total & $\begin{array}{l}\text { Santa } \\
\text { Clara }\end{array}$ & $\begin{array}{c}\text { San } \\
\text { Francisco }\end{array}$ & $\begin{array}{c}\text { Contra } \\
\text { Costa }\end{array}$ \\
\hline Number of cases with valid data & 240 & 156 & 31 & 53 \\
\hline $\begin{array}{l}\text { Percentage of those who successfully } \\
\text { completed programs }\end{array}$ & $59.2 \%$ & $56.4 \%$ & $71.0 \%$ & $60.4 \%$ \\
\hline & \multicolumn{4}{|c|}{ Prior Juvenile Delinquency* } \\
\hline & & Yes & No & \\
\hline Number of cases with valid data & & 120 & 123 & \\
\hline $\begin{array}{l}\text { Percentage of those who successfully } \\
\text { completed programs }\end{array}$ & & $46.7 \%$ & $69.9 \%$ & \\
\hline
\end{tabular}

Exhibit 3.15 explores this relationship further by measuring program completion success rates while controlling for prior juvenile delinquency. The cross-tabulation shows that (1) Santa Clara County has the lowest rate of successful program completion, and (2) offenders with prior delinquency records are less likely to successfully complete probation and program requirements than those without prior records. Statistical tests did not show significance in the complex relationship between county, prior juvenile delinquency, and successful program completion. The lower rates of successful program completion in Santa Clara County are likely a result of the high levels of intensive supervision afforded to juveniles who commit family or domestic violence, a legal culture that stresses law enforcement, a large number of terms of conditions placed on probationers, and a challenging batterer intervention program for teens. 


\section{Exhibit 3.15: Successful Completion of Program/Probation, Controlling for Prior Delinquency within County}

\begin{tabular}{ccccc} 
& Total & $\begin{array}{c}\text { Santa } \\
\text { Clara }\end{array}$ & $\begin{array}{c}\text { San } \\
\text { Francisco }\end{array}$ & $\begin{array}{c}\text { Contra } \\
\text { Costa }\end{array}$ \\
\cline { 2 - 5 } $\begin{array}{c}\text { Number of juveniles with prior delinquency records } \\
\text {--Percentage of those who successfully completed } \\
\text { programs }\end{array}$ & 120 & 65 & 15 & 40 \\
$\begin{array}{c}\text { Number of juveniles without prior delinquency records } \\
\text {--Percentage of those who successfully completed } \\
\text { programs }\end{array}$ & 123 & 91 & 16 & 16 \\
\hline & $69.9 \%$ & $65.9 \%$ & $87.5 \%$ & $75.0 \%$ \\
\hline
\end{tabular}

Finally, the determinants of successful program completion were explored using logistic regression analysis. Exhibit 3.16 lists the factors that were expected to influence the success of program completion.

\section{Exhibit 3.16: Factors Expected to Influence Program Completion}

\begin{tabular}{|l|}
\hline Background Variables \\
\hline 1. Site $1=$ Santa Clara; $2=$ San Francisco; $3=$ Contra Costa \\
\hline 2. Intervention 1=yes (SC \& SF); $2=$ no (CC) \\
\hline 3. Type (domestic violence vs. family violence) \\
\hline 4. Offender gender $1=$ male; 2 = female \\
\hline 5. Victim gender $1=$ =male 2 = female \\
\hline 6. Offender Age \\
\hline $\begin{array}{l}\text { 7. Race/ethnicity (1= African American, } 2=\text { Caucasian, 3=Hispanic, 4=Other (includes Asian, Pacific Islander, } \\
\text { multi-racial, other) }\end{array}$ \\
\hline 8. Number of prior referrals (prior juvenile delinquency) \\
\hline 9. Mental illness (1=yes; $2=$ not indicated) \\
\hline $\begin{array}{l}\text { 10. Victim-Offender Relationship (1=domestic partner; 2=parent/stepparent/parents' cohabitating partner; } \\
\text { 3=sibling; 4=other) }\end{array}$ \\
\hline $\begin{array}{l}\text { 11. Parental violence (child abuse, domestic violence) (yes/not indicated) -offender was abused as child } \\
\text { AND/OR parents have history of domestic/family violence) }\end{array}$ \\
\hline $\begin{array}{l}\text { 12. Substance abuse (yes/not indicated) -offender diagnosed with Substance Abuse Disorder AND/OR incident } \\
\text { occurred when offender was under influence of drugs or alcohol AND/OR offender violated probation } \\
\text { condition of abstaining from using alcohol or other drugs }\end{array}$ \\
\hline Incident Data \\
\hline 13. Severity of incident (mild, moderate, severe) \\
\hline 14. Youth admitted to charges (yes, no) \\
\hline Intervention Data \\
\hline 15. Number of days institutionalized \\
\hline 16. Number of court reviews \\
\hline 17. Disposition (1=informal probation; 2=formal probation) \\
\hline 18. Number of probation violations \\
\hline $\begin{array}{l}\text { 19. Probation supervision (1=no probation; 2= probation only; 3=probation + elec. monitoring; 4=probation \& } \\
\text { placement outside home (with or without electronic monitoring)) }\end{array}$ \\
\hline
\end{tabular}


Factors were input into a logistic regression analysis, with results shown in Exhibit 3.17.19

Exhibit 3.17: Logistic Regression Parameters for Probability of Successful Program Completion

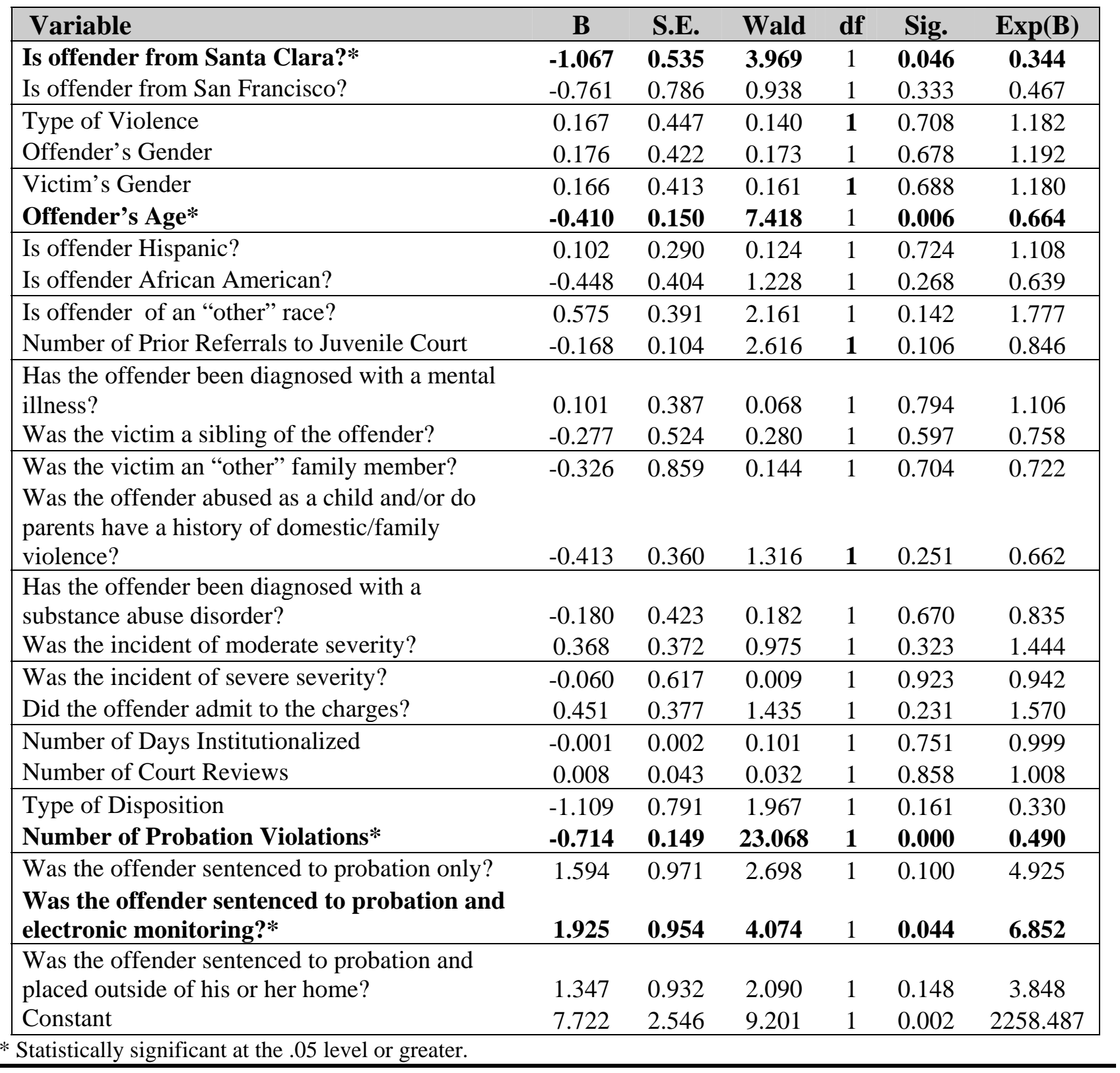

Results of the analysis showed the following statistically significant results:

1. Offenders who violated probation, controlling for all other factors, were less likely to successfully complete the probation program than those who did not violate probation.

19 Unless otherwise noted, all non-continuous variables are coded as dichotomies, with " 1 ” indicating "yes" and " 0 " indicating "no." For both the offender and the victim's gender, "1" indicates female and "0" indicates male. For Type of Violence, "1" indicates domestic violence while " 0 " indicates family violence. For Type of Disposition, "1" indicates Formal Probation while "0" indicates Informal Probation. 
2. Controlling for all other factors, offenders who were subjected to electronic monitoring while on probation were more likely to successfully complete the program, when compared to those not on electronic monitoring.

3. All things being equal, offenders in Santa Clara County were less likely to successfully complete the probation program.

4. Younger offenders, when controlling for all other factors, were more likely to successfully completing the probation program when compared to older offenders.

Unlike the bivariate analysis that showed a significant relationship between prior juvenile delinquency and successful program completion, the multivariate analysis showed that prior juvenile delinquency was not a significant factor in predicting program success, at least when all other factors were controlled. Instead, the factors that best predicted successful program completion were probation violations, electronic monitoring, county, and age of offender.

The strong relationship between probation violations and successful program completion was expected. However, the relationships between county, electronic monitoring, and age of offender call for further exploration. In particular, the significance of the use of electronic monitoring, which was used in Santa Clara and Contra Costa counties, to successful program completion offers a strategy that could make a positive impact on program completion. Additionally, the importance of age to successful program completion suggests that program success could be impacted by programs that were designed to meet the needs of varying age groups. Finally, the high number of conditions placed on probationers and the intensive supervision of offenders in Santa Clara County appear to decrease the likelihood that teens can successfully complete the program as designed.

\section{Summary of Findings}

Probation practices vary across counties. Santa Clara County uses primarily formal probation consistently and uses electronic monitoring and/or out of home placement in the majority of cases. San Francisco County probation practices tend to rely more on informal probation and do not include the use of electronic monitoring. Contra Costa County probation practices fall between 
Santa Clara County’s “law enforcement” approach and San Francisco County’s “therapeutic approach”. Contra Costa County typically uses formal probation in domestic/family violence cases, and makes some use of electronic monitoring and out of home placement.

The majority of domestic violence offenders in all three counties were ordered to attend, participate in, and satisfactorily complete a domestic violence intervention program. In addition, juvenile domestic/family violence offenders received conditions of probation similar to those expected in the general juvenile caseload. The most common conditions ordered, for both domestic and family violence offenders, include (1) attend school regularly, (2) submit to warrantless search and seizure, (3) comply with curfews, (4) abstain from alcohol or drugs, and (5) participate in individual counseling. About six of every ten offenders were institutionalized in each of the three counties. Offenders with a prior juvenile delinquency record were significantly more likely to be institutionalized than those without a prior record. Additionally, offenders with prior records served substantially longer durations in an institution (median of 60 days) than those without prior records (median of 26 days). About six of every ten offenders were institutionalized in each of the three counties. Offenders with a prior juvenile delinquency record were significantly more likely to be institutionalized than those without a prior record. Additionally, offenders with prior records served substantially longer durations in an institution (median of 60 days) than those without prior records (median of 26 days).

More than half of all probationers violated the terms and conditions of probation at least once. Among those who committed probation violations, the median number of violations was two-a figure that was consistent across counties. Probationers with prior juvenile records were more likely to violate probation than those without records. The three most common violations across counties were failure to (1) attend school regularly, (2) comply with curfews, and (3) abstain from alcohol or other drugs. Cases were closed, on average, 611 days after the incident (the median 
was 579 days). While probation was typically assigned for one year, probationers could expect to spend at least 18 months on probation. The additional time is accounted for by the high percentage of probation violators.

The majority of probationers successfully completed the probation program. Santa Clara County had a lower rate of successful completion (56 percent) when compared to San Francisco County (71 percent) and Contra Costa County (60 percent). At the bivariate level, the most significant factor in determining successful program completion was prior juvenile delinquency. Juveniles with prior records were much less likely to successfully complete the program than those without prior records (47 percent versus 70 percent).

Logistic regression showed that four variables significantly influenced the probability of successful program completion: (1) violation of probation, (2) electronic monitoring, (3) county, and (4) age of the offender. All things being equal, the likelihood of successfully completing the probation program increased if the offender did not violate probation, the offender was placed on electronic monitoring, the offender was not in Santa Clara County, and the offender was young. Results suggest real-world strategies, such as electronic monitoring and age-specific programming, which could positively impact successful program completion. Furthermore, the relatively lower rates of successful program completion in Santa Clara County are likely to reflect the high levels of intensive supervision and legal culture, rather than offender performance.

\section{Policy Implications}

Juvenile offenders of domestic/family violence are a diverse group. While the majority of offenders have prior records, there is a sizeable minority of offenders who are facing the juvenile justice system for the first time. Programs that treat all offenders with the same intensity of sanctions may be counterproductive. Graduated sanctions that take into account the severity of the 
incident and extenuating circumstances may offer a more balanced approach that recognizes differences in the needs and experiences of the juvenile population. The ability and willingness of juveniles to successfully complete a probation program varies significantly between first-time offenders and repeat offenders. Juveniles with prior records are least likely to successfully complete probation. Further studies should be conducted on how juveniles respond to each facet of an intervention program and strategies that can be taken to improve successful completion rates.

Batterer intervention programs that have been developed for adult batterers are often plagued by the one-size-fits all assumption. Batterers are presumed to suffer from the same malady, thus requiring the same treatment. Studies testing the effectiveness of adult battering intervention programs have been inconclusive. Yet these same programs are being modeled and modified for teens. There is a dire need for an empirically-based design of intervention programs geared toward teens who commit domestic violence offenses. Additionally, the involvement of family dynamics in the course of family violence crimes calls for the design of intervention programs specific to family violence.

The teen batterer intervention programs also need to be more comparable across different service providers, with consistent expectations for what constitutes failure and completion. Studies of whether teen group programs are more effective than individual counseling should be conducted. Also, in California, 52 weeks of adult batterers programs are mandated and funded. No such provisions or funding exist for teen batterers programs. The curriculum for the teen batterers program in Santa Clara County has been modified for a teen population and typically lasts for 26 weeks. Funding is a perpetual problem. Future studies should also look at the effectiveness of shorter programs versus longer programs, and which type of curriculum is best suited for males versus females, and different cultural groups. Better funding for these interventions should also be explored. 
Finally, a sizeable proportion of juvenile domestic/family violence offenders have been diagnosed with mental health issues. In these cases, mental health programs, such as a specialized mental health court that can offer additional services may be more suitable than a delinquency juvenile domestic/family violence court-based intervention program. At minimum, a mental health component should complement justice system remedies. The intersection of mental health illness and juvenile delinquency, including teen domestic and family violence, will have an impact on the design and effectiveness of intervention programs. 


\section{4 - Recidivism}

This chapter explores recidivism, measured as the re-arrest of the juvenile offender. Arrest data includes official juvenile and adult arrest records. Advanced statistical tools were used to examine the effects of the intervention programs in Santa Clara and San Francisco counties.

\section{Recidivism Measures}

Data collected on recidivism came from two sources. First, juvenile record files were used to document information on arrests and convictions subsequent to the domestic/family violence incident studied here. Second, staff from each county provided the research team with adult records for each subject, using the records from CJIC, the California Criminal Justice Information Control. Subsequent arrests for domestic or family violence-related offenses were identified separately from other arrests. Information on arrests was much more reliable than conviction data. Consequently, recidivism is measured here as a subsequent arrest.

Exhibit 4.1 shows the general recidivism rates for each county. Data is provided for arrests for any offense and for offenses that fall under the category of domestic or family violence.

\section{Exhibit 4.1: Percentage of Offenders who Recidivate, by County}

Number of juveniles Percent re-arrested on any offense Percent re-arrested on domestic or family violence offense

\begin{tabular}{cccc} 
Total & $\begin{array}{c}\text { Santa } \\
\text { Clara }\end{array}$ & $\begin{array}{c}\text { San } \\
\text { Francisco }\end{array}$ & $\begin{array}{c}\text { Contra } \\
\text { Costa }\end{array}$ \\
\hline 302 & 200 & 40 & 62 \\
\hline 48.3 & 47.5 & 52.5 & 48.4 \\
\hline 32.3 & 33.3 & 27.5 & 32.3 \\
\hline
\end{tabular}

The data indicate a general recidivism rate of 48 percent and a domestic/family violence recidivism rate of 32 percent. A second level of analysis incorporates program completion into the analysis to 
better understand how participation in and successful completion of probation and program requirements affect recidivism. Exhibit 4.2 shows recidivism data by county and program completion. The analysis does not include cases in which the success of the program completion could not be determined. Juveniles who successfully completed probation and corresponding requirements were re-arrested at a rate of 37 percent, compared to 58 percent for those who did not successfully complete the program. The Santa Clara County juveniles who successfully completed the program had the lowest general re-arrest rate (33 percent); however, this same group had a rate of re-arrest for domestic/family violence offenses (27 percent) that was similar to their counterparts in San Francisco and Contra Costa counties. Variances were not statistically significant.

\section{Exhibit 4.2: Percentage of Offenders who Recidivate, by Program Completion and County}

\begin{tabular}{lcccc} 
& Total & $\begin{array}{c}\text { Santa } \\
\text { Clara }\end{array}$ & $\begin{array}{c}\text { San } \\
\text { Francisco }\end{array}$ & $\begin{array}{c}\text { Contra } \\
\text { Costa }\end{array}$ \\
\hline Juvenile Successfully Completed the Program & & & & \\
Number of juveniles & 142 & 88 & 22 & 32 \\
Percent re-arrested on any offense & 37.3 & 33.0 & 50.0 & 40.6 \\
Percent re-arrested on domestic/family violence offense & 26.1 & 27.3 & 22.7 & 25.0 \\
\hline Juvenile Did Not Successfully Complete the Program & & & & \\
Number of juveniles & 160 & 112 & 18 & 30 \\
Percent re-arrested on any offense & 58.1 & 58.9 & 55.6 & 56.7 \\
Percent re-arrested on domestic/family violence offense & 37.9 & 38.1 & 33.3 & 40.0 \\
\hline
\end{tabular}

The differences within counties suggest a large effect of successful program completion on general recidivism in Santa Clara County when compared to the other two counties. In Santa Clara County, 59 percent of juveniles who did not successfully complete the program recidivated, compared to 33 percent of those who completed the program-a difference of 26 percentage points. Similar differences in San Francisco County and Contra Costa County were 6 and 16 percentage points, respectively. However, this relationship did not hold when examining recidivism rates for domestic and family violence offenses only. 
A third tier of inquiry is to gauge the importance of prior juvenile delinquency, a factor that influenced many aspects of this study. Exhibit 4.3 presents the percentage of offenders who recidivate, by prior juvenile delinquency and county. The analysis shows that 56 percent of juveniles with prior records were arrested for a subsequent offense, compared with 40 percent of those without prior records. There was no discernible variance between counties.

\section{Exhibit 4.3: Percentage of Offenders who Recidivate, by Prior Juvenile Delinquency and County}

\begin{tabular}{lcccc} 
& Total & $\begin{array}{c}\text { Santa } \\
\text { Clara }\end{array}$ & $\begin{array}{c}\text { San } \\
\text { Francisco }\end{array}$ & $\begin{array}{c}\text { Contra } \\
\text { Costa }\end{array}$ \\
\hline Juveniles with Prior Records & & & & \\
Number of juveniles & 151 & 87 & 21 & 43 \\
Percent re-arrested on any offense & 56.3 & 56.3 & 66.7 & 51.2 \\
Percent re-arrested on domestic/family violence offense & 36.4 & 40.2 & 33.3 & 30.2 \\
\hline Juvenile without Prior Records & & & & \\
Number of juveniles & 151 & 113 & 19 & 19 \\
Percent re-arrested on any offense & 40.4 & 40.7 & 36.8 & 42.1 \\
Percent re-arrested on domestic/family violence offense & 28.3 & 28.1 & 21.1 & 36.8 \\
\hline & & & &
\end{tabular}

\section{Time to Recidivism}

Time to general recidivism was examined to explore any time-sensitive programmatic

effects. There were two factors that affected the analysis. First, time to recidivate on a domestic or family violence offence could not be calculated as dates particular to each type of offense were not collected. Second, there were 35 cases in which an offender was re-arrested but the date was not provided. The cases with missing dates were primarily from Santa Clara County and were for arrests made when the offender reached adulthood. Consequently, the time to recidivism data may be affected by the number of cases in which the date of re-arrest was unknown-these cases would be counted in the overall recidivism figures but would not show up in the six-month incremental 
time series results. Fortunately, the fact that all of the re-arrests were pulled from adult records make increase the probability that most of these cases occurred after a two-year period.

Exhibit 4.4 shows the percentage of offenders that recidivated at each site by the indicated time, measured from the date of the incident that brought them to the attention of the court until the recidivistic event. Data is provided for six month periods, up to two years following the date of the incident. ${ }^{20}$ Results show that when the analysis is run by the date of re-arrest, offenders from Santa Clara County took longer to recidivate than offenders from any other site. Further, offenders from Contra Costa County recidivated at a faster rate than offenders from any other site. Another approach to examining recidivism over time is a survival analysis using the Kaplan-Meier technique was conducted. The Kaplan-Meier analysis compared the probability of recidivating over time among the three sites, but did not control for the influence of other independent variables on this probability. The average survival times for offenders from Contra Costa, San Francisco, and Santa Clara were 1,395, 1,239 and 1,409 days, respectively.

\section{Exhibit 4.4: Percent of Recidivism by the Amount of Time Since the Incident, by County}

\begin{tabular}{lccccc} 
& \multicolumn{5}{c}{ Number of Months Since Incident } \\
& 6 & 12 & 18 & 24 & Overall \\
\cline { 2 - 6 } Contra Costa & 14.5 & 25.8 & 29 & 37.1 & 48.3 \\
San Francisco & 12.5 & 20 & 25 & 30 & 52.5 \\
Santa Clara & 8.5 & 18.5 & 22.5 & 24 & 47.5
\end{tabular}

The effects of prior juvenile delinquency, in conjunction with county, were then analyzed to determine if the time to recidivism was an artifact of differences in the juvenile population. Results are shown in Exhibit 4.5. Two conclusions can be drawn from this analysis:

\section{The specialized intervention programs in both Santa Clara and San Francisco counties have a deterrent effect on first-time offenders. The deterrent effect,}

\footnotetext{
20 The majority of offenders could not be tracked for a period longer than 24 months as their date of incident was too recent to provide this analysis.
} 
which lasted up to two years (the time period included in this study), was especially apparent in Santa Clara County, where just 3 percent of first-time offenders recidivated within six months after the incident, compared to 16 percent in Contra Costa County.

2. Recidivism rates for offenders with prior records are remarkably consistent across sites. One year after the incident, 28 to 30 percent of offenders with prior delinquency had recidivated, regardless of any specialized intervention. This data suggests that the court-based intervention programs are more effective with first-time offenders than repeat offenders.

Exhibit 4.5: Percent of Recidivism by the Amount of Time Since the Incident, by County and Prior Delinquency

No Prior Juvenile Delinquency

\begin{tabular}{|lccccc|}
\hline & \multicolumn{5}{c}{ Number of Months Since Incident } \\
& 6 & 12 & 18 & 24 & Overall \\
\cline { 2 - 6 } Contra Costa & 15.8 & 21.1 & 26.3 & 31.5 & 42.1 \\
San Francisco & 10.5 & 10.5 & 10.5 & 10.5 & 36.8 \\
Santa Clara & 2.7 & 9.7 & 13.3 & 15 & 40.7 \\
\hline
\end{tabular}

Prior Juvenile Delinquency

\begin{tabular}{|lccccc|}
\hline & \multicolumn{5}{c}{ Number of Months Since Incident } \\
& 6 & 12 & 18 & 24 & Overall \\
\cline { 2 - 6 } Contra Costa & 14 & 27.9 & 30.2 & 41.9 & 51.2 \\
San Francisco & 14.3 & 28.6 & 38.1 & 42.8 & 66.6 \\
Santa Clara & 16.1 & 29.9 & 34.5 & 35.6 & 56.3 \\
\hline
\end{tabular}

\section{Factors Affecting Recidivism}

General recidivism rates, or re-arrests for any offense, were used to study programmatic effects. The relatively low number of re-arrests specifically for domestic/family violence offenses resulted in small cell sizes for which sophisticated analysis was inappropriate. Similarly, due to the difficulties in coding participation/completion of the teen batterers' group, a reliable indicator of the batterer intervention programs was not available for inclusion in the logistic regression. Exhibit 4.6 
shows the variables that were expected to influence the probability of re-arrest, classified into three

categories: (1) background variables, (2) incident data, and (3) intervention data.

\section{Exhibit 4.3: Factors Expected to Influence the Probability of Re-arrest}

\section{Background Variables}

1. Site $1=$ Santa Clara; $2=$ San Francisco; $3=$ Contra Costa

2. Intervention $1=$ yes (SC \& SF); $2=$ no (CC)

3. Type (domestic violence vs. family violence)

4. Offender gender $1=$ male; $2=$ female

5. Victim gender $1=$ male $2=$ female

6. Offender Age

7. Race/ethnicity (1= African American, 2=Caucasian, 3=Hispanic, 4=Other (includes Asian, Pacific Islander, multi-racial, other)

8. Number of prior referrals (prior juvenile delinquency)

9. Mental illness (1=yes; $2=$ not indicated)

10. Victim-Offender Relationship (1=domestic partner; 2=parent/stepparent/parents' cohabitating partner; $3=$ sibling; $4=$ other)

11. Parental violence (child abuse, domestic violence) (yes/not indicated) -offender was abused as child AND/OR parents have history of domestic/family violence)

12. Substance abuse (yes/not indicated) -offender diagnosed with Substance Abuse Disorder AND/OR incident occurred when offender was under influence of drugs or alcohol AND/OR offender violated probation condition of abstaining from using alcohol or other drugs

\section{Incident Data}

13. Severity of incident (mild, moderate, severe)

14. Youth admitted to charges (yes, no)

\section{Intervention Data}

15. Number of days institutionalized

16. Number of court reviews

17. Disposition (1=informal probation; $2=$ formal probation)

18. Number of probation violations

19. Probation supervision (1=no probation; $2=$ probation only; $3=$ probation + elec. monitoring; 4=probation \& placement outside home (with or without electronic monitoring))

20. Program completion ( $0=$ successful; $1=$ unsuccessful)

To test the impact of the intervention program in relationship to independent variables, logistic regression was used to sort through the factors that may contribute to recidivism. The inclusion of program completion in the logistic regression eliminated those cases in which the success of program completion could not be determined, and those cases that were transferred out of the specialized program. For instance, offenders with serious mental health problems may have 
been transferred out of a domestic or family violence program to receive mental health treatment.

Therefore, the logistic regression analysis uses a subset of cases. Exhibit 4.4 shows the estimates for the parameters of the logistic regression. ${ }^{21}$

\section{Exhibit 4.4: Logistic Regression Parameters for Probability of Re-arrest}

\begin{tabular}{|c|c|c|c|c|c|c|}
\hline Variable & B & S.E. & Wald & df & Sig. & $\operatorname{Exp}(\mathrm{B})$ \\
\hline Is offender from Santa Clara? & 0.900 & 0.533 & 2.855 & 1 & 0.091 & 2.459 \\
\hline Is offender from San Francisco? & 0.991 & 0.785 & 1.596 & 1 & 0.206 & 2.695 \\
\hline Type of Violence* & -1.144 & 0.473 & 5.856 & 1 & 0.016 & 0.318 \\
\hline Offender's Gender & -0.700 & 0.404 & 3.007 & 1 & 0.083 & 0.497 \\
\hline Victim's Gender* & 0.912 & 0.422 & 4.667 & 1 & 0.031 & 2.489 \\
\hline Offender's Age & -0.006 & 0.127 & 0.002 & 1 & 0.965 & 0.994 \\
\hline Is offender Hispanic? & -0.458 & 0.326 & 1.967 & 1 & 0.161 & 0.633 \\
\hline Is offender African American? & 0.313 & 0.463 & 0.456 & 1 & 0.500 & 1.367 \\
\hline Is offender of an "other” race? & -0.122 & 0.421 & 0.083 & 1 & 0.773 & 0.886 \\
\hline Number of Prior Referrals to Juvenile Court* & 0.420 & 0.123 & 11.631 & 1 & 0.001 & 1.522 \\
\hline $\begin{array}{l}\text { Has the offender been diagnosed with a mental } \\
\text { illness? }\end{array}$ & -0.647 & 0.370 & 3.052 & 1 & 0.081 & 0.524 \\
\hline Was the victim a sibling of the offender? & 0.396 & 0.478 & 0.687 & 1 & 0.407 & 1.486 \\
\hline Was the victim an "other" family member? & 0.113 & 0.859 & 0.017 & 1 & 0.895 & 1.120 \\
\hline $\begin{array}{l}\text { Was the offender abused as a child and/or do } \\
\text { parents have a history of domestic/family } \\
\text { violence?* }\end{array}$ & 0.742 & 0.347 & 4.578 & 1 & 0.032 & 2.100 \\
\hline $\begin{array}{l}\text { Has the offender been diagnosed with a } \\
\text { substance abuse disorder? }\end{array}$ & 0.469 & 0.420 & 1.246 & 1 & 0.264 & 1.599 \\
\hline Was the incident of moderate severity? & 0.145 & 0.350 & 0.172 & 1 & 0.678 & 1.156 \\
\hline Was the incident of severe severity? & -0.275 & 0.589 & 0.218 & 1 & 0.641 & 0.760 \\
\hline Did the offender admit to the charges? & -0.444 & 0.370 & 1.441 & 1 & 0.230 & 0.641 \\
\hline Number of Days Institutionalized & -0.002 & 0.002 & 1.853 & 1 & 0.173 & 0.998 \\
\hline Number of Court Reviews & -0.018 & 0.045 & 0.153 & 1 & 0.696 & 0.983 \\
\hline Type of Disposition & -0.358 & 0.727 & 0.242 & 1 & 0.623 & 0.699 \\
\hline Number of Probation Violations* & 0.390 & 0.141 & 7.716 & 1 & 0.005 & 1.478 \\
\hline Was the offender sentenced to probation only? & 0.114 & 0.902 & 0.016 & 1 & 0.900 & 1.120 \\
\hline $\begin{array}{l}\text { Was the offender sentenced to probation and } \\
\text { electronic monitoring? }\end{array}$ & 0.252 & 0.891 & 0.080 & 1 & 0.777 & 1.287 \\
\hline $\begin{array}{l}\text { Was the offender sentenced to probation and } \\
\text { placed outside of his or her home? }\end{array}$ & 0.332 & 0.876 & 0.143 & 1 & 0.705 & 1.393 \\
\hline $\begin{array}{l}\text { Did the offender successfully complete the } \\
\text { program?* }\end{array}$ & 0.808 & 0.365 & 4.911 & 1 & 0.027 & 2.245 \\
\hline Constant & -1.531 & 2.164 & 0.501 & 1 & 0.479 & 0.216 \\
\hline
\end{tabular}

* Statistically significant at the .05 level or greater.

21 Unless otherwise noted, all non-continuous variables are coded as dichotomies, with " 1 " indicating "yes" and " 0 " indicating "no." For both the offender and the victim's gender, "1" indicates female and "0" indicates male. For Type of Violence, " 1 ” indicates domestic violence while " 0 " indicates family violence. For Type of Disposition, "1" indicates Formal Probation while "0" indicates Informal Probation. 
One way to assess the validity of the regression model (i.e., to test its "goodness of fit") is to examine how accurately predictions of recidivism based on the results of the logistic regression correspond to actual (observed) recidivism. If the predicted probability of recidivism (on the basis of the logistic regression) was .5 or greater, the offender was predicted to be a recidivist. Exhibit 4.5 provides relevant data. The regression model is able to predict recidivism much more accurately than could be predicted on the basis of the null hypothesis, according to which the regression model will predict with no more accuracy than the observed probabilities. On the basis of the null hypothesis alone, 50 percent of the offenders (121/243) will be correctly classified, simply by predicting that every one in the study will be classified into the most frequently occurring alternative (i.e., non-recidivism). However, the regression model actually correctly classifies 71.2 percent of offenders.

\section{Exhibit 4.5: Comparison of Predicted with Observed Recidivism}

\begin{tabular}{|c|c|c|c|c|c|c|}
\hline $\begin{array}{l}\text { Observed } \\
\text { Category }\end{array}$ & $\begin{array}{c}\text { Non- } \\
\text { Recidivists } \\
\end{array}$ & $\begin{array}{l}\text { Predicted } \\
\text { \% of Observed } \\
\text { Category } \\
\text { Classified as } \\
\text { Non- } \\
\text { Recidivists } \\
\end{array}$ & Recidivists & $\begin{array}{c}\text { \% of } \\
\text { Observed } \\
\text { Category } \\
\text { Classified as } \\
\text { Recidivists } \\
\end{array}$ & Total & $\begin{array}{c}\text { Percentage } \\
\text { of Observed } \\
\text { Category } \\
\text { Correctly } \\
\text { Classified } \\
\end{array}$ \\
\hline Non-Recidivists & 89 & $73.6 \%$ & 32 & $26.4 \%$ & 121 & $73.6 \%$ \\
\hline Recidivists & 38 & $31.1 \%$ & 84 & $68.9 \%$ & 122 & $68.9 \%$ \\
\hline Total & 127 & $52.3 \%$ & 116 & $47.7 \%$ & 243 & $71.2 \%$ \\
\hline
\end{tabular}

The results provide strong evidence that the model is capable of explaining much of the variation in the probability of recidivism. We next turn to the substantiative implications of the results generated by the logit model. 
Because the estimated coefficients in Exhibit 4.4 (listed in the column labeled "B") are difficult to interpret in and of themselves22, the odds ratios (shown in the column labeled "Exp(B)" in Exhibit 4.4) are typically used to interpret the results of the regression. When the odds ratio is greater than 1.00 , it shows the change in the odds of recidivating when the independent variable increases by one unit. Alternatively, when the odds ratio is less than one, the inverse of the odds ratio represents the change in the odds of not recidivating when the independent variable increases by one unit.

Exhibit 4.4 shows that six variables significantly influenced the probability of recidivating:

- The type of violence,

- The victim's gender,

- The number of prior referrals of the offender to juvenile court,

- Whether the offender was abused as a child and/or the parents have a history of domestic/family violence,

- The number of probation violations, and

- Whether the offender successfully completed the program.

If the incident was a family violence incident, the odds of recidivism was increased by .3 when compared to domestic violence incidents. Having a female victim increased the odds of recidivism by 2.5 times compared to the odds when the victim was a male. Each prior referral to juvenile court increased the odds of recidivism by 1.5 times. Having been abused as a child and/or having parents with a history of domestic/family violence doubled (2.1) the odds of recidivism, all things being equal. Each probation violation occurring while the offender was either participating in the program or on probation increased the odds of recidivating by 1.5 times. Finally, failure to successfully complete the program increased the odds of recidivating by 2.2 when compared to those who successfully completed the program.

22 The estimated coefficients in Exhibit 4.4 measure the change in the log of the odds that a juvenile offender will recidivate when the independent variable in question increases by one unit. 
In short, the explanatory model that emerges from the logistic regression of the probability of re-arrest largely reflects characteristics of the offender, and, in one instance, of the victim. Offenders with a female victim, prior referrals to juvenile court, having been abused as a child and/or having parents with a history of domestic/family violence, and accumulating probation violations while participating in the intervention program or probation have higher odds of recidivism than offenders without these characteristics. Also, the type of violence had a significant effect, with family violence offenders more likely to recidivate than domestic violence offenders.

There is evidence from the logistic regression that the successful completion of the probation program, regardless of the nature of the program, has a powerful effect on recidivism. While county and program-specific intervention variables (including probation supervision and court reviews) did not have a significant effect when all other factors were controlled, the significance of program completion should not be overlooked. Strategies that increase successful completion of the program, without compromising the program, are worth exploring.

\section{Summary of Findings}

The general recidivism rate, measured as re-arrests, ranged from 48 percent in Santa Clara and Contra Costa counties to 53 percent in San Francisco County. Recidivism for a domestic or family violence offense showed little variance between counties (28 to 33 percent). Two factors had a strong effect on recidivism rates. First, offenders who successfully completed the probation program were least likely to recidivate. This was true across all counties, regardless of the nature of the probation program. Second, offenders with prior records were much more likely to recidivate than first-time offenders. This relationship was also consistent across counties.

At first glance, it would appear that the court-based intervention programs in Santa Clara and San Francisco counties did not affect recidivism rates. However, time-to-recidivism showed that 
offenders from Santa Clara County took longer to recidivate. This suggests that the intervention implemented in Santa Clara County especially, had an effect on recidivism lasting up to two years following the incident. The statistical tests then added an element of control to the equation-prior juvenile delinquency. Here findings showed that the specialized intervention programs in both Santa Clara and San Francisco counties had a deterrent effect on first-time offenders that lasted up to two years following the incident. The effect was especially apparent in Santa Clara County, where just three percent of first-time offenders recidivated within six months after the incident, compared to sixteen percent in Contra Costa County. The data also showed that recidivism rates for offenders with prior records were remarkably consistent across sites over time. In conclusion, the court-based intervention programs appear to have a substantial deterrent effect on first-time offenders, but have little to no effect on offenders with prior records.

The time series analysis was complemented by multivariate logistic regression analysis to determine factors that affected recidivism. Logistic regression showed that six variables significantly influenced the probability of recidivating: (1) the type of violence, (2) the victim's gender, (3) the number of prior referrals of the offender to juvenile court, (4) whether the offender was abused as a child and/or the parents have a history of domestic/family violence, (5) the number of probation violations, and (6) successful program completion. While most of these variables were background factors that could not be influenced by the justice system, the significant relationship between program completion and recidivism must be underscored.

Finally, the analysis in this chapter uses a very narrow definition of recidivism-re-arrests as identified through official reports. It is possible that there are other beneficial effects of the specialized programs, such as greater victim safety or attitudinal changes that are more difficult to observe and measure. The fact that the short-term survival analysis (as measured through a 24 month period) shows a deterrent effect on recidivism, especially for first-time offenders, is an 
encouraging result. This study also demonstrates however, that the personal background characteristics of the offender, such as a family history of abuse and domestic violence, and his/her prior delinquency, make it very difficult to effect change in this population.

\section{Policy Implications}

The fact that the survival analysis (as measured through a 24 month period) shows a deterrent effect on recidivism, especially for first-time offenders, is an encouraging result for the specialized juvenile domestic/family violence court programs. Results also indicate that early intervention has a deterrent effect. This study suggests that a court-based intervention program for juveniles who commit crimes of domestic or family violence is especially effective for first time offenders who have not yet "hardened" into a destructive behavior pattern. This study also demonstrates that the personal background characteristics of the offender, such as a family history of abuse and domestic violence, and prior delinquency, make it very difficult to effect change in this population. A graduated sanctions approach may be the best way to deal with this diverse group of minor offenders, with more serious sanctions reserved for the most serious cases.

A persistent debate in the juvenile justice system is the balance between negative sanctions as consequences for behavior and therapeutic approaches. It is instructive to note that the only significant program intervention variable included in the logistic regression analysis was successful completion of the program (which included completion of all court ordered programs). Number of days institutionalized, number of court reviews, types of probation and disposition did not have a significant effect on the probability of re-arrest. While individual sanctions did not have a direct impact on recidivism, other factors of the program that could not be analyzed independently, such as counseling and educational components of the program, may attribute to the significant relationship between successful program completion and lower recidivism rates. The policy implication 
therefore is that juvenile domestic/family violence courts should focus on improving and expanding treatment and intervention part of their programs. In sum, strategies designed to improve probation/program success rates, without compromising the program, should have a deterrent effect on juvenile offenders of domestic and family violence. 


\section{References}

Arriaga, X.B, \& Foshee, V.A. (2004). Adolescent dating violence: Do adolescents follow their friends’ or their parents’ footsteps? Journal of Interpersonal Violence, 19, 162-184.

Bank, L., \& Burraston, B. (2001). Abusive home environments as predictors of poor adjustment during adolescence and early childhood. Journal of Community Psychology, 29, 195-217.

Bethke, T.M. and D. Dejoy. 1993. "An Experimental Study of Factors Influencing the Acceptability of Dating Violence.” Journal of Interpersonal Violence 8: 36-42.

Breslin, F.C., D.S. Riggs, K.D. O'Leary, and I. Arias. 1990. "Family Precursors: Expected and Actual Consequences of Dating Aggression.” Journal of Interpersonal Violence 5: 247-258.

Brezina, T. 1999. "Teenage Violence Toward Parents as an Adaptation to Family Strain: Evidence from a National Study of Male Adolescents.” Youth and Society 30: 416-444.

Bureau of Justice Statistics. 2001. Criminal Victimization in United States: National Crime Victimization Survey. Washington, DC: U.S. Department of Justice (NCJ 184938).

California Welfare and Institutions Code.

Center on Juvenile and Criminal Justice. 2003. Intro to California's Juvenile Justice System. Retrieved March 6, 2006 from http://www.cjcj.org/jjic/intra.php

Chapple. C. (2003). Examining intergenerational violence: Violent role modeling or weak parental controls? Violence and Victims, 18, 143-162.

Foo, L. and G. Margolin. 1994. “A Multivariate Investigation of Dating Violence.” Journal of Interpersonal Violence 10: 351-377.

Foshee, L.; Bauman, K.E.; Linder, G.F.; Benefield, T., \& Suchindran, C. (2004). Assessing the long term effects of the Safe Dates program and a booster in preventing and reducing adolescent dating violence victimization and perpetration. American Journal of Public Health, 94, 619-624.

Harrykissoon, S. D., V.I. Rickert, and C.M. Wiemann. 2002. “Prevalence and Patterns of Intimate Partner Violence Among Adolescent Mothers during the Postpartum Period.” Archives of Pediatrics and Adolescent Medicine 156(4): 325-330.

Justice Research and Statistics Association. 1995. Innovative Courts Programs: Results from State and Local Program Workshops. Washington, DC: Justice Research and Statistics Association.

Lane, K.D., and P.A. Gwartney-Gibbs. 1985. "Violence in the Context of Dating and Sex.” Journal of Family Issues 6: 45-59.

Langer, L. 1997. Final Report of the Juvenile Domestic Violence Project. Miami, FL: $11^{\text {th }}$ District Court. 
Lavoie, F.; Herbert, M.; Tremblay, R.; Vitaro, F.; Vezina, L.; \& McDuff, P. (2002). History of family dysfunction and perpetration of dating violence by adolescent boys: A longitudinal study. Journal of Adolescent Health, 30, 375-383.

Levesque, R.J.R. 1997. “Dating Violence, Adolescents, and the Law.” Virginia Journal of Social Policy and the Law 4: 339-378.

Lockwood, D. 1997. Violence Among Middle School and High School Students: Analysis and Implications for Prevention (Research in Brief). Washington, DC: National Institute of Justice.

Makepeace, J.M. 1987. "Social Factors and Victim Offender Differences in Courtship Violence.” Family Relations 36: 87-91.

Marshall, L., and P. Rose. 1990. "Premarital Violence: The Impact of Family of Origin Violence, Stress, and Reciprocity.” Violence and Victims 5: 51-64.

Mones, P. 1994. “Battered Child Syndrome: Understanding Parricide.” Trial 30: 24-27.

Morris, R.E., M.M. Anderson, and G.W. Knox. 2002. “Incarcerated Adolescents' Experiences as Perpetrators of Sexual Assault.” Archives of Pediatrics and Adolescent Medicine 156(8): 831835.

National Center for Victims of Crime. 2002. Public Policy Issues: Dating Violence. Internet articles (www.ncvc.org).

National Institute of Justice. 2000. Extent, Nature, and Consequences of Intimate Partner Violence. Washington, DC: U.S. Department of Justice, National Institute of Justice.

O’Keefe, M. 1997. “Predictors of Dating Violence Among High School Students.” Journal of Interpersonal Violence 12: 546-568.

Owens-Manley, J. 1999. "Battered Women and Their Children: A Public Policy Response." Affilia: Journal of Women \& Social Work 14: 439-459.

Sagatun, I., and L. Edwards. 1995. Child Abuse and the Legal System. Chicago: Nelson Hall.

Sagatun-Edwards, I., E. Hyman, T. Lafontaine, and E. Nelson-Serrano. 2003. “The Santa Clara County Juvenile Domestic and Family Violence Court.” Journal of the Center for Families, Children \& the Courts 4: 91-113.

Silverman, J.G., A. Raj, L.A. Mucci, J.E. Hathaway. 2001. "Dating Violence Against Adolescent Girls and Associated Substance Use, Unhealthy Weight Control, Sexual Risk Behavior, Pregnancy, and Suicidality.” Journal of the American Medical Association (JAMA) 286: 572579.

Suarez, K. 1994. “Teenage Dating Violence: The Need for Expanded Awareness and Legislation.” California Law Review 82: 423-471. 
Wiehe, V. 1997. Sibling Abuse: Hidden Physical, Emotional, and Sexual Trauma. Thousand Oaks, CA: Sage.

Wilson, C.D., and M.E. Fromuth. 1997. Characteristics of Abusive Sibling Relationships and Correlations with Later Relationships. Chicago: Presentation at the American Psychological Association Conference.

Wolfe, D.A., and C. Feiring. 2000. "Dating Violence Through the Lens of Adolescent Romantic Relationships.” Child Maltreatment 5(4): 360-3 


\section{Attachments}

Attachment A: Coding Sheet

Attachment B: Decision Points

Attachment C: Implementation Guide for Juvenile Justice Agencies 
This document is a research report submitted to the U.S. Department of Justice. This report has not been published by the Department. Opinions or points of view expressed are those of the author(s) and do not necessarily reflect the official position or policies of the U.S. Department of Justice.

\section{Attachment A: Coding Sheet}




\section{CODING INFORMATION}

Coder Initials: (coder)

1. ID \#: (id)

(county)

3. Coding Date:

(codedate)

4. Petition \#:

(petitnum)

5. Probation File \#:

(probfile)

\section{BACKGROUND INFORMATION \\ Offender}

27. Date of birth:

(birthday)

28. Gender: Male $\square(1) \quad$ Female $\square(2) \quad$ (gender)

29. Ethnicity: African American $\square(1)$ American

Indian $\square(2) \quad$ Asian $\square(3) \quad$ Caucasian $\square(4)$

Hispanic $\square(5) \quad$ Pacific Islander $\square(6) \quad$ Multi-

racial $\square(7) \quad$ Other $\square(8) \quad$ (ethnic)

Specify:

(ethnic2)

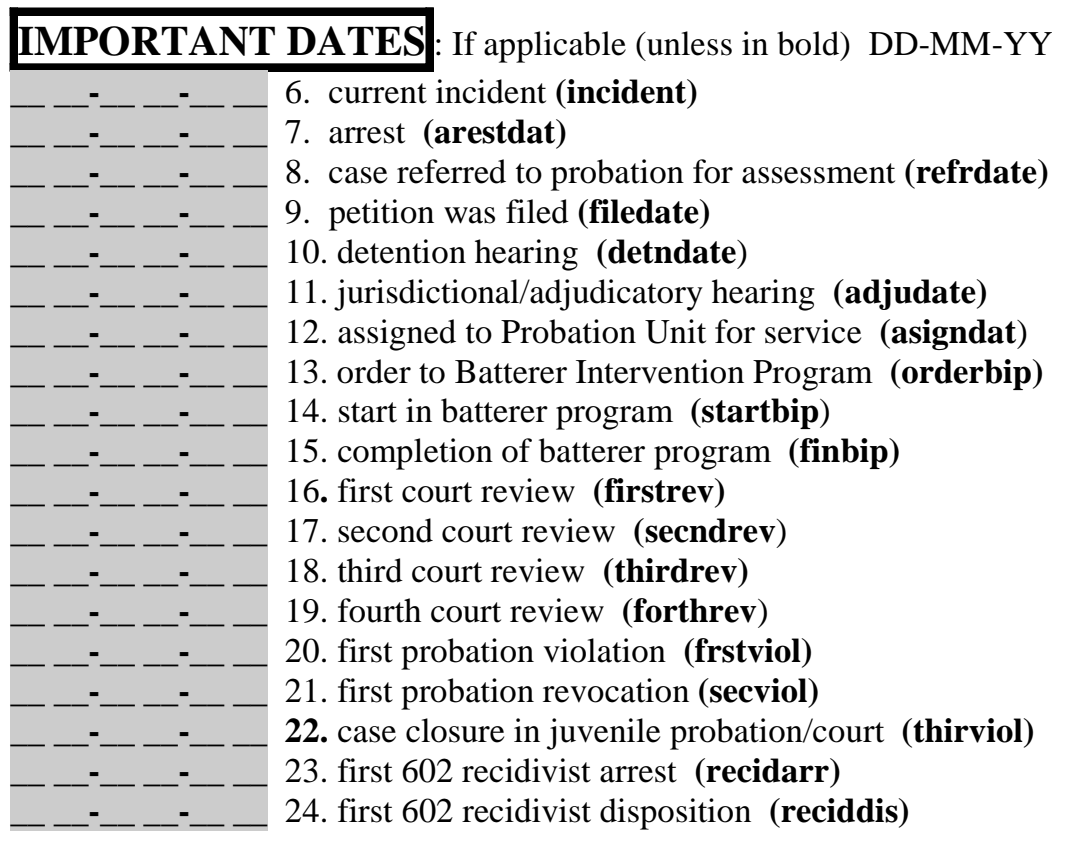

IMPORTANT DATES: If applicable (unless in bold) DD-MM-YY

7. arrest (arestdat)

8. case referred to probation for assessment (refrdate)

9. petition was filed (filedate)

10. detention hearing (detndate)

11. jurisdictional/adjudicatory hearing (adjudate)

12. assigned to Probation Unit for service (asigndat)

13. order to Batterer Intervention Program (orderbip)

14. start in batterer program (startbip)

15. completion of batterer program (finbip)

16. first court review (firstrev)

17. second court review (secndrev)

18. third court review (thirdrev)

19. fourth court review (forthrev)

20. first probation violation (frstviol)

21. first probation revocation (secviol)

23. first 602 recidivist arrest (recidarr)

24. first 602 recidivist disposition (reciddis)

Offender's living situation at time of incident 30. There is no information (noinfo)

31. Living at home (athome)

32. Living with both mother and father (bothmf)

33. If yes to \#32, is mother a stepmother? (stepmom)

34. If yes to \#32, is father a stepfather? (stepdad)

35. Living with mother only? (onlymom)

36. If yes to \#35, does mother live with a cohabiting partner? (mompart)

37. If yes to \#36, is the partner male or female? (mompart2)

Male $\square(1) \quad$ Female $\square(2) \quad$ Don’t Know $\square(3) \quad$ N/A $\square(-8)$

\begin{tabular}{l|c|c|c|c}
\hline 38. Living with father only? (onlydad) & $\mathrm{Y}(1)$ & $\mathrm{N}(2)$ & $\mathrm{DK}(3)$ & $\mathrm{NA}(-8)$ \\
\hline 39. If yes to \#38, does the father live with a cohabiting partner? (dadpart) & $\square$ & $\square$ & $\square$ & \\
\cline { 1 - 3 }
\end{tabular}

40. If yes to \#39, is the partner male or female? (dadpart2)

Male $\square(1) \quad$ Female $\square(2) \quad$ Don't Know $\square(3) \quad$ N/A $\square(-8)$

41. Are there other primary caretakers? (othercar)

\begin{tabular}{|c|c|c|l}
\hline $\mathrm{Y}(1)$ & $\mathrm{N}(2)$ & $\mathrm{DK}(3)$ & \\
\hline$\square$ & $\square$ & $\square$ &
\end{tabular}

42. If yes to \#41, are the caretakers: Grandparents $\square(1) \quad$ Older brother or sister $\square(2) \quad$ Other relative $\square(3)$

Shelter or group home $\square(4)$ Other $\square(5) \quad$ Not applicable $\square(-8) \quad$ (othrcar2) Explain Other:

(othrcar3)

\begin{tabular}{l|c|c|c|c} 
& $\mathrm{Y}(1)$ & No (2) & DK (3) & NA (-8) \\
\hline 43. Is a language other than English spoken in the home? (englhome) & $\square$ & $\square$ & $\square$ & \\
\cline { 1 - 3 } 44. If yes to \#43, do the caretakers speak English? (englcare) & $\square$ & $\square$ & $\square$ & $\square$ \\
\hline 45. If yes to \#43, does the minor speak English? (minoreng) & $\square$ & $\square$ & $\square$ & $\square$ \\
\hline 46. Was an interpreter used in any proceeding? (interp) & $\square$ & $\square$ & $\square$ &
\end{tabular}

47. If yes to \#46, who needed an interpreter?: Offender $\square(1) \quad$ Victim $\square(2) \quad$ Caretaker $\square(3) \quad$ Person other than victim $\square(4)$ Not applicable $\square(-8) \quad$ (interwho)

48. Which language, other than English, is spoken? Spanish $\square(1) \quad$ Vietnamese $\square(2) \quad$ Khmer (Cambodian) $\square(3) \quad$ Chinese (Cantonese, Mandarin, other Chinese dialect) $\square(4) \quad$ Tagalog (Phillippines) $\square(5) \quad$ Russian $\square(6) \quad$ Korean $\square(7) \quad$ Other $\square(8)$ Not applicable/none $\square(-8) \quad$ (language) Specify Other: (language2) 
This document is a research report submitted to the U.S. Department of Justice. This report has not been published by the Department. Opinions or points of view expressed are those of the author(s) and do not necessarily reflect the official position or policies of the U.S. Department of Justice.

49. Offender has a mental illness? (mental) Yes $\square$ (1) No $\square$ (2) Don’t Know $\square$ (3)

\begin{tabular}{lc|ll} 
& $Y(1)$ & \\
\hline 50. bipolar? (bipolar) & $\square$ & 57. post traumatic stress disorder? (ptsd) \\
\hline 51. schizophrenic? (schizo) & $\square$ & 58. eating disorder? (eat) \\
\hline 52. borderline personality disorder? (border) & $\square$ & 59. learning disability? (learn) \\
\hline 53. conduct disorder? (conduct) & $\square$ & 60. mental retardation? (retard) \\
\hline 54. ADHD? (adhd) & $\square$ & 61. substance abuse disorder? (subst) \\
\hline 55. depression? (depress) & $\square$ & 62. paranoid personality disorder? (paranoi) \\
\hline 56. anxiety disorder? (anxiety) & $\square$ \\
\hline
\end{tabular}

64. Ever been diagnosed with another mental disorder?

(other) Specify Other:_ (other2)

65. Prior juvenile delinquency? (priorjuv) $\quad$ Yes $\square(1) \quad$ No $\square(2) \quad$ Don’t Know $\square(3)$

66. Number of prior referrals: ___ or $\mathrm{NA} \square(-8) \quad$ (priorref)

67. Age at first 602 offense: ___ (firstage)

68. Is this the offender's first DV/FV offense? (firstdfv)

69. If no to \#68, the offender's age at first DV/FV offense:

\begin{tabular}{|c|c|c} 
Y (1) & No (2) & DK (3) \\
\hline$\square$ & $\square$ & $\square$
\end{tabular}

NA $\square(-8)$ (commkids)

71. Number of offender's children, not in common with the victim: $\quad 0 \square \quad 1 \square \quad 2 \square \quad 3+\square \quad$ DK $\square$ (4) NA $\square \quad$ (-8) (othrkids)

71.b Are any of offender’s children living with offender? Yes $\square$ (1) No $\square$ (2) Don’t Know $\square$ (3) NA $\square$ (-8) (livkids)

72. If minor and victim had a child/children together, has that child ever been referred as a 300 case? (kidabuse)

73. Was the offender an abused child? (teenabus)

74. If yes to \#73, was the offender ever a dependent child of the court (300 referral)? (cortteen)

75. Did offender's parents have a history of DV? (parentdv)

76. Did offender's parents have a criminal justice official record (parcjrec)

77. Did the offender mention parental criminal activity? (parcrim)

78. Did the offender's parents have substance abuse problems? (parsubs)

79. Age of offender at current DV/FV offense: __ (ageteen)

80. Does the offender have a health problem other than mental illness? (health) 81. Specify:

(health2)

82. Does the responsible adult caretaker(s) have any health problems, including mental illness and alcohol/substance abuse? (carhelth) Specify:

(carhelth2)

\begin{tabular}{|c|c|c|c|}
\hline$\square$ & $\square$ & $\square$ & 두 \\
\hline$\square$ & $\square$ & $\square$ & \\
\hline$\square$ & $\square$ & $\square$ & 무 \\
\hline$\square$ & $\square$ & $\square$ & \\
\hline$\square$ & $\square$ & $\square$ & \\
\hline$\square$ & $\square$ & $\square$ & \\
\hline$\square$ & $\square$ & $\square$ & \\
\hline
\end{tabular}

\begin{tabular}{|c|c|c|}
\hline$\square$ & $\square$ & $\square$ \\
\hline$\square$ & $\square$ & $\square$ \\
\hline
\end{tabular}

\section{VICTIM}

83. Age of victim at time of incident: ___ (agevictm)

84. Race/ethnicity of victim: African American $\square(1) \quad$ American Indian $\square(2) \quad$ Asian $\square(3) \quad$ Caucasian $\square(4) \quad$ Hispanic $\square(5)$

Pacific Islander $\square(6) \quad$ Multi-racial $\square(7) \quad$ Other $\square(8) \quad$ (racevict) Specify Other:

\begin{tabular}{|c|c|c|c|c|}
\hline & $\mathrm{Y}(1)$ & $\mathrm{N}(2)$ & DK (3) & NA $(-8)$ \\
\hline $\begin{array}{l}\text { 85. Was the victim an offender in previous DV/FV incidents not involving the } \\
\text { offender? (vicoffen) }\end{array}$ & $\square$ & $\square$ & $\square$ & \\
\hline $\begin{array}{l}\text { 86. Was the victim a victim in previous DV/FV incidents not involving this } \\
\text { offender? (victvict) }\end{array}$ & $\square$ & $\square$ & $\square$ & \\
\hline 87. Does victim have prior 602 criminal offenses? (victcrim) & $\square$ & $\square$ & $\square$ & \\
\hline 88. Does the victim have children, not with the offender? (vickids) & $\square$ & $\square$ & $\square$ & \\
\hline 89. Was the victim an abused child? (vicabuse) & $\square$ & $\square$ & $\square$ & \\
\hline $\begin{array}{l}\text { 90. If yes to \#89, was the victim ever a dependent child of the court (300 } \\
\text { referral)? (cortvic) }\end{array}$ & $\square$ & $\square$ & $\square$ & $\square$ \\
\hline 91. Did victim’s parents have a history of DV? (vicpardv) & $\square$ & $\square$ & $\square$ & \\
\hline 92. Did victim’s parents have a criminal record? (vicparcj) & $\square$ & $\square$ & $\square$ & \\
\hline 93. Did victim’s parents have a substance abuse history? (vicpasub) & $\square$ & $\square$ & $\square$ & \\
\hline
\end{tabular}




\section{CURRENT INCIDENT DATA}

\begin{tabular}{|c|c|c|c|}
\hline & Yes (1) & & s (1) \\
\hline 94. 243e (offense1) & $\square$ & 104. 602 (offens11) & $\square$ \\
\hline 95. 273.5 (offense2) & $\square$ & 105. 647 (offens12) & $\square$ \\
\hline 96. 422 (offense3) & $\square$ & 106. 236 (offens13) & $\square$ \\
\hline 97.417 (offense4) & $\square$ & 107. 148 (offens14) & $\square$ \\
\hline 98. 664 (offense5) & $\square$ & 108. 646-9 (offens15) & $\square$ \\
\hline 99. 245 (offense6) & $\square$ & 109. 166 (offens16) & $\square$ \\
\hline 100. 240 (offense7) & $\square$ & 110. 289 (offens17) & $\square$ \\
\hline 101. 242 (offense8 & $\square$ & 111.777 (offens18) & $\square$ \\
\hline 102. 261 (offense9 & $\square$ & 112. 12020 (offens19) & $\square$ \\
\hline 103. 594 (offens10 & $\square$ & 113. other (offens20) & $\square$ \\
\hline
\end{tabular}

114. Type of offense: Domestic Violence $\square(1) \quad$ Family Violence $\square(2) \quad$ (type)

115. If family violence, who was the primary victim? Mother $\square(01) \quad$ Stepmother $\square(02) \quad$ Father $\square(03) \quad$ Stepfather $\square(04)$

Mother's male cohabiting partner $\square(05) \quad$ Mother's female cohabiting partner $\square(06) \quad$ Father's female cohabitating partner $\square(07)$

Father's male cohabiting partner $\square(08) \quad$ Brother(s) $\square(9) \quad$ Sister(s) $\square(10) \quad$ Grandmother $\square(11) \quad$ Grandfather $\square(12)$

Offender's own child $\square(13)$ Other family $\square(14) \quad$ Not Applicable $\square(-8) \quad$ (primvict)

Specify Other:

(primvict2)

116. What gender was the primary victim? Male $\square(1) \quad$ Female $\square(2) \quad$ Don’t know $\square(3) \quad$ (vicgendr)

117. If $D V$, was the violence against: Opposite sex $\square(1) \quad$ Same sex $\square(2) \quad$ Don’t know $\square(3) \quad$ Not applicable (if FV) $\square(-8)$ (violwho)

\begin{tabular}{l|c|c|c|c} 
& Y (1) & No (2) & DK (3) & NA (-8) \\
\hline 118. Is the current victim a repeat victim for this offender? (repetvic) & $\square$ & $\square$ & $\square$ & \\
\hline 119. Was previous incident against a different victim? (diffvic) & $\square$ & $\square$ & $\square$ & \\
\hline 120. Did offender have multiple victims in current incident? (manyvic1) & $\square$ & $\square$ & $\square$ & \\
\hline 121. Did offender have multiple victims in prior incidents? (manyvic2) & $\square$ & $\square$ & $\square$ & $\square$ \\
\hline $\begin{array}{l}\text { 122. Was the offender under the influence of alcohol at the time of the current } \\
\text { incident? (alcohol) }\end{array}$ & $\square$ & $\square$ & $\square$ & \\
\hline $\begin{array}{l}\text { 123. Was the offender under the influence of drugs at the time of the current } \\
\text { incident? (drugs) }\end{array}$ & $\square$ & $\square$ & $\square$ & \\
\hline 124. Was minor attending school at the time of the incident? (attschol) & $\square$ & $\square$ & $\square$ \\
\hline 125. Did minor and victim attend the same school? (samschol) & $\square$ & $\square$ & $\square$ \\
\hline 126. Did offender and victim live together at the time of the incident? (cohab) & $\square$ & $\square$ & $\square$ \\
\hline 127. Did violence happen when victim was pregnant? (violpreg) & $\square$ & $\square$ & $\square$ & $\square$ \\
\hline 128. Was the victim also initially charged in the offense? (viccharg) & $\square$ & $\square$ & $\square$ \\
\hline $\begin{array}{l}\text { 129. Was there a pattern of interactive violence between the victim and } \\
\text { offender in their relationship? (violpatt) QUOTE FROM FILE }\end{array}$ & $\square$ & $\square$ & $\square$ &
\end{tabular}

130. What is the degree of severity in the current offense? Mild $\square(1)$ Moderate $\square(2)$ Severe $\square(3) \quad$ (degree) QUOTE FROM FILE 
131. What was the primary method of violence for the primary offender? Choose one:

Gun $\square(1) \quad$ Knife $\square(2) \quad$ Other objects $\square(3) \quad$ Physical with no weapons or objects $\square(4) \quad$ (method) \begin{tabular}{l|l|l} 
What acts of violence were committed? & $\mathrm{Y}(1)$ \\
\hline
\end{tabular}

\begin{tabular}{|ll|}
\hline 132. Verbal (verbal) & $\square$ \\
\hline 133. Struck with open hand (hand) & $\square$ \\
\hline 134. Struck with closed fist (fist) & $\square$ \\
\hline 135. Kicked (kicked) & $\square$ \\
\hline 136. Pushed (pushed) & $\square$ \\
\hline 137. Choked/strangled (choke) & $\square$ \\
\hline 138. Physically restrained (restrain) & $\square$ \\
\hline 139. Biting (bite) & $\square$ \\
\hline 140. Scratching (scratch) & $\square$ \\
\hline 141. Smothering (smother) & $\square$ \\
\hline
\end{tabular}

\begin{tabular}{|l|c} 
& $\mathrm{Y}(1)$ \\
\hline 142. Financial abuse/theft (theft) & $\square$ \\
\hline 143. Stalking/harassment, including electronic (stalk) & $\square$ \\
\hline 144. Sexual (sexual) & $\square$ \\
\hline 145. Shoving into object (object) & $\square$ \\
\hline 146. Animal cruelty (animal) & $\square$ \\
\hline 147. Vandalism against personal belongings of victim (vandal) & $\square$ \\
\hline 148. Gunshot (gunshot) & $\square$ \\
\hline 149. Stabbed (stabbed) & $\square$ \\
\hline 150. Other (otheract) & $\square$ \\
\hline
\end{tabular}

151. Was the current offense a: Misdemeanor $\square(1) \quad$ Felony $\square(2) \quad$ (misfel)

152. Did the offender have accomplices? (assist)

\begin{tabular}{c|c|c|c}
\hline $\mathrm{Y}(1)$ & No (2) & DK (3) \\
\hline$\square$ & $\square$ & $\square$
\end{tabular}

\section{INTERVENTION DATA}

\begin{tabular}{l|c|c|c|c}
\hline 153.Was youth detained in juvenile hall prior to detention/jurisdictional hearing? (detained) & Y (1) & No (2) & DK (3) \\
\hline 154. Was case assigned to DV/FV court? (assign) & $\square$ & $\square$ & $\square$ \\
\hline 155. & $\square$ & $\square$ &
\end{tabular}

155. If no to \#154, which court handled the case? Mental Health Court $\square(1)$ Drug Court $\square$ (2) Other regular calendar $\square$ (3)

NA $\square(-8) \quad$ (assign2) Specify (if other) (assign3)

156. Number of court reviews:

157. Assigned to specialized DV/FV probation unit? $\quad$ Yes $\square(1) \quad$ No $\square(2) \quad$ DK $\square(3) \quad N A \square(-8) \quad$ (special)

158. If yes to \#157, which section? $\quad \mathrm{DV} \square(1) \quad \mathrm{FV} \square(2) \quad$ Other $\square(3) \quad \mathrm{NA} \square(-8) \quad$ (unit)

159. If answered "other," what type of unit? Gang $\square(1) \quad$ Drugs $\square(2) \quad$ Mental Health $\square(3) \quad$ Geographic unit $\square(4) \quad$ Assigned to school probation $\square(5)$ NA $\square(-8) \quad$ (othrunit)

160. Was there a detention hearing? (dethear)

161. If yes to \#160, was youth detained in JH after detention and before jurisdictional? (dethear2)

162. Disposition: Informal probation $\square(1) \quad$ Formal probation $\square(2) \quad$ (disposit)

163. If formal probation: Probation only $\square(1)$ Probation and electronic monitoring $\square(2) \quad$ Probation and placement outside home $\square(3)$ Probation, placement outside home, and electronic monitoring $\square(4) \quad$ Other $\square$ (5) NA $\square(-8) \quad$ (dispos2)

Specify Other: (dispos3)

164. If placement outside home, where?: Group home $\square(1) \quad$ Juvenile hall $\square(2) \quad$ County ranch $\square(3) \quad$ CYA camp $\square(4)$

CYA institution $\square(5) \quad$ Foster care $\square(6) \quad$ Other $\square(7) \quad$ NA if placement not outside home $\square(-8)$

Explain Other: (outhom2)

165. Did youth admit/agree with charges? (okteen)

166. Did offender have a restraining order against victim? (rovic)

167. Was there a prior stayaway/protective order for the offender regarding the victim? (povic)

168. Did victim have a restraining order against the offender ? (rooffend)

169. Was there a prior stayaway/protective order for the victim regarding the offender? (pooffend)

170. If youth was institutionalized, for how many days was minor in custody: or NA $\square(-8)$ (custody)

171. If ordered to batterers program, which program?: Chris Hickley - SC $\square(1)$ Center for Human Development - SC $\square(2) \quad$ Anger Management $\square(3) \quad$ Jeffrey Proctor's Program $\square(4) \quad$ Kid's Turn $\square(5) \quad$ MOVE (Men Overcoming Violence) $\square(6) \quad$ Other $\square(7)$ Not applicable because not ordered $\square(-8) \quad$ (battprog) Explain Other:

172. For how many weeks was the program ordered: ___ or $\mathrm{NA} \square(-8) \quad$ (weeks)

173. If ordered, was there a delay in starting the program? Yes $\square(1) \quad$ No $\square(2) \quad$ DK $\square(3) \quad N A \square(-8) \quad$ (delay)

174. If there was a delay, what was the reason: Not available in primary language $\square(1) \quad$ Mental health treatment needed $\square(2)$

Substance abuse treatment $\square(3) \quad$ Youth did not contact the program $\square(4) \quad$ No space available in the program $\square(5)$

Youth could not pay cost of program $\square(6) \quad$ Other $\square(7) \quad$ Not applicable if not ordered or no delay $\square(-8) \quad$ (delay2)

Specify Other:

(delay3) 
175. No contact with victim or victim's family (condi1)

176. Restricted contact (condi2)

177. No harassing or stalking (condi3)

178. Comply with stay away orders (condi4)

179. Do not possess or use firearms (condi5)

180. Abstain from using alcohol or other drugs (condi6)

181. Submit to drug testing (condi7)

182. Undergo substance abuse assessment and treatment as directed by probation officer (condi8)

183. Submit to unannounced home visits (condi9)

184. Submit to warrantless search and seizure (condi10)

185. Comply with electronic monitoring, if ordered (condi11)

186. Cooperate with child protective services, if involved (condi12)

187. Pay ordered child support (condi13)

188. Pay restitution as directed (condi14)

189. Pay fees for group batterers' intervention program (condi15)

190. Pay fines as directed (condi16)

191. Attend, participate in, and satisfactorily complete a domestic violence intervention program (condi17)

192. Comply with curfews (condi18)

193. Perform community service (condi19)

194. Stay away from gangs (condi20)

195. Attend, participate in, and satisfactorily complete a parenting program (ex. Parenting Without Violence) (condi21)

196. Individual counseling (condi22)

197. Attend school regularly (condi23)

\begin{tabular}{|c|c|c|c|c|}
\hline & $\mathrm{Y}(1)$ & $\mathrm{N}(2)$ & $\begin{array}{l}\text { DK } \\
(3)\end{array}$ & $\begin{array}{l}\text { NA }(- \\
8)\end{array}$ \\
\hline $\begin{array}{l}\text { 198. Were parents of victims contacted (n/a if victim not a minor)? } \\
\text { (viccont) }\end{array}$ & $\square$ & $\square$ & $\square$ & $\square$ \\
\hline 199. Was victim assistance provided? (vicassis) & $\square$ & $\square$ & $\square$ & \\
\hline 200. Was victim referred to LACY? (lacy) & $\square$ & $\square$ & $\square$ & \\
\hline 201. Was victim referred to support/advocacy groups? (support) & $\square$ & $\square$ & $\square$ & \\
\hline $\begin{array}{l}\text { 202. Were the victims satisfied with services ( } \mathrm{n} / \mathrm{a} \text { if victim is parent, } \\
\text { etc.)? (satserv) }\end{array}$ & $\square$ & $\square$ & $\square$ & $\square$ \\
\hline
\end{tabular}


This document is a research report submitted to the U.S. Department of Justice. This report has not been published by the Department. Opinions or points of view expressed are those of the author(s) and do not necessarily reflect the official position or policies of the U.S. Department of Justice.

\section{OUTCOME VARIABLES}

\section{Intervention Outcomes}

\begin{tabular}{|c|c|c|c|c|}
\hline & $\mathrm{Y}(1)$ & No $(2)$ & DK (3) & NA $(-8)$ \\
\hline 203. Was minor attending school when the case was closed? (teenatt) & $\square$ & $\square$ & $\square$ & \\
\hline 204. Was minor working when the case was closed? (teenwork) & $\square$ & $\square$ & $\square$ & \\
\hline \multirow{3}{*}{$\begin{array}{l}\text { 205. If a stay away order was issued, did youth comply? (comply) } \\
\text { 206. Batterer's Intervention Program completed? Yes } \square(1) \quad \text { No } \square(2) \\
\text { (bipfin) }\end{array}$} & $\square$ & $\square$ & $\square$ & $\square$ \\
\hline & \multicolumn{2}{|c|}{ Partially $\square(3)$} & Don’t Know $\square(4)$ & Not applicable $\square(-8)$ \\
\hline & $\mathrm{Y}(1)$ & No (2) & DK (3) & NA $(-8)$ \\
\hline $\begin{array}{l}\text { 207. Did minor have to start BIP program more than once? } \\
\text { (bipagain) }\end{array}$ & $\square$ & $\square$ & $\square$ & $\square$ \\
\hline
\end{tabular}

208. Number of probation violations: __

If probation was violated, which conditions were violated? $\quad \mathrm{Y}(1)$

209. No contact with victim or victim's family (provio1)

210. No harassing or stalking (provio2)

211. Comply with stay away orders (provio3)

212. Do not possess or use firearms (provio4)

213. Abstain from using alcohol or other drugs (provio5)

214. Submit to drug testing (provio6)

215. Undergo substance abuse assessment and treatment as directed by

probation officer (provio7)

216. Submit to unannounced home visits (provio8)

217. Submit to warrantless search and seizure (provio9)

218. Comply with electronic monitoring, if ordered (provio10)

219. Cooperate with child protective services, if involved (provio11)

220. Pay ordered child support (provio12)

221. Pay restitution as directed (provio13)

222. Pay fees for group batterers' intervention program (provio14)

223. Pay fines as directed (provio15)

224. Attend, participate in, and satisfactorily complete a domestic violence

intervention program (provio16)

225. Comply with curfews (provio17)

226. Perform community service (provio18)

227. Stay away from gangs (provio19)

228. Attend, participate in, and satisfactorily complete a parenting program

(ex. Parenting Without Violence) (provio20)

229. Individual counseling (provio21)

230b. Attend school regularly (provio22)

231. Did youth complete all programs? $\quad$ Yes $\square(1) \quad$ No $\square(2) \quad$ DK $\square(3) \quad N A \square(-8) \quad$ (allfin)

232. Was youth's adjustment a success? Yes $\square(1) \quad$ No $\square(2) \quad$ Partial $\square(3) \quad$ (success)

233. Did offender and victim live together when case was closed? $\quad$ Yes $\square(1) \quad$ No $\square(2) \quad$ DK $\square(3) \quad$ (postlive)

234. Reason for closure: Successful completion $\square(1) \quad$ Minor disappeared/moved $\square(2) \quad$ Now in adult system $\square(3) \quad$ Other $\square(4)$ (closure) Explain Other : (closure2)

235. Did victim report more safety after intervention? (vicsafe)

236. Did victim(s) give a different story than the offender? (diffvic) 


\section{JUVENILE RECIDIVISM OUTCOMES}

\begin{tabular}{l|c}
\hline 237. Was minor ever arrested for any new 602 offenses? (newarest) & $\mathrm{Y}(1)$ \\
\hline 238. Was minor ever “convicted” for any new 602 offense? (newconv) & $\square$ \\
\hline & $\square$ \\
\hline
\end{tabular}

241. Number of new referrals:

(newrefer)

242. What type of new arrests: $\overline{\mathrm{DV}} \overline{27} \overline{\mathrm{C}} \overline{\mathrm{V}} \square(1) \quad$ Other DV/FV $\square(2) \quad$ Property crimes $\square(3) \quad$ Other personal crimes $\square(4)$ Vehicular offenses $\square(5) \quad$ Other $\square(6) \quad$ Not applicable or no new arrests $\square(-8) \quad$ (newtype)

243. Number of new juvenile DV/FV violations:

(newdvfv)

\begin{tabular}{llc}
\multicolumn{1}{l}{ Arrests } & Yes (1) \\
\hline $244.243 e$ & (arrest1) & $\square$ \\
\hline 245.273 .5 (arrest2) & $\square$ \\
\hline 246.422 & (arrest3) & $\square$ \\
\hline 247.417 & (arrest4) & $\square$ \\
\hline 248.664 & (arrest5) & $\square$ \\
\hline 249.245 & (arrest6) & $\square$ \\
\hline 250.240 & (arrest7) & $\square$ \\
\hline 251.242 & (arrest8) & $\square$ \\
\hline 252.261 & (arrest9) & $\square$ \\
\hline 253.594 & (arrest10) & $\square$
\end{tabular}

\begin{tabular}{|llc} 
& & Yes (1) \\
\hline 254.602 & (arrest11) & $\square$ \\
\hline 255.647 & (arrest12) & $\square$ \\
\hline 256.236 & (arrest13) & $\square$ \\
\hline 257.148 & (arrest14) & $\square$ \\
\hline $258.646-9$ & (arrest15) & $\square$ \\
\hline 259.166 & (arrest16) & $\square$ \\
\hline 260.289 & (arrest17) & $\square$ \\
\hline 261.777 & (arrest18) & $\square$ \\
\hline 262.12020 & (arrest19) & $\square$ \\
\hline 263.0 other & (arrest20) & $\square$
\end{tabular}

Convictions

\begin{tabular}{llc|}
\multicolumn{2}{l}{ Convictions } & Yes (1) \\
\hline $264.243 \mathrm{e}$ & (convct1) & $\square$ \\
\hline 265.273 .5 & (convct2) & $\square$ \\
\hline 266.422 & (convct3) & $\square$ \\
\hline 267.417 & (convct4) & $\square$ \\
\hline 268.664 & (convct5) & $\square$ \\
\hline 269.245 & (convct6) & $\square$ \\
\hline 270.240 & (convct7) & $\square$ \\
\hline 271.242 & (convct8) & $\square$ \\
\hline 272.261 & (convct9) & $\square$ \\
\hline 273.594 & (convct10) & $\square$
\end{tabular}

\begin{tabular}{|llc} 
& & Yes (1) \\
\hline 274.602 & (convct11) & $\square$ \\
\hline 275.647 & (convct12) & $\square$ \\
\hline 276.236 & (convct13) & $\square$ \\
\hline 277.148 & (convct14) & $\square$ \\
\hline $278.646-9$ & (convct15) & $\square$ \\
\hline 279.166 & (convct16) & $\square$ \\
\hline 280.289 & (convct17) & $\square$ \\
\hline 281.777 & (convct18) & $\square$ \\
\hline 282.12020 & (convct19) & $\square$ \\
\hline 283. other & (convct2) & $\square$
\end{tabular}

284. Was first new juvenile DV/FV a: Misdemeanor $\square(1) \quad$ Felony $\square(2) \quad$ NA $\square(-8) \quad$ (newdvfv2) \begin{tabular}{l|l} 
Sentencing Outcomes & Y (1)
\end{tabular}

\begin{tabular}{lc}
\hline 285. Probation (prob) & $\square$ \\
\hline 286. Juvenile Hall (juvhall) & $\square$ \\
\hline 287. Prison (prison) & $\square$ \\
\hline 288. Fines (fines) & $\square$ \\
\hline 289. Restitution (restitute) & $\square$ \\
\hline 290. Electronic monitoring (electmon) & $\square$ \\
\hline 291. Batterer's intervention (bip) & $\square$
\end{tabular}


Descriptive Text and do not necessarily reflect the official position or policies of the U.S. Department of Justice.

1. Offender's family background (especially in terms of child abuse/neglect victimization)

2. Description of actual incident

3. Description of success/failure and reasons for such 


\section{ADULT RECIDIVISM OUTCOMES}

Coder Initials:

1. ID \#:

(coder)

2. County: S.C. $\square(1) \quad$ S.F. $\square(2) \quad$ C.C. $\square(3)$ (county)
3. New Coding Date:

4. Petition \#:

(ncodeda)

5. Probation File \# (petitnum) (probfile)

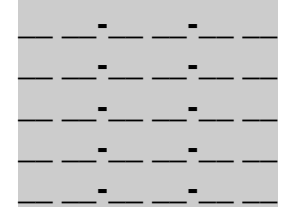

25. first adult arrest (adultarr)

26. first adult conviction (adultcon)

26a. first adult DV/FV referral (adfvref)

26b. first adult DV/FV arrest (adfvarr)

26c. first adult DV/FV conviction (adfvcon)

\begin{tabular}{l|c} 
300. Was minor ever arrested for any new adult criminal offenses? (newadarr) & $Y(1)$ \\
\hline 301. Was minor ever convicted for any new adult criminal offenses? (newadcon) & $\square$ \\
\hline 302. Wu
\end{tabular}

302. Number of new adult criminal referrals:

(newarefe)

303. What type of new arrests: DV273.5 $\square(1) \quad$ Other DV/FV $\square(2) \quad$ Property crimes $\square(3) \quad$ Other personal crimes $\square(4)$

Vehicular offenses $\square(5) \quad$ Other $\square(6) \quad$ Not applicable or no new arrests $\square(-8) \quad$ (newatype)

304. Number of new DV/FV referrals: ___ _ (newadvfv) arrests: __ _ _ (newadfva) convictions:

(newadfvc)

\begin{tabular}{llc|} 
Arrests & Yes (1) \\
\hline $305.243 e \quad$ (aarest1) & $\square$ \\
\hline 306.273 .5 (aarest2) & $\square$ \\
\hline $307.422 \quad$ (aarest3) & $\square$ \\
\hline $308.417 \quad$ (aarest4) & $\square$ \\
\hline $309.664 \quad$ (aarest5) & $\square$ \\
\hline $310.245 \quad$ (aarest6) & $\square$ \\
\hline 311.240 (aarest7) & $\square$ \\
\hline 312.242 (aarest8) & $\square$ \\
\hline $313.261 \quad$ (aarest9) & $\square$ \\
\hline 314.594 (aarest10) & $\square$
\end{tabular}

\begin{tabular}{|llc} 
& Yes (1) \\
\hline 315.602 & (aarest11) & $\square$ \\
\hline 316.647 & (aarest12) & $\square$ \\
\hline 317.236 & (aarest13) & $\square$ \\
\hline 318.148 & (aarest14) & $\square$ \\
\hline $319.646-9$ & (aarest15) & $\square$ \\
\hline 320.166 & (aarest16) & $\square$ \\
\hline 321.289 & (aarest17) & $\square$ \\
\hline 322.777 & (aarest18) & $\square$ \\
\hline 323.12020 & (aarest19) & $\square$ \\
\hline 324.0 other & (aarest20) & $\square$
\end{tabular}

Convictions

Yes (1)

\begin{tabular}{lll}
\hline $325.243 e$ & (aconvc1) & $\square$ \\
\hline 326.273 .5 & (aconvc2) & $\square$ \\
\hline 327.422 & (aconvc3) & $\square$ \\
\hline 328.417 & (aconvc4) & $\square$ \\
\hline 329.664 & (aconvc5) & $\square$ \\
\hline 330.245 & (aconvc6) & $\square$ \\
\hline 331.240 & (aconvc7) & $\square$ \\
\hline 332.242 & (aconvc8) & $\square$ \\
\hline 333.261 & (aconvc9) & $\square$ \\
\hline 334.594 & (aconvc10) & $\square$
\end{tabular}

\begin{tabular}{|llc} 
& Yes (1) \\
\hline 335.602 & (aconvc11) & $\square$ \\
\hline 336.647 & (aconvc12) & $\square$ \\
\hline 337.236 & (aconvc13) & $\square$ \\
\hline 338.148 & (aconvc14) & $\square$ \\
\hline $339.646-9$ & (aconvc15) & $\square$ \\
\hline 340.166 & (aconvc16) & $\square$ \\
\hline 341.289 & (aconvc17) & $\square$ \\
\hline 342.777 & (aconvc18) & $\square$ \\
\hline 343.12020 & (aconvc19) & $\square$ \\
\hline 344.0 other & (aconvc20) & $\square$
\end{tabular}

345. Was first new adult DV/FV a: Misdemeanor $\square(1) \quad$ Felony $\square(2) \quad$ NA $\square(-8)$ (newdvfv3)

Sentencing Outcomes

346. Probation (proba)

$\mathrm{Y}(1)$

347. County jail (jaila)

$\square$

348. Prison (prisona)

349. Fines (finesa)

350. Restitution (restitua)

351. Electronic monitoring (electmoa)

352. Batterer's intervention (bipa)

353. Age at first adult criminal offense (if available):

354. Is this case now in the adult probation DV/FV unit?

or NA $\square(-8) \quad$ (adultage)

Yes $\square$ (1) No $\square(2) \quad$ DK $\square(3) \quad N A \square(-8)$ (adultpro) 
This document is a research report submitted to the U.S. Department of Justice. This report has not been published by the Department. Opinions or points of view expressed are those of the author(s) and do not necessarily reflect the official position or policies of the U.S. Department of Justice.

\section{Attachment B: Decision Points}




\section{Attachment B}

\section{Decision Points in the California Juvenile Justice System}

Options for law enforcement: (W\&I 625 et seq)

1. Do nothing

2. Warn

3. Issue citation to report to probation officer

4. Arrest and deliver to probation officer

Options for Probation Officer

1. At citation hearing

A. Warn

B. Informal supervision (W \& I section 654; note that sections 654 and 654.2 can not be used if certain serious crimes are charged - see 654.3 for eligibility criteria.)

C. Take the case to DA for consideration of filing a petition.

2. At juvenile hall intake

A. Warn and release

B. Informal supervision (W\&I section 654; see 654.3 for eligibility criteria)

C. Release and take the case to the D.A. for filing

D. Detain and take the case to the D.A. for filing

Options for the District Attorney

1. Decline to file a petition

2. Decline to file and agree to informal supervuision (654)

3. File a petition

Options for the juvenile court after a petition has been filed

1. Dismiss case

2. Order the minor to comlete serv ices within 6 months and dismiss petition if services are completed (654.2)

3. After hearing evidence, without finding the minor a ward of the court, place the minor on

probation for six months. If the minor successfully completes the court ordered program in the sixth month period, the petition can be dismissed (W\&I 725).

4. Declare the minor a ward of the court and place him/her on probation (W\&I 725). 

been published by the Department. Opinions or points of view expressed are those of the author(s) and do not necessarily reflect the official position or policies of the U.S. Department of Justice.

Attachment C: Implementation Guide for Juvenile Justice Agencies 


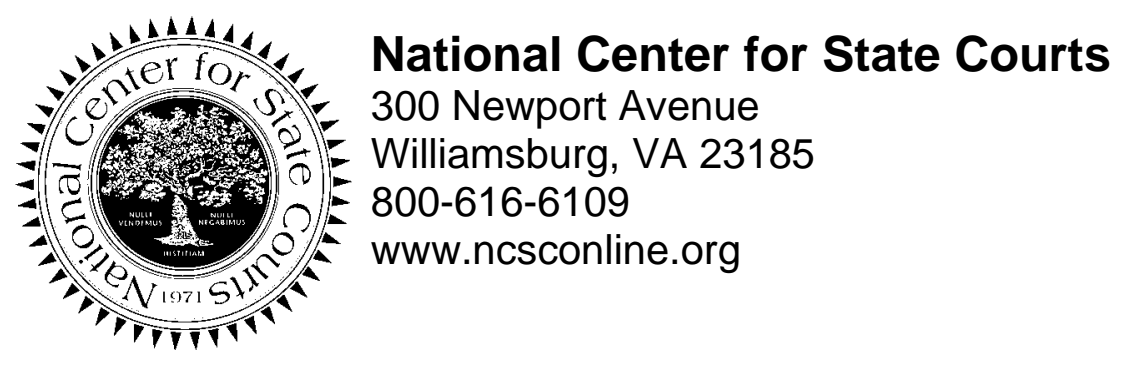

\section{Implementation Guide for Juvenile Justice Agencies}

Starting a Specialized Juvenile Domestic and Family Violence Court Program

Brenda K. Uekert, Ph.D., National Center for State Courts Inger Sagatun-Edwards, Ph.D., San Jose State University Ann Crowe, Ed.D., American Probation and Parole Association 
July 31, 2006

\section{Prepared for National Institute of Justice}

This project was supported by Grant No. 2003-IJ-CX-1031 awarded to the National Center for State Courts by the National Institute of Justice. Points of view in this document are those of the authors and do not necessarily represent the official position or policies of the National Institute of Justice or the National Center for State Courts. 
It's everyone—police, judges, probation, the community—giving the perpetrator the same message so he knows there's no way out for him. That we as a community, won't tolerate domestic violence. — Judge Eugene Hyman, Santa Clara County Superior Court ${ }^{23}$

In the last decade, specialization has become the norm in larger jurisdictions in the adult justice system — particularly in the area of domestic violence. Many metropolitan areas now have special teams of domestic violence law enforcement officers, prosecutors, probation officers, victim advocates, and even courts. For the most part, this trend has not impacted the nation’s juvenile justice system, where domestic and family violence often goes undetected and untreated.

In California, two court-based programs have led the effort to reform the traditional juvenile court response to domestic and family violence. In 1999, the Santa Clara County Juvenile Domestic and Family Violence Court was established in San Jose, California—-the first of its kind in the nation. ${ }^{24}$ In September 2001, a similar program began operating in San Francisco County's Unified Family Court. The courts address both the problem of juvenile "domestic violence" (violence perpetrated by a youth against an intimate, such as a spouse, girlfriend/boyfriend, or a date) and "family violence" (physical abuse perpetrated by a youth against a parent, sibling, or family member)..$^{25}$

The Santa Clara County and San Francisco County juvenile domestic/family violence court programs share several features. First, the courts have a designated judge who oversees a

23 Quoted from Michelle Guido, “County tries to break cycle of domestic violence early, Pioneering justice system gives special attention to juveniles who batter," San Jose Mercury News, March 25, 2000.

24 The program was partly funded by the Juvenile Delinquency Prevention Branch of California's Office of Criminal Justice.

25 Santa Clara County has a population of about 1.7 million people-San Jose is the largest city. The population of San Francisco County is 776,733, based on data from the 2000 census. 
specialized calendar that features periodic review hearings. Second, the probation departments have specialized units with intensive supervision of domestic and family violence offenders. Third, the programs are highly collaborative, with participation from local law enforcement, probation, courts, district attorneys, public defenders, victim assistance, and service providers. Fourth, community service providers play a critical role in the intervention programs.

Despite their similarities, the Santa Clara County and San Francisco County court programs differ in their philosophy, with the Santa Clara County court program having a law enforcement protocol requiring all juvenile domestic and family violence cases to be delivered to the Juvenile Hall, and the court favoring declaring the minors a ward of the court with formal probation. The San Francisco County court program does not have a law enforcement protocol and favors ordering the minor to complete services within six months and dismissing the petition if services are completed, or placing the minor on probation for six months with petitions dismissed if the minor completes all court-ordered conditions in a six month period (Deferred Entry Judgment). Both counties include a number of intervention/treatment programs aimed at preventing further juvenile and domestic violence.

The purpose of this implementation guide is to outline the general steps required to set up a similar approach in communities across the country. The content of the guide is based on interviews conducted in 2004 and 2005 by staff from the National Center for State Courts, the American Probation and Parole Association, and San Jose State University. While the Santa Clara County and San Francisco County programs have different orientations, they offer lessons in how programs can be adapted to "fit” the legal culture of the larger justice community.

The Santa Clara County and San Francisco County specialized court programs were initiated by juvenile court judges. These types of specialized programs can be developed under 
the leadership of other agencies, such as the prosecutor's office or probation/community corrections, but will need the approval of the juvenile court judge(s) if cases under court supervision are involved. Ultimately, the courts and all key agencies must collaborate to develop a program that provides a consistent message to juvenile offenders and their victims. Success of a program is more likely with the leadership of judges as all parties are more likely to attend meetings when called by a judge.

Seven steps can be followed to implement a similar type of program in your jurisdiction: (1) identify the problem, (2) build the team, (3) draft a response protocol, (4) provide services, (5) communicate regularly, (6) train staff, and (7) evaluate the program.

\section{Step 1: Identify the Problem}

The first step in the development of any new program is to recognize the extent of juvenile domestic and family violence and how it impacts the justice system. Most cases do not come into the system pre-labeled as domestic violence (e.g., intimate partner violence) and family violence (e.g., sibling and parental violence). Rather, they are brought into the system as violations of specific juvenile codes, such as assault, battery, and threats of violence. In fact, a number of states define domestic violence as a crime between adults, thereby ignoring violence among intimates and family members at the juvenile level. Other states may exclude minors based on cohabitation relationship and children in common restrictions. ${ }^{26}$ The underlying basis of the problem may never be addressed by anyone in the juvenile justice system. ${ }^{27}$

26 Many states, such as California, now include dating violence in their domestic violence penal codes.

27 However, to some extent, domestic and family violence is addressed in family courts and dependency courts. In these cases, the juvenile is most often considered the victim, not the offender. Some in-take juvenile justice assessment protocols now also include questions about a family violence or child abuse history. 
Most courts and justice agencies are responsive by nature, not proactive. Consequently, very often it is a particular incident or event that catapults action. In Santa Clara County, findings from the Domestic Violence Council’s Death Review Committee helped launch the specialized program in the juvenile court. The Committee, which has periodically reviewed all domestic violence-related deaths in the county since 1993, found that many of the total domestic violence-related deaths occurred in relationships that started when the victim was underage. These findings, coupled with a judge who was strongly committed to combating domestic violence among adolescents, initiated communication across agencies and the development of a court-based intervention program. Two years later, a similarly inspired judge, using the protocols already established in Santa Clara County, launched a comparable program in the San Francisco County Superior Court.

The Santa Clara County and San Francisco County courts address both domestic violence and family violence cases that involve adolescent offenders. When the Santa Clara County court began operations, staff were surprised by the relatively small number of domestic violence cases compared to the family violence cases - about two-thirds of cases involve family violence. In addition, the dynamics and background of domestic violence offenders are much different than family violence offenders. For instance, domestic violence offenders tend to be older adolescents, whereas family violence offenders are younger and often have a history of mental illness and/or abuse as a child. In order to develop a plan, the extent of the problem should first be documented. This can be done by selecting certain types of case files, documenting the number of cases that involve a domestic or family relationship, and reviewing sample cases. This information can then be used to determine the area of focus (domestic and/or family violence). 
This document is a research report submitted to the U.S. Department of Justice. This report has not been published by the Department. Opinions or points of view expressed are those of the author(s) and do not necessarily reflect the official position or policies of the U.S. Department of Justice.

\section{Determine the Extent of the Problem}

A review of case files is an excellent tool to determine the extent of domestic and family violence in the community. The review will involve the following:

1. Determine which code violations are likely to include an incident involving a domestic or family violence relationship.

2. Pull case files from a specific period of time.

3. Identify incidents that involved a domestic or family relationship.

A small jurisdiction might have the capacity to review all juvenile cases that enter the justice system over a specific period of time. But larger jurisdictions should start by selecting specific code violations that may involve a case of domestic or family violence. For instance, the California codes most relevant to juvenile domestic/family violence are:

Penal Code 273.5 - willfully inflicting upon a person who is his or her spouse, former spouse, cohabitant, former cohabitant, or the mother or father of his or her child, corporal injury resulting in a traumatic condition.

Penal Code 243(e) - battery committed against a spouse, a person with whom the defendant is cohabiting, a person who is the parent of the defendant's child, former spouse, fiancé, or fiancée, or a person with whom the defendant currently has, or has previously had, a dating or engagement relationship.

Penal Code 245 - assault upon the person of another with a deadly weapon or instrument other than a firearm or by any means of force likely to produce great bodily injury.

Penal Code 422 - any person who willfully threatens to commit a crime which will result in death or great bodily injury to another person, with the specific intent that the statement, made verbally, in writing, or by means of an electronic communication device, is to be taken as a threat.

Additional penal code offenses, such as terrorist threats, stalking, and vandalism of property, are also often included as qualifying offenses for the specialized juvenile and domestic violence courts if the offense is related to a girlfriend/boyfriend or a family relationship.

Once the relevant codes have been selected, begin pulling case files. Generally, probation department files are more likely to have background information that law enforcement 
or court files often lack. Use the files that contain the best information. Then select a time period. Smaller jurisdictions might pull cases from the last six months; larger jurisdictions might draw on a one month sample. Once the cases are pulled, the following information should be documented:

\begin{tabular}{|l|c|c|}
\hline How many cases were pulled? & & $\begin{array}{c}\text { Percent of } \\
\text { Total Cases }\end{array}$ \\
\cline { 1 - 2 } Over what time period? & & \\
$\begin{array}{l}\text { How many incidents involved a domestic } \\
\text { offender-victim relationship (intimate } \\
\text { partner, spouse, girlfriend/boyfriend, date)? }\end{array}$ & - & \\
\cline { 1 - 2 } $\begin{array}{l}\text { How many incidents involved a family } \\
\text { offender-victim relationship (parent, sibling, } \\
\text { or family member)? }\end{array}$ & - & \\
\hline
\end{tabular}

Upon completing this exercise, you will have a very good sense of the extent of the problem in your jurisdiction and how many cases pass through your agency without intervention geared toward domestic or family violence. You will also learn what proportion of cases are domestic violence versus family violence.

\section{Review Sample Cases}

If you have staff who can review case files and record information from those that involved a domestic or family violence incident, you may want to document some key variables (e.g., age, relationship, nature of incident, case outcomes, provision of services, sentences). But if you are short-staffed and stretched for time —-typical of most justice agencies these days_-pull out a few of the recent cases that involved a domestic or family relationship. Review the cases and document the following:

1. What was the nature of the incident?

2. What were the backgrounds of the offender and victim? Pay particular attention to previous encounters with the justice system, family background, school status, mental health, and substance abuse issues. 
3. What was the outcome of the case? In cases where the offender was adjudicated, what dispositions and services were ordered?

The review of sample cases will accomplish two things. First, the review will result in greater awareness of the nature of the violence and backgrounds of the parties involved. Second, the review will show how the current justice system responds to domestic and family violence cases, and whether current interventions take into account the relationship dynamics. The immediate job is to make a convincing case of the seriousness of the problem and the potential role of a specialized court-based program.

\section{Determine Area of Focus}

Domestic violence does not involve the same dynamics as family violence. Domestic violence among juveniles seems to mirror adult domestic violence-power and control issues are prevalent. Family violence cases are, in some ways, more complex. Although both juvenile violence and family violence juveniles may have a family history of parental violence and child abuse, it is even more common for family violence offenders to have been, at one time, a victim of child abuse or neglect as reported to social service agencies. Mental health issues are also more common in family violence than in domestic violence. Consequently, interventions should be modeled to meet the specific needs of the offenders and victims.

The Santa Clara County court program offers an example of how the area of focus may evolve over time. Originally, juvenile domestic violence, or teen dating violence or relationship violence, was the social issue of most concern to the court. But when the program was designed, family violence was folded into the mix. A single protocol was designed to address both domestic and family violence. The interventions were based on the Duluth batterer intervention 
model—domestic and family violence offenders participated in group programs. ${ }^{28}$ But in 2005 the high volume of cases, combined with a budget crisis and recognition of the differences in the two types of violence, led to family violence cases no longer being included in the specialized probation unit.

While at least some elements of an intervention program can address both domestic and family violence cases_-careful consideration should be given to the uniqueness of each type of case. Several questions may guide you in determining the area of focus.

1. Which of the two types of violence is most prevalent in the jurisdiction?

2. What resources are available to address each problem?

3. What is the political climate? Is there greater incentive/motivation to address domestic violence or family violence?

4. What types of local services are available in the areas of domestic and family violence for juveniles?

Success is critical to the endurance of any program. To increase the chance of success, use the strengths of the community to develop an intervention program. On the one hand, if you have excellent service providers in the domestic violence area, then you may want to initially concentrate on domestic violence cases. The advantage of this approach is that the caseload should be manageable, as the volume of cases is small compared to family violence cases. On the other hand, it may make more sense for you to address family violence cases, at least initially. Perhaps your community mental health and social services agencies have stellar programs that can be incorporated into the design of your program. Write down the advantages and disadvantages of each option to determine the approach that best fits your community.

28 The Duluth model is based on the feminist theory that patriarchal ideology, which encourages men to control their partners, causes domestic violence. 


\section{Step 2: Build the Team}

The second step is to build your team. The courts and probation/community corrections are logical starting points in most communities. Team-building will require participation from key players, which will require an understanding of local legal culture. The goal of the program should be consistency, and to establish that consistency, you'll need a number of agencies operating from the same playbook to achieve necessary buy-in.

\section{Recruit Key Players}

Most jurisdictions are now familiar with problem-solving or specialized courts.

Certainly, with the widespread use of drug courts nationwide, justice agencies should have some familiarity with specialized courts. However, agencies may be less aware of such courts offered at the juvenile level and may have little knowledge of the extent of domestic and family violence in the youth population. Furthermore, in many jurisdictions, the juvenile courts have been treated as little more than a training ground for inexperienced justice staff. These factors present challenges to building a team that can implement innovative programming at the juvenile level.

Key players — with decision-making powers_-must be recruited to support the concept of a specialized program for juvenile domestic and/or family violence. Additionally, the team will need to include line staff who will "champion" the implementation of the program and provide logistical support. In nearly every jurisdiction, judges have a great deal of authority and can recruit local leaders quite easily. In both Santa Clara County and San Franciso counties, a juvenile court judge led the charge to develop a specialized court program. But the courts and judges are not always proactive, so leadership may come from a different corner. For instance, the prosecutor's office may be particularly proactive in some jurisdictions; in others, it might be community corrections that has welcomed innovation. The identity of the leadership agency(ies) 
is less important than their ability to recruit key players. While line staff may embrace a new approach, it is key decision-makers who must lend their support, and quite often office resources, to the implementation of a new program. Judges can play a pivotal role in such efforts. Judges must be involved if cases are referred to the court system and placed on formal probation or informal probation with court supervision (as in San Francisco County).

The goal of any intervention program should be consistency. The juvenile offender must receive a consistent message from each agency that his or her behavior is unacceptable. The victim/survivor should be offered and provided services from all relevant agencies. Agencies that must participate in developing a consistent program include law enforcement, prosecution, public defenders, court, probation/community corrections, victim assistance, and offender services-it is important to have the involvement of both policy-making and line staff from these agencies. But these programs require input from the community as well. In addition to getting agencies on board, outreach to social service providers, batterer intervention programs, mental health agencies, and schools can go a long way toward developing an effective intervention.

\section{Consider Local Legal Culture}

There may be pockets of resistance to the development of a domestic or family violence intervention program for juveniles. Some agencies have a history of resistance to new ideas and may oppose the development of a specialized court program for any number of reasons (e.g., budgetary impact, the insignificance of the problem, lack of support of specialized programs). But the primary challenge to the development of problem-solving programs is the traditional adversarial legal culture that pits prosecutors against defense attorneys.

The Santa Clara County and San Francisco County experiments offer a rich contrast in how similar programs can be developed in very different legal cultures. The issue of debate in 
the creation of a specialized program at the juvenile level is one of adjudication and formality. In general, although there are exceptions, the Santa Clara County court program can be labeled a post-adjudication model. There is a coherent law enforcement protocol that requires bringing domestic/family violence suspects to Juvenile Hall, the case is typically brought to the district attorney to issue a petition, and the minors tend to be made a ward of the court with formal probation. The court views juvenile domestic and family violence as a very serious issue that needs a strong justice system reaction. In San Francisco, the court favors a pre-adjudication model, in which the offender "volunteers" to participate in a program without finding the minor a ward of the court. If the juvenile fulfills the conditions of the court, the petition is dismissed with the minor having no delinquent record for this offense.

Each approach has advantages and disadvantages. There are two aspects that should be seriously considered. First, in the post-adjudication model, offenders are required to admit their guilt and take responsibility for their actions_-often considered a first step in accepting help in a batterer intervention program. In contrast, the pre-adjudication model does not require, and even forbids, such an admission in a court of law. Second, the post-adjudication model is more punitive in nature; it is a law enforcement approach that results in an official record that can impact a juvenile's career opportunities. ${ }^{29}$ The other alternative- - the pre-adjudication modelis more therapeutic in nature, although in both models treatment and intervention are integral parts of the court programs. There is no single "right" or "wrong” approach. Each of the programs involves periodic court reviews, high levels of supervision, and treatment/intervention services and is a reflection of the larger justice system context. In general, Santa Clara County

29 Juvenile records in California may later be sealed or destroyed upon application. 
has long had a tradition of a strong law enforcement and active prosecution of crime ${ }^{30}$; a similar strong law enforcement model simply would not fit into San Francisco’s much more liberal legal culture. A careful consideration of the local legal culture, and identifying the advantages and disadvantages of multiple approaches, should help agencies develop a program that has “buy-in” from all key agencies.

\section{Draft a Plan}

Finally, gather the team and all the information you've just collected to draft a plan. Start by drafting a mission statement. Then write down all the local agencies and service providers that would contribute to the court program in an ideal world. Provide the data you collected on the anticipated caseload. Describe the types of cases and the current response. Explain why a specialized program is needed and how people will benefit. The "how to" part of the program (staffing, resources, protocol) should be a collaborative effort.

\section{Step 3: Draft a Response Protocol}

The third step in the process is to draft a response protocol. But before a protocol is drafted, the team must agree on a specific goal. For example, the Santa Clara County court program's priority is to protect victims and the community, to hold offenders accountable for their actions, and to prevent further violence. The specific goals of the program will guide the response protocols, which should address (1) referral and assessment, (2) specialized investigative and judicial procedures, (3) probation conditions and offender programs, (4) victim services and advocacy, and (5) probation supervision procedures.

\footnotetext{
30 Santa Clara County's largest city, San Jose is recognized as the safest large city in the U.S. in terms of crime statistics.
} 


\section{Establish Procedures to Identify Cases}

Local law enforcement agencies are likely to have a protocol that guides their response to adult cases of domestic or family violence. But few agencies explicitly address domestic and family violence that involves a juvenile offender. For an intervention program to work effectively, law enforcement officers must physically transport juvenile offenders to Juvenile Hall or a similar intake center. Informal responses, such as warnings and separating the parties, will be counterproductive to creating a consistent response.

The Santa Clara response protocol for law enforcement requires officers to take minors into custody, not to cite and release them. At Juvenile Hall, the intake officer screens cases by first looking at the relationship between the parties_-the parent-child relationship or the dating or prior dating relationship. If the case involves a domestic violence or family violence incident, the intake officer also does an extensive family history assessment in terms of parental family violence or child abuse. If the case qualifies as an act of domestic or family violence, it is sent to the specialized domestic/family violence probation unit for further risk assessment and to the District Attorney’s Office for review. The San Francisco County court program works similarly; however, the program does not have a law enforcement protocol that requires officers to bring domestic/family violence offenders to Juvenile Hall. As a result, the San Francisco County court has far fewer cases than the Santa Clara County court, and those cases that come to the attention of the court may be more serious.

The risk assessment tools used in the two counties also vary. In Santa Clara County, the specialized court program has developed an extensive risk assessment protocol specific to the domestic and family violence cases, and all such suspected cases are sent to the specialized probation unit for further assessment. In San Francisco County the probation department uses a 
one-page assessment form that focuses on public safety issues and whether the suspect will fail to appear in court. Rather than relying on a formal instrument, the probation intake officers screen cases by examining the relationship between the parties and the nature of the charge. The screening officer may also use instruments that gauge mental health problems. The classification of a case as domestic or family violence is somewhat subjective and can be overridden by the courts or specialized staff. Additionally, there are no specialized and validated assessment instruments for juvenile domestic or family violence at this time.

\section{Designate Specialized Staff}

Specialized court programs require designated staff to provide consistency and efficiency. A response protocol must outline specialized procedures for each agency. Specialization is likely to involve the following agencies: courts, probation/community corrections, prosecutor's office, and the public defender's office. Both Santa Clara County and San Francisco County have specialized probation units and designated prosecutors, defense attorneys, and judges to handle domestic/family violence cases. A standing court order permits information exchange among all agencies collaborating in the court program.

The specialized courts use a dedicated docket to hear the cases. In Santa Clara County, review, jurisdictional, and dispositional hearings occur at a special court session held once every week, with detention hearings held every day. The frequency of hearings will be determined by both the volume of cases and the availability of the judge and courtroom. Timing is also likely to be a factor as juveniles who have been detained must have a detention hearing within two business days. In San Francisco County, the dedicated docket takes place once every two weeks. Consequently, detention hearings occur on a generalized docket, and some cases may not be assigned to the specialized court. While some jurisdictions may not have the caseload or 
resources to warrant specialized court programs, a number of these specialized procedures can be used to address domestic/family violence cases.

Dedicated and specialized staff introduce a cautionary aspect to the program. Staff turnover can have a huge impact on the programs. Most justice agencies use a rotational system in which staff typically spend a relatively short time in one unit before transferring to another. This rotational system can result in an ever-changing team and presents challenges to maintaining the enthusiasm, consistency, and effectiveness of a program. For instance, staff changes, in combination with budget problems, have led to a noticeable change in the momentum of the Santa Clara County and San Francisco County programs—-the Santa Clara County court program has been downsized to exclude family violence offenders from the specialized probation caseload, while the San Francisco County program continues to include both.

\section{Establish Probation Conditions and Offender Programs}

The protocol should outline typical probation conditions and offender programs that will be used for this population. A sample of typical probation conditions and programs offered in Santa Clara County follows: 31

- Protective or "stay away” orders;

- Attendance at 26-week batterer intervention programs;

- Frequent court review of the probationer for compliance with probation;

- Detention in a county facility, as well as placement services, long-term California Youth Authority alternative placement, or the California Youth Authority, to ensure safety and accountability;

- Parenting Without Violence classes if the youth has a child;

- Restitution to the victim for any losses related to the offense;

31 The probation conditions reflect California codes; they may not be options in all states. 
- Prohibition against weapons possession or the presence of weapons in the offender's home;

- Search of the person or place of residence or business of the minor and seizure of any items prohibited by conditions of probation or the law by law enforcement, probation, or the offender's school teachers at any time of the day or night, with or without probable cause, and with or without warrant;

- Counseling and education if substance abuse issues are present and special education accommodations when necessary;

- Drug and alcohol testing of the offender at the request of any police officer or probation officer with or without probable cause, and with or without a warrant;

- Strict curfew, compliance with protective orders, and school attendance to prevent new law violations;

- Mandatory school, employment, or vocational training attendance;

- Fines and fees to hold the offender accountable;

- Gang orders (if applicable) to help prevent new criminal offenses; and

- Psychological or family counseling.

Graduated responses are common in specialized programs, with the intensity of sanctions or positive responses increasing with levels of compliance or noncompliance. The programs emphasize treatment and therapeutic programs. A key factor in developing protocol is the availability of programs in the community to serve domestic and/or family violence offenders and payment for services. In particular, there are very few teen-oriented battering programs, and the literature on the effectiveness of programs is sparse. Domestic violence batterers and family violence offenders were typically placed in the same program, even though the nature of the problem and offender backgrounds are quite different. Santa Clara County began to address this issue in 2005-by no longer assigning family cases to the juvenile domestic violence court program. Instead, family violence cases with a mental health problem are assigned to the mental health court calendar, while those without are assigned to regular court calendars and regular probation units. The problem with this approach is that these family violence offenders may no longer get the interventions specifically geared towards their family violence issues. In terms of 
implementing a new program, the team should assess the strengths and weaknesses of community programs before determining the types of programs that can be offered in an appropriate and effective fashion.

Offender programs must take into consideration gender issues. The vast majority of domestic violence offenders are male. However, in both counties, between 11 and 14 percent of the domestic violence offenders were female. Family violence is more often committed by both male and female juveniles. In San Francisco County and Santa Clara counties, almost 40 percent of family violence offenders were female. The offender programs, all of which include group therapy, must consider whether young men and women have similar issues that can be addressed in either a single group or separate groups. In both counties, male and female offenders are assigned to different batterer's intervention groups. The family violence offenders are also more likely to demonstrate mental illnesses and have a history of abuse as a child—all factors to consider when providing intervention programs to accommodate specific needs.

Payment for services must be addressed in a protocol and can be a major stumbling block. The Santa Clara County and San Francisco County experiences highlight the issue. San Francisco County has a considerable number of resources-many of those resources are provided through county public health funds. Through public health programs, the San Francisco County intervention program has been able to offer batterer intervention counseling at little to no charge to either the justice agencies or the offender. In Santa Clara County, public health does not cover the teen batterers' intervention program and only pays for referrals for mental health issues. Offenders were required to co-pay for each session (\$15 per session) of a 26-week program, with the probation department paying for remaining costs of the program. The positive aspect of this arrangement is that minors and their families may be more committed 
to the program because they have to bear a financial burden; the negative aspect is that minors may be dropped from the program or drop out because of inability or unwillingness to pay. In 2005 county budget problems in Santa Clara County resulted in a crisis in the probation department, with service providers being compensated at minimal levels or incurring delays in payment.

There are advantages and disadvantages to requiring teens to pay for treatment and intervention services. In Santa Clara County, payment is seen as a way to gain commitments from offenders and for offenders to take responsibility for their actions. Yet the provision of interventions should not hinge on the ability to pay. In addition, parents or dating partners who have been victimized by a juvenile may end up paying on behalf of the youth. The protocol must take into consideration payment of services and how to accommodate those who cannot afford the fee.

\section{Determine How to Serve Victims}

Victim services and advocacy must be addressed in the protocol. In Santa Clara County and San Francisco counties, victims are offered direct and confidential victim advocacy, referrals to support groups and other community resources, legal assistance, a support person at court, and assistance with restitution claims. Specialized probation officers provide an important link to victims. Officers explain the value of protection orders and can help victims file a victims-ofcrime claim. Probation officers can also contact the adolescent victim's family to explain the probation conditions and refer the parents to free advocacy services. But similar to adult domestic and family violence, few victims take advantage of such services.

Victim assistance notifies the victims, as required by law in California, of the offender's custody status, the charges, and pending court hearings and refers victims to domestic violence 
advocacy agencies. In Santa Clara County, Legal Assistance to Children and Youth (a nonprofit organization run by the Santa Clara County Bar Association) offers free assistance to victims with children with a variety of legal matters, such as paternity, custody, visitation, and support orders. In San Francisco County, adolescent girls are referred to the SAGE program, which assists women and girls who have experienced sexual exploitation, assault, and trauma.

Family violence cases require additional consideration when drafting restitutions protocols. When a case is adjudicated, the offender may be ordered to pay restitution. But what happens when the victim is the teen's sibling or parent? Do the parents end up paying restitution on behalf of their child? While restitution and victims-of-crime claims were created to enhance victims’ rights, parents who are victims of violence committed by their children may ultimately be footing their own bill.

\section{Develop Probation Supervision Procedures}

The protocol should address the level of probation supervision afforded juvenile domestic and family violence offenders. In the Santa Clara County and San Francisco County programs, intensive supervision is used in these types of cases. Specialized officers enforce protective orders, review monthly reports from the batterer intervention program, provide referrals to rehabilitative, educational, and vocational services, and may make frequent unannounced visits at the offender's home, school, and work. The officers have the authority to make random searches for weapons and illegal drugs and can order drug testing.

Intensive supervision raises staffing issues, as it requires a lighter caseload for probation officers. For instance, in San Francisco County the caseload for the juvenile domestic violence probation unit is capped at 26 teens; in Santa Clara County, it is capped at 35 per probation officer. Specialized caseloads may prove difficult to maintain during lean budget years. In 
2005, Santa Clara County faced a budget crisis that led to a major staffing shortage in the probation department. In response, the probation department eliminated specialized probation officers to monitor family violence offenders, choosing instead to mix these cases into the general caseload handled by the geographic units.

\section{Review Protocols Annually}

The response protocols should be reviewed annually. Political climate, laws, staffing, and budgets change on an annual basis, and the protocols should be reviewed and modified as appropriate. All of the agencies should come together to review current operations and revisiting each aspect of the protocol. An annual review should also head off unilateral actions taken by a single agency that can disrupt or halt the entire program. While the annual review might be seen as a rather tedious task, it provides the opportunity for “cross-pollination” among agencies and community groups, especially those that rarely work together. Perspectives from different disciplines strengthen policies, procedures, and protocols and provide opportunities for teambuilding and an awareness of practices of other groups and disciplines.

\section{Step 4: Provide Services}

The fourth step in the implementation of an intervention program is to provide services. Services can be provided by an assortment of agencies, such as probation, victim assistance, and community-based service providers. The important factor here is that services are evidencebased — they are based on treatment/intervention literature, led by competent professionals, and appropriate to the clients they serve. In addition, there has to be funding to provide services.

\section{Examine the Content of Programs}


The intervention programs should distinguish domestic violence from family violence. There are very few programs designed for juveniles, which limits the ability of the implementation team to set standards but not to specify desired outcomes. However, there is an abundance of information available on adult-based batterer intervention programs. Service providers that address power and control themes and modify the batterer intervention platform for teenagers are appropriate to domestic violence. In Santa Clara County, the batterer intervention program was originally based on the Duluth model. In San Francisco County, the program derives from the MOVE (Men Overcoming Violence) curriculum, which is an adult domestic violence program. In addition, the San Francisco County program works with SAGE to provide a life skills class for girls. Generally, the court-based programs are heavily oriented toward treatment/intervention services for offenders. Different providers offer special services, such as Spanish-language programs for domestic violence offenders only.

The greatest challenge may be to develop meaningful programs that address the problem of family violence. A particular concern is that family violence is often a function of the family unit-intervention should include family members, not just the juvenile. In fact, about four of every ten family violence offenders have a history of being abused as a child. In addition, about two of every three family violence offenders have a history of mental illness. Consequently, the provision of services in family violence cases could involve an array of programs that address the larger family unit and provide mental health counseling.

Finally, the ability to provide meaningful services may be compounded by the language and cultural heterogeneity of the community served. English may not be the native language of either victims or offenders; and the larger family unit may have limited English proficiency. In 
addition, there may be cultural gender stereotyping that may impact the effectiveness of a program that is designed without the diversity of the community in mind.

\section{Secure Funding}

Services cannot take place without some level of funding. The budgetary impact on justice agencies, as well as cost-benefits ratios, have not been measured by either the Santa Clara County or San Francisco County programs. In Santa Clara County, the Board of Supervisors originally funded additional probation officers for the specialized domestic/family violence unit, the Superior Court agreed to a weekly domestic/family violence calendar, and a grant from the state through San Jose State University funded some of the interventions and program evaluations. Subsequent loss of additional county and state grant funds, combined with a budget crisis, has led to difficulties in sustaining the full original program. In San Francisco County, internal funds were used to shift resources to the specialized court and caseloads. In addition, San Francisco County has been particularly innovative working with the public health sector to assist with the provision of services, especially in family violence cases.

It is reasonable to expect offenders to pay for some level of services. Few juvenile offenders and their families can afford to pay the entire cost of a program. While some level of offender co-pay may be required, a sliding scale must be used to ensure that all offenders have access to the services. The bulk of the program will have to be paid for through local funds or grants. Grants work very well in the short term, especially with start-up costs. But most grants are limited to a short amount of time, with the requirement that local agencies will have to develop a sustainability plan for the program to continue beyond the life of the grant. 


\section{Step 5: Communicate Regularly}

Regular communication between participating organizations is necessary to maintain the integrity and consistency of the program. As staff rotate in and out of the program, regularly scheduled meetings and events among staff provide a training ground as well as an opportunity to refine operations. In Santa Clara County, monthly meetings are convened by the judge, with regular attendance expected. ${ }^{32}$ Attendance at the meetings has declined with staff changes but has recently experienced rejuvenation. In San Francisco County, court conferences are held prior to the biweekly court sessions to discuss each case. The court conferences include the judge, the district attorney, public defender, and probation officer. San Francisco County also has a tradition of an annual "retreat" to discuss the program.

Communication can occur at the programmatic or individual case level. Key agencies and service providers must be represented at meetings that discuss program operations. Meetings that focus on individual cases are best conducted in court conferences between those individuals serving on each case. The advantage of the specialized team is that court conferences can be held efficiently because all of the cases on the specialized docket are handled by the same people. The important factor is that the program offers a regular means to communicate. In addition, the meetings must include key members from the participating agency. The program will decline and staff will lose enthusiasm when an agency drops out of regular meetings or sends staff with little knowledge of the program to represent the agency. Those with decision-making authority need to be involved. The meetings must have an agenda and work to build a collaborative team.

32 Participation includes all probation officers assigned to the specialized unit, representatives from the district attorneys and public defenders offices handling the domestic/family violence cases, court personnel, all service 


\section{Step 6: Train Staff}

The final step is to train staff. There are a number of national, state, and local training programs that address domestic and/or family violence, but few address violence at the juvenile level. The Santa Clara County and San Francisco County programs primarily depend on internal agency training to maintain the quality of the program. The implementation of a new program requires a core of dedicated staff who have participated in highly regarded training programs. But training levels are very difficult to maintain as new staff rotate into specialized positions. Therefore, a mentorship program may be the most effective way to train staff. An internal mentorship program takes advantage of the skills and experiences of seasoned professionals and is a cost-effective way to train staff in the midst of deficient training budgets. In addition, staff should develop benchbooks and guides to retain program consistency.

\section{Step 7: Evaluate the Program}

Evaluation is an important tool. A properly conducted independent evaluation of the court program serves three essential purposes. First, the evaluation is an internal tool that can be used to refine and improve program operations. Second, the evaluation adds a level of accountability and allows staff to measure performance over time. Third, the evaluation serves as a valuable funding tool that can be used to justify the existence of a program and secure external funding.

The Santa Clara County program was established with an evaluation component—-the evaluation was carried out by researchers from San Jose State University. The San Francisco program has only recently been evaluated by a research team led by the National Center for State 
Courts. Program staff should work with independent evaluators to determine (1) specific

measurable goals, (2) sources of data, and (3) factors that will affect goal attainment. In addition to collecting quantifiable data (e.g., number of probation violations, new arrests), the evaluation team should collect qualitative information from case files, which contain contextual information that may help explain program outcomes.

The evaluation component should focus on several areas, such as offender and victim backgrounds, the nature of violence, probation conditions and violations, and subsequent arrests and convictions. Ideally, a domestic/family violence court program will result in a lower recidivism rate in comparison to domestic/family violence offenders who did not participate in the court program. Realistically, lowering the recidivism rate may be an impractical goal for the simple reason that many of the program participants have long histories of delinquency and come from abusive or neglectful families—-factors strongly associated with recidivism.

\section{Conclusion}

Both the Santa Clara County and the San Francisco County specialized juvenile domestic and family violence courts have proven to be innovative programs addressing a serious social issue. Case information demonstrates that many of the offenders assigned to these courts come from families with a history of parental domestic violence, child abuse, criminal behaviors, and substance abuse. Many of the minors have mental health issues. Most have prior histories of delinquency, and many already have children at a very young age. While the background of these minors makes it very difficult to effect change, the evaluation conducted by the National Center for State Courts found that the specialized court program had a deterrent effect for first time offenders and those that completed the entire court ordered programs. Minors with prior delinquency were less likely to complete the program, and more likely to recidivate. 
In order to break "the cycle of violence" it is important to initiate programs that address the pressing issues of juvenile domestic violence (teen relationship violence) and family violence. The two counties have found similar, yet different ways of doing so. In constructing such specialized courts, it is important to be cognizant of the problem of "casting too wide a net,” especially in the family violence cases which often could be seen as status offenses (being beyond the control of parents). Our results showed that the interventions were most beneficial for younger and first time offenders. Care must be taken to initiate programs with age appropriate services and graduated sanctions. 